\title{
The Effect of Cervical Spine Manipulation on the Postural Sway of Patients with Non-Specific Neck Pain
}

\author{
Alison Fisher
}

2013

A research thesis submitted in partial fulfilment of the requirements for the degree of Master of Osteopathy 


\section{Declaration}

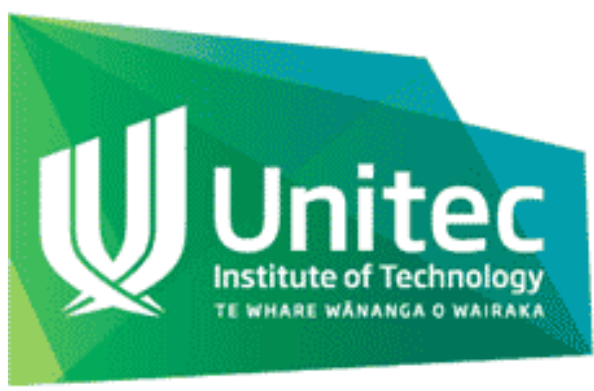

Name of Candidate: Alison Fisher

This Thesis entitled: "The effect of cervical spine manipulation on the postural sway of patients with non-specific neck pain" is submitted in partial fulfilment of the requirements for the Unitec degree of: Master of Osteopathy.

\section{Candidate's declaration}

I confirm that:

- This Thesis Project represents my own work;

- The contribution of supervisors and others to this work was consistent with the Unitec Regulations and Policies.

- Research for this work has been conducted in accordance with the Unitec Research Ethics Committee Policy and Procedures, and has fulfilled any requirements set for this project by the Unitec Research Ethics Committee.

Research Ethics Committee Approval Number: 2011-1188

Candidate Signature:

Date:

Student number: 1305048 


\section{Acknowledgements}

I would like to give my sincere thanks to the following people who have supported me throughout this process

To the participants who were so were so kind, and so very patient. I realise that 75 seconds is an awfully long time to stand still. Thank you.

To the Osteopath who gave his time and expertise, often with little warning and with a platefull of other commitments. Thank you so very much.

To Dr Catherine Bacon and Jamie Mannion. I am so privileged to have had you both as my supervisors. I cannot thank you enough for the endless hours you have put into reading through my work, and for the knowledge and the expertise that you have given me so generously throughout this whole process. I truly appreciate it.

To mum, and to Greg. For the love, encouragement and support you have given me for so long. I would not be here without you. Thank you for believing in me.

To Lorelei and to Josh. For the love and support that you have given me so generously. Thank you doesn't come close. I will never forget it. 


\section{Abstract}

Objective: Neck pain has been associated with impaired proprioceptive performance which may be improved by cervical manipulation. This crossover study aimed to determine whether a high velocity, low amplitude manipulation affected postural sway in adults with nonspecific neck pain.

Methods: Ten participants received, in random order, 7-days apart, a high velocity, low amplitude manipulation applied to a dysfunctional spinal segment and a passive headmovement control. Four parameters of postural sway were measured before, immediately following, and at 5 and 10 minutes after each procedure.

Results: Results showed no differences between interventions in change in any of the parameters. When changes before and immediately following each procedure were analysed separately, only the control showed a significant change in the length of centre of pressure path (an increase from median $=118 \mathrm{~mm} ; \mathrm{IQR}=93-137 \mathrm{~mm}$ to an increase to $132 \mathrm{~mm} ; 112-147$; $p=0.02)$.

Conclusion: This study failed to show any evidence that manipulation of a dysfunctional cervical segment influences postural sway. Given the ability of the postural control system to reweight the hierarchy of sensory information in order to compensate for inadequacies in any one component, it is possible that any improvements in the mechanisms controlling postural sway elicited by the manipulative intervention may have been concealed.

Key Indexing Terms: Neck Pain; Central Nervous System; Cervical Manipulation; Neuronal Plasticity; Balance, Postural 


\section{Table of Contents}

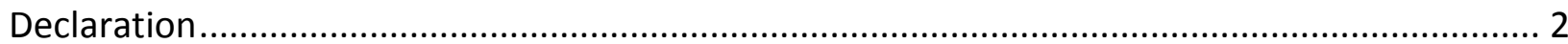

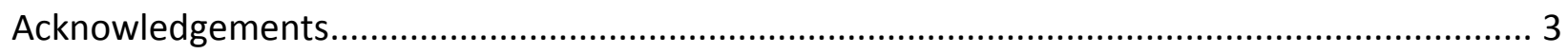

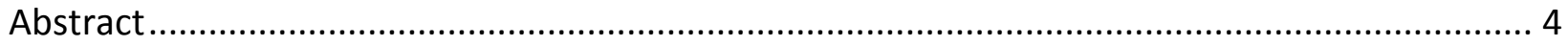

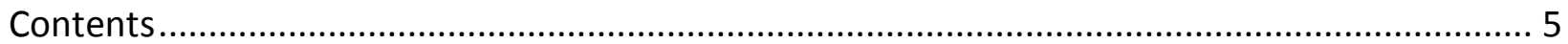

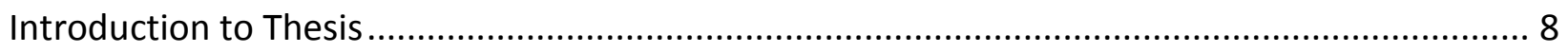

Section One : Literature review..............................................................11

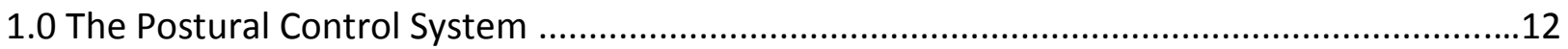

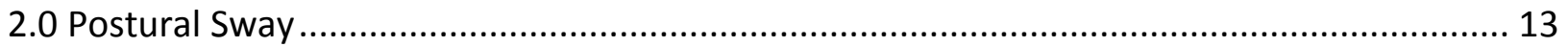

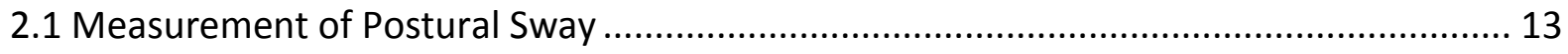

3.0 Functional Anatomy of the Cervical Region............................................................. 14

3.1 The Proprioceptive Properties of the Cervical Region ............................................... 15

3.2 The Role of the Cervical Region in the Postural Control System ................................... 15

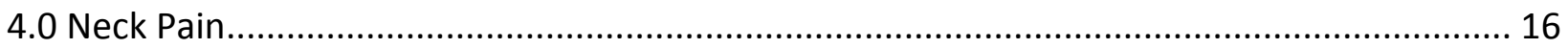

4.1 Prevalence of Neck Pain within the New Zealand Population....................................... 16

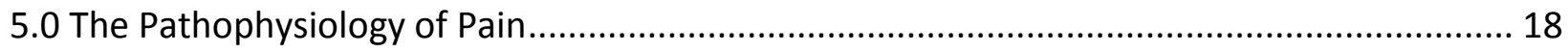

6.0 The Complex Response to Pain ....................................................................................... 20

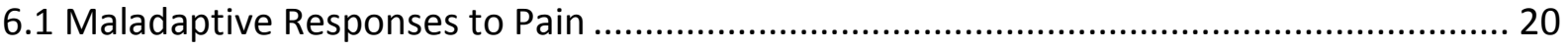

7.0 Pain-Induced Changes in Neuromuscular Performance ................................................. 21

7.1 Pain-Induced Impairment of Proprioceptive Function ............................................... 22

7.2 Changes within the Central Nervous System ............................................................. 25

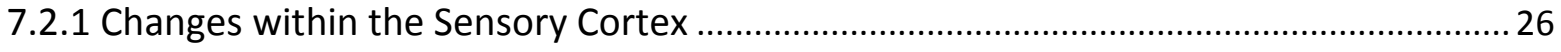

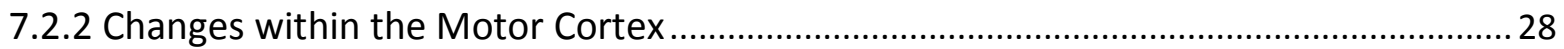

7.3 Pain-Induced Changes in Functional Performance .................................................... 30

7.3.1 Altered Muscle Patterning During Functional Tasks...................................................... 30

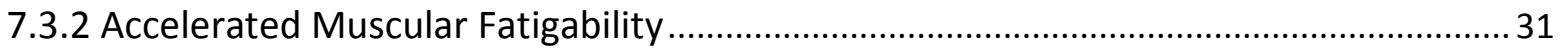

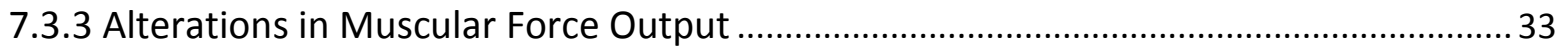




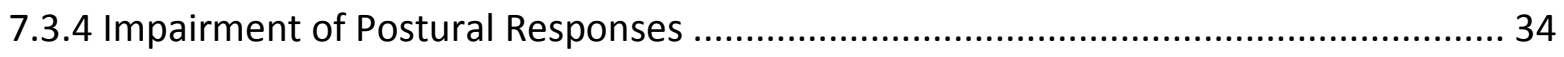

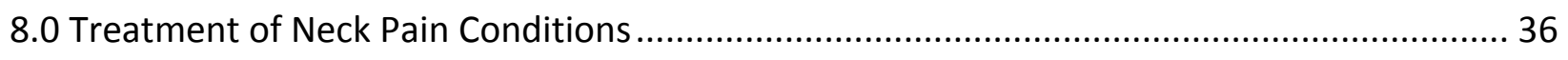

8.1 Spinal Manipulation and Segmental Dysfunction .......................................................... 36

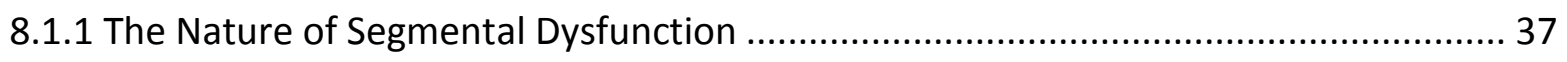

9.0 Spinal Manipulation to Address Abnormal Sensorimotor Integration and Motor Function . 39

9.1 Analgesic Effects of Spinal Manipulation ........................................................................ 40

9.1.1 Spinal Manipulation in Clinical Pain ....................................................................... 40

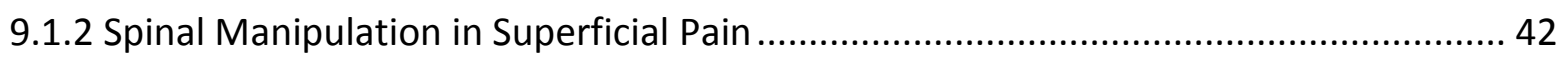

9.2 Neurophysiological response to manipulation ............................................................ 43

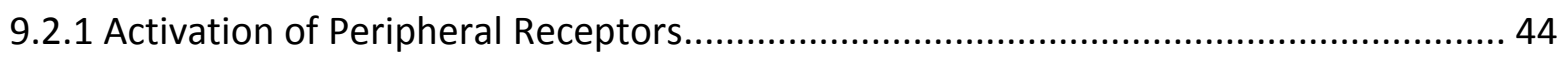

9.2.2 Cervical Spine Manipulation and Sensory Processing ................................................. 46

9.2.2.1 Cervical Spine Manipulation and Surround Inhibition.......................................... 47

9.2.3 Cervical Spine Manipulation and Motor Performance ................................................ 50

9.2.4 Cervical Spine Manipulation and Postural Sway ....................................................... 51

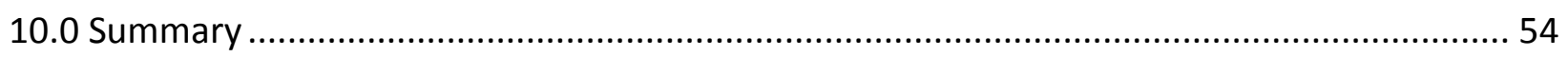

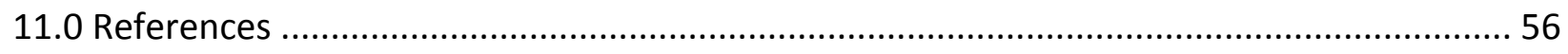

Section Two - Manuscript............................................................................. 81

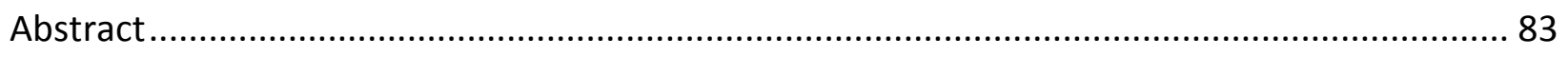

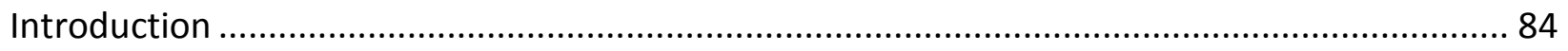

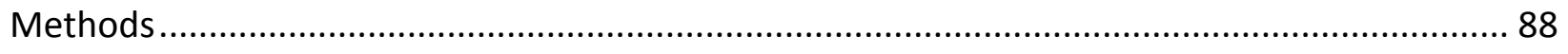

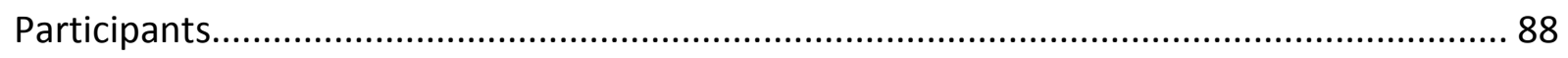

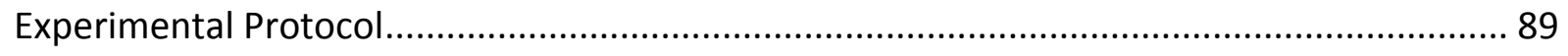

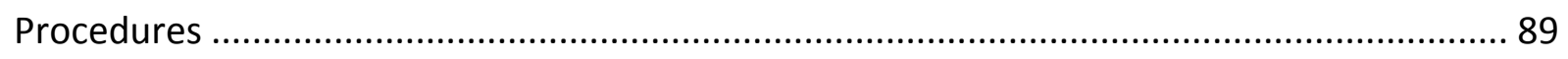

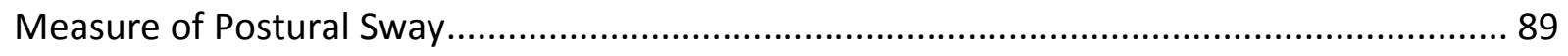

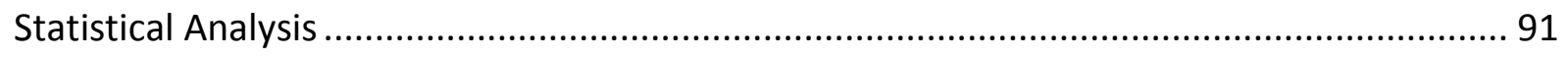

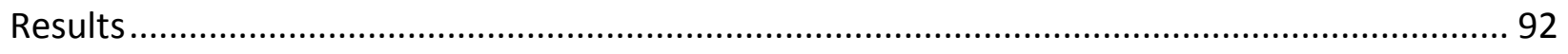

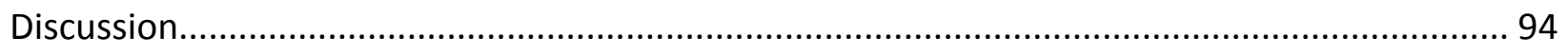

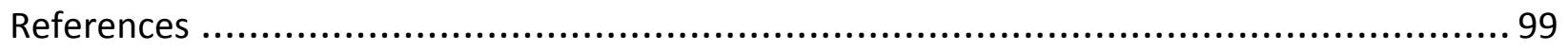




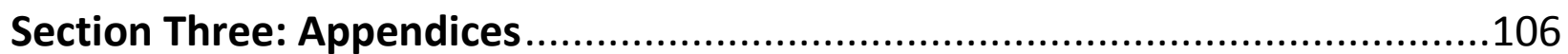

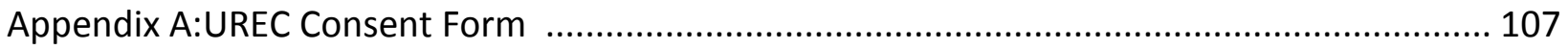

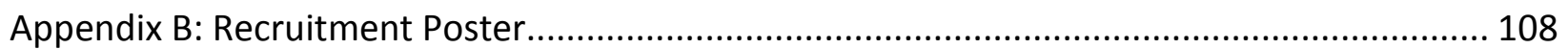

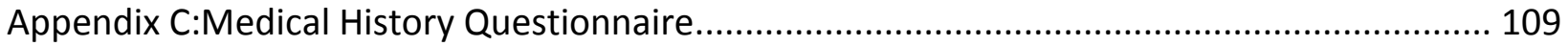

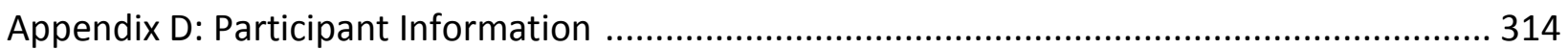

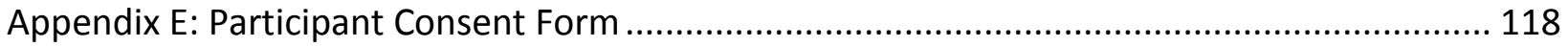

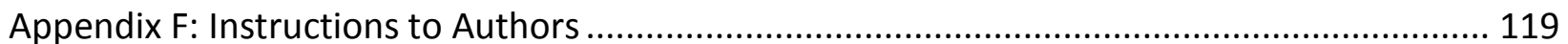




\section{Introduction to Thesis}

Effective control over posture is essential in order to provide a stable platform from which to execute voluntary movements of the head, limbs and torso, to maintain balance during upright stance and to respond appropriately to the numerous destabilising forces that act upon the body (Kristjansson \& Treleaven, 2009; Windhorst, 2007). The maintenance of stable, upright posture is achieved through the complex process of sensorimotor integration through which the main sensory modalities of vision, vestibular and proprioceptive input are coordinated with numerous postural reflexes to produce functional motor output (Lackner \& DiZio, 2000; Maurer, Mergner, Bolha, \& Hlavacka, 2000). The cervical region plays an especially important role in supplying proprioceptive information to the postural control system. This is reflected by the dense concentration of proprioceptive organs within cervical musculature and the extensive network of connections that cervical afferents form with numerous subsystems and postural reflexes that contribute to maintaining homeostasis of the head, neck and body (Humphreys, 2008; Kristjansson \& Treleaven, 2009; Treleaven, 2008).

Disruption to any one of the components of the postural control system may have consequences in terms of the ability of the body to maintain adequate control over posture (Ruhe, Fejer, \& Walker, 2011). This reduced efficiency has consequences in terms of increased postural sway, impaired reaction times, dysfunctional motor performance and an increase in energy expenditure to maintain upright stance (Alexander \& LaPier, 1998; Deliagina, Zelenin, Beloozerova, \& Orlovsky, 2007).

Research has shown that individuals suffering neck pain demonstrate increased postural sway in comparison to asymptomatic controls (Field, Treleaven, \& Jull, 2008; Madeleine, Prietzel, Svarrer, \& Arendt-Nielsen, 2004; Röijezon, Björklund, \& Djupsjöbacka, 2011). It is proposed that this impairment in postural control is the result of impaired cervical proprioceptive input and 
maladaptive changes in the central process of sensorimotor integration (Haavik \& Murphy, 2012; Ruhe et al., 2011; Treleaven, 2008). Maladaptive changes in response to pain and altered proprioceptive input have been observed on numerous levels of the central nervous system (Avanzino et al., 2013; Tinazzi et al., 2000; Wall, Xu, \& Wang, 2002). Such changes are thought to be responsible for the development, maintenance and progression of functional disturbances seen in neck pain patients (Haavik \& Murphy, 2012; Kristjansson \& Treleaven, 2009; Wall et al., 2002).

Reports of increased postural sway in neck pain sufferers highlights the fact that subjective feelings of pain are not the only factor that needs to be addressed in the treatment and rehabilitation of these individuals. Indeed, it has been argued by some that addressing disturbances to sensorimotor performance may be of fundamental importance to rehabilitating these patients and to preventing the development of chronic or recurrent conditions (Kristjansson \& Treleaven, 2009; Treleaven, 2008).

Recent studies have presented findings that suggest that high velocity, low amplitude (HVLA) spinal manipulation may have analgesic, neuromodulatory and functional effects in individuals with neck pain (Coronado et al., 2012; Haavik \& Murphy, 2012; Sterling, Jull, \& Wright, 2001). Examples include improved motor activity within cervical and upper limb musculature (Sterling et al., 2001; Suter \& McMorland, 2002) improved head and upper limb repositioning accuracy (Haavik \& Murphy, 2011; Heikkilä, Johansson, \& Wenngren, 2000) and altered cortical activity suggestive of improvements in sensory processing and sensorimotor integration (Haavik-Taylor \& Murphy, 2007, 2008, 2010). Together, these findings suggest that a central mechanism of action underlies the effects of HVLA manipulation however; the research surrounding the extent of functional changes following cervical spine manipulation is scarce.

There is clearly a need for further investigation into the clinical applications of cervical spine manipulation in patients with neck pain. This study aimed to explore the effect of single HVLA thrust to a dysfunctional cervical segment on the postural sway of individuals with non-specific neck pain. This work will extend on the small number of studies that have demonstrated 
improvements in sway following cervical manipulation to asymptomatic individuals. In addition it may contribute to the growing body of research surrounding the applications of this technique in a clinical setting.

This thesis is presented in three sections. Section 1 contains the literature review which provides background information regarding postural control and postural sway and the role of the cervical region within the postural control system. The review then places a particular emphasis on neck pain as it explores the body's complex neuromuscular response to pain and the recent theory that maladaptive changes may be responsible for the impairments in postural sway that has been observed in individuals with neck pain. Finally, the review will present the most recent evidence surrounding the analgesic and neuromodualatory effects of cervical spine manipulation before exploring the possible applications of the technique as a therapeutic tool to address neck pain-induced increases in postural sway. Section 2 contains the manuscript formatted in accordance to the submission requirements of the Journal of Manipulative and Physiological Therapeutics. Section 3 (appendices) contains all other relevant material supplementary to this thesis. 


\section{Section One}

Literature Review 


\subsection{The Postural Control System}

Postural control refers to the ability of the body to maintain equilibrium of the centre of mass over its base of support (Harringe, Halvorsen, Renström, \& Werner, 2008). Efficient control over posture is necessary to provide the stability required to stand, ambulate and to safely perform voluntary movements that would otherwise disturb postural equilibrium (Deliagina, Zelenin, Beloozerova, \& Orlovsky, 2007). Stable posture is especially important in groups such as athletes and the elderly where impaired balance may predispose falls and subsequent injury (Harringe et al., 2008).

Maintaining control over upright posture is a highly complex task. It requires the coordinated activity of over 700 postural muscles which, in turn, exert control over the estimated 200 degrees of freedom present throughout the joints of the body (Massion, 1994). The postural control system refers to the complex network of central and peripheral structures that collaborate to maintain control over posture. Multiple sensory inputs from the visual, vestibular and proprioceptive systems are integrated within the sensorimotor centres of the brain to produce functional output in the form of motor commands (Jull, Sterling, Falla, Treleaven, \& O'Leary, 2008; Lackner \& DiZio, 2000; Morningstar, Pettibon, Schlappi, Schlappi, \& Ireland, 2005). This sensory information is also used to generate an internal schema of the body's configuration that provides a reference framework with which the body orientates itself to the surrounding world (Lackner \& DiZio, 2000; Windhorst, 2007). Working in conjunction with these systems, several postural reflexes also play a role in maintaining equilibrium of the head, neck and body (Humphreys, 2008; Morningstar et al., 2005; Treleaven, 2008b). The integrity of the postural control system is essential in order for the central nervous system to generate appropriate motor responses to destabilising forces such as gravity, voluntary limb movement, and respiration (Deliagina et al., 2007; Hodges, Gurfinkel, Brumagne, Smith, \& Cordo, 2002). Alteration of any one of the components of this intricate system may therefore have a consequential effect on the ability of the body to maintain adequate control over posture. 


\subsection{Postural Sway}

During upright, bipedal stance, the body's centre of gravity naturally oscillates over its base of support. This oscillation is known as postural sway and is the product of the interplay between the destabilising forces acting upon the body and the compensatory actions of the postural control system (Alexander \& LaPier, 1998; Massion, 1994). Disorders that interfere with any component of the postural control system will therefore influence the characteristics of postural sway and affect the body's ability to effectively respond to perturbations to balance. This reduced efficiency has consequences in terms of increased postural sway, impaired reaction times, dysfunctional motor performance and an increase in energy expenditure to maintain upright stance (Alexander \& LaPier, 1998; Deliagina et al., 2007). Increased postural sway has been recognised as a risk factor for sustaining lower limb injury in young athletes (Dallinga, Benjaminse, \& Lemmink, 2012; de Noronha, Refshauge, Herbert, \& Kilbreath, 2006) and has been associated with increased falls risk in older populations (Tucker, Kavanagh, Morrison, \& Barrett, 2009, 2010b). Thus, postural stability has important implications for the treatment and rehabilitation of all aspects of the population.

\subsection{Measurement of Postural Sway}

The influence of different factors on postural sway has been the focus of much clinical and scientific study. A variety of tools have been used in order to measure the subtle oscillations that constitute sway. Of these, the force plate is most frequently utilised (Ruhe, Fejer, \& Walker, 2010). Through use of mechanically sensitive sensors located on the plates' surface, it is possible to obtain quantitative data regarding deviations in the position of the body's centre

of pressure (COP) over time (Dehner et al., 2008). In simple terms, the COP is the point at which the pressure of the body over the soles of the feet would be if it were concentrated in one spot. It is not to be confused with the centre of mass which is a point equivalent to the position of the total body mass and is commonly accepted to be located around the S2 segment during upright posture (Ruhe et al., 2010). It has now been established that the two trajectories 
display identical mean positions when recorded over a long duration (Rougier, 2008).

Measurement of the different parameters of COP displacement therefore gives important insight into the position of the body's mass and the activity of the postural control system as it attempts to maintain equilibrium over its base of support (Rougier, 2008; Ruhe et al., 2010).

Posturography is now being utilised in sporting, clinical and experimental environments as a non-invasive clinical assessment tool to obtain objective, detailed information regarding balance and postural control. This information has many applications including the screening and diagnosis of balance disorders and as a clinical outcome measure in physical therapy and clinical studies (Cohen, Blatchly, \& Gombash, 1993; Visser, Carpenter, van der Kooij, \& Bloem, 2008). Results from studies utilising posturographic analysis have shown that a wide range of factors may have a deleterious effect on postural sway. These include external factors such as sleep deprivation, environmental toxins and prescription medication (Allain, Bentue-Ferrer, Polard, Akwa, \& Patat, 2005; Karita et al., 2006; Sack et al., 1993). Internal factors include age, pathology affecting the neurological, visual, and vestibular systems and musculoskeletal complaints (Brumagne, Cordo, \& Verschueren, 2004; Visser et al., 2008). Neck pain, of both traumatic and non-traumatic origin, is an example of a common musculoskeletal complaint that has been associated with increased measures of postural sway.

\subsection{Functional Anatomy of the Cervical Region}

The neck, or cervical region, is a complex and intricate structure that enables fine motor control of the head in three dimensions of movement. Its structure allows for the precise orientation of the major sensory organs of the head whilst also maintaining stability and control against destabilising forces (Falla \& Farina, 2008). The osseo-ligamentous structure of the cervical spine itself is inherently unstable, contributing a mere $20 \%$ to the mechanical stability of the structure. The remaining $80 \%$ is provided by the surrounding neck musculature (Hodges, 2000; Panjabi et al., 1998). While the ligaments provide support at end of range postures, the 
paraspinal musculature is responsible for providing dynamic support and control during daily activities (Hodges, 2000).

\subsection{The Proprioceptive Properties of the Cervical Region}

The cervical region is one of the most refined proprioceptive areas in the human body (Humphreys, 2008). This is reflected by the abundance of muscle spindles and mechanoreceptors located within the joint capsules, ligaments and paraspinal musculature. This is especially true of the suboccipital musculature which possess around 200 spindles/g of muscle (Boyd-Clark, Briggs, \& Galea, 2002; Kulkarni, Babu, \& Chandy, 2001). By comparison, the first lumbrical in the thumb contains a mere 16 spindles/g of muscle, and the gluteus maximus contains a mere 0.8 spindles/g (Liu, Thornell, \& Pedrosa-Domellöf, 2003; Treleaven, 2008a). The proprioceptive capability of the cervical spine is drawn upon by numerous supraspinal and reflex mechanisms. Many of these are involved in the regulation of postural homeostasis.

\subsection{The Role of the Cervical Region in the Postural Control System}

The cervical region plays a significant role in providing proprioceptive information to several components of the postural control system. It is characterised by extensive connections to the central nervous system including the vestibular nuclear complex and the superior colliculus, which are major relay centres for coordination of gaze and postural stability (Kristjansson \& Treleaven, 2009; Straka, Vibert, Vidal, Moore, \& Dutia, 2005). Cervical afferents are also directly linked to visual and vestibular systems (Heikkilä, Johansson, \& Wenngren, 2000; Treleaven, 2008a) and converge on the central cervical nucleus which serves as a pathway to the cerebellum where vestibular, ocular and proprioceptive information is integrated (Kristjansson \& Treleaven, 2009). In addition, sensory information from the cervical region contributes directly to several postural reflexes; the cervico-collic reflex, the cervico-ocular reflex, the tonic neck reflex and the vestibulospinal reflex, which are involved with ensuring the stability of the head and neck and coordination of postural homeostasis (Humphreys, 2008; Morningstar et al., 
2005; Treleaven, 2008a; Windhorst, 2007). The central nervous system also draws upon proprioceptive information from cervical tissues to aid in the creation of an internal reference frame, or body schema, with which it orientates the body in relation to both itself and the surrounding world (Lackner \& DiZio, 2000; Proske \& Gandevia, 2012). This schema is used as a

reference frame within which kinaesthetic information is interpreted and motor commands are generated (Massion, 1994).

Ideally, the body should be able to generate rapid motor responses to counter small deviations in the body's COP and thus to maintain balance. Any condition affecting the components of the postural control system may impair this process (Ruhe, Fejer, \& Walker, 2011). The neck, as a significant contributor to the postural control system, is of particular importance. Numerous painful conditions that affect the neck have been associated with increased postural sway. These include nonspecific neck pain (Field, Treleaven, \& Jull, 2008; Jull, Sterling, et al., 2008; Vuillerme \& Pinsault, 2009), whiplash (Dehner et al., 2008; Sjostrom et al., 2003; Treleaven, 2007), osteoarthritis (Boucher, Descarreaux, \& Normand, 2008) and muscular fatigue (Schieppati, Nardone, \& Schmid, 2003; Stapley, Beretta, Toffola, \& Schieppati, 2006).

\subsection{Neck Pain}

By definition, neck pain is pain perceived as arising in a region bounded superiorly by the superior nuchal line, laterally by the lateral margins of the neck, and inferiorly by an imaginary transverse line through the T1 spinous process (Bogduk, 2011). This description simply defines the location in which the pain is felt; the actual cause of the pain may lie outside of these perimeters.

\subsection{Prevalence of Neck Pain within the New Zealand Population}

Neck pain is a common complaint that affects people of every age and nationality. While the statistics vary between populations the 12-month prevalence of neck pain is estimated to lie 
between $30 \%$ and $50 \%$ with a lifetime prevalence of $43 \%$ to $66.7 \%$ (Côté, Cassidy, \& Carroll, 1998; Côté et al., 2009). These figures are drawn from data from cross sectional and cohort studies that include 86 different populations conducted in countries around the world, predominantly in North America and Europe (Côté et al., 2009). Neck pain is also associated with a high recurrence rate and, subsequently, high economic costs (Lindstrøm, Schomacher, Farina, Rechter, \& Falla, 2011; McNair, Portero, Chiquet, Mawston, \& Lavaste, 2007).

There is a paucity of data concerning the prevalence of neck pain within the New Zealand population. The New Zealand Accident Compensation Corporation (ACC) provides personal cover for injuries resulting from accidents in the home, workplace or community (ACC, 2012). An analysis of data from the ACC database was conducted for the period July 2011 - July 2012 (ACC, 2012). In an effort to more accurately estimate statistics that would reflect complaints seen by manual therapists, the search was limited to diagnoses related to concussion, gradual onset, soft tissue injury, and occupational, non-occupational and idiopathic (unknown) causes. Consequently, diagnoses related to fractures, amputations, self-inflicted injury, facial injuries such as dental, ear or eye, and those restricted to the skin or superficial regions ( i.e. burns and laceration), and poisoning were excluded. From this analysis, New Zealand appears to have an annual incidence of approximately $1.95 \%$ based on 86360 new claims reported during that period (ACC, 2012; Bascand, 2012). When this figure was combined with the 108000 already active claims, as of July, 2011, the national prevalence rate of accident-related neck pain was estimated to be $4.40 \%$, with a resulting total cost to the country of approximately $\$ 70$ million (ACC, 2012) . Neck pain, as reported by ACC, cannot be compared directly to previous estimates of overall neck pain prevalence because ACC only provides cover for neck pain that is a direct result of an accident or work-related factor. The statistics retrieved from the ACC database only reflect claims accepted by ACC, and therefore do not include neck pain of insidious onset, nontraumatic origin, or trauma-induced neck pain that was not lodged with ACC. Therefore, a $4 \%$ prevalence of injury-related neck pain is likely to vastly under-represent the overall prevalence of neck pain amongst the New Zealand population. 
Manual therapists are frequently consulted for treatment and rehabilitation of neck pain conditions. Considering the importance of the cervical region to the postural control system, it seems that the continued research into effective treatment techniques is of utmost importance for the successful rehabilitation of these patients. Such development is assisted by the growing body of research surrounding the pathophysiology of the pain response, and the influence of pain-induced changes on the functional performance of the neuromusculoskeletal system during everyday motor tasks.

\subsection{The Pathophysiology of Pain}

Pain is an inherently disagreeable sensation which is the product of an extraordinarily complex and interactive series of mechanisms integrated at all levels of the nervous system. There are three different classifications of pain, each with their own characteristic perceptual, emotional and neurophysiological qualities (Guyton \& Hall, 2006; Henderson, Bandler, Gandevia, \& Macefield, 2006; Serpell, 2005). Somatic or musculoskeletal pain is derived from the skin, muscles and other structures. Neurogenic pain results from direct injury to a nerve or the central nervous system itself, and visceral pain is due to the stimulation of low density nociceptors located within the visceral system (Guyton \& Hall, 2006; Millan, 1999; Serpell, 2005). Most commonly it is slow, somatic pain that is associated with musculoskeletal injury and therefore it is this pain that forms the primary focus for manual therapists and medical specialists (Serpell, 2005). Within the structures of the musculoskeletal system there are two

recognised types of pain: superficial, or cutaneous, pain and deep pain (Henderson et al., 2006). These types of pain originate from stimulation of nociceptors, which are widespread through the superficial layers of the skin as well as deeper structures including periosteum, arterial walls, muscles, ligaments, joint capsules, annulus fibrosis of the intervertebral discs and the falx and tentorial membranes of the cranial vault (Guyton \& Hall, 2006; Holm, Indahl, \& Solomonow, 2002). 
The affective response elicited by pain of deep origin (muscles, joints and viscera) is quite distinct from that evoked by cutaneous pain. Perceptually, pain of cutaneous origin is easily localised, possesses a sharp and/or hot-burning quality. Cutaneous pain generally triggers what is termed 'active emotional coping' response which is characterised by 'fight or flight' behaviours and the reflexive pain withdrawal reflex (Bandler, Keay, Floyd, \& Price, 2000; Guyton \& Hall, 2006; Henderson et al., 2006). Deep pain, by comparison, is often described as "dull, diffuse, throbbing, or inescapable" and is often difficult to localise (Henderson et al., 2006). Deep pain generally evokes a reaction of quiescence and decreased responsiveness to the environment, termed 'passive emotional coping' (Bandler et al., 2000; Henderson et al., 2006)

Cutaneous and deep somatic pain each produces distinctly different patterns in regional brain activity. Functional MRI scans have identified signal differences in regions implicated in emotion, stimulus localisation and motor control. Furthermore, these signal changes were seen to be correlated with participant reported changes in pain intensity (Henderson et al., 2006). Similar findings of distinct supraspinal changes have been observed by other authors (Bandler et al., 2000; Keay \& Bandler, 2002). It is thought that these supraspinal changes may be responsible for the different perceptual and behavioural characteristics elicited by deep and cutaneous pain (Bandler et al., 2000; Henderson et al., 2006).

Musculoskeletal conditions such as strains, tears and overuse fatigue typically evoke lasting deep pain characterised by behavioural changes and adaptations to motor performance. It is this deep pain, and its associated functional changes, that manual therapists predominately manage. Therefore, unless specified, subsequent use of the term "pain" in this literature review will refer to deep somatic pain. 


\subsection{The Complex Response to Pain}

Changes in response to pain have been observed on many levels of the neuromuscular system. These range from simple alterations in neurological activity within muscles to more complex adaptions in muscle patterning, sensory processing and motor programming that involve both spinal reflex and supraspinal centres (Bie, Brown, \& Naguib, 2011; Hodges, 2011; Wall, Xu, \& Wang, 2002). These pain induced changes are the target of clinical interventions yet the understanding of the physiological mechanisms underlying pain adaptation remains limited. Over the years a number of authors have proposed theories to explain these changes. Well known examples include Travell's 'pain-spasm-pain' cycle and Lund's pain adaptation model (Lund, Donga, Widmer, \& Stohler, 1991; Travell, Rinzler, \& Herman, 1942). In contrast to these early theories that predict uniform, stereotypical responses, recent research has demonstrated that the neuromuscular response to pain is in fact, a complex phenomenon. Instead of a simple reflex mechanism, it is proposed that the response to pain is mediated by many different levels of the nervous system, involves changes to multiple components of the motor system and is unique to each individual (Falla, 2004; Haavik \& Murphy, 2012; Hodges, 2011; Van Dieën, Selen, \& Cholewicki, 2003).

\subsection{Maladaptive Responses to Pain}

A basic assumption would be that the complex responses to pain are geared toward protecting the body from perceived threat (Hodges, 2011; Wall et al., 2002). Reflex responses that are designed for this purpose are present throughout the body. Simple examples include the pain withdrawal and gag reflexes (Guyton \& Hall, 2006).

Within the neuromuscular system, pain has been associated with elaborate changes in motor strategy, muscular performance and central processing of sensory information. These pain induced changes in functional performance are thought to be further examples of the body's 
attempt to protect tissues from further harm (Falla, 2004; Hodges, 2011). Although such protective adaptations may prove to be beneficial in the initial period following injury, for example in the redistribution of loads and forces away from damaged tissues, the failure of these adaptations to resolve may in fact prove to be detrimental to the body in the longer term (Hodges, 2011). This phenomenon is well recognised in rehabilitation and is known as maladaptation (Flor, 2008).

It has been proposed that maladaptive changes also occur within the central nervous system. Neuroplastic changes in both the sensory and motor cortices have been seen to take place after only brief periods of painful stimulation (Henderson et al., 2006; Tinazzi, Fiaschi, et al., 2000; Wall et al., 2002). In conjunction with the alterations seen within the musculoskeletal system, it is suggested that these central changes may contribute to the development of chronicity of symptoms and provide an explanation for the changes in muscle activity and functional performance deficits seen in patients with painful disorders (Falla \& Farina, 2008; Flor, 2008; Haavik \& Murphy, 2012; Hodges, 2011).

\subsection{Pain-Induced Changes in Neuromuscular Performance}

People move differently in pain. Indeed, almost every aspect of the motor system, from the movement strategy of muscle groups to the morphology of individual muscle fibres, has been seen to undergo change in the presence of pain (Falla, 2004; Mannion, 1999). It has been suggested that these responses are mediated by neuroplastic changes within the central nervous system itself (Le Pera et al., 2001; Le Pera et al., 2000; Schabrun \& Hodges, 2012). The long term consequences of these neuromuscular adaptations may have implications for clinical practice as the restoration of motor and kinaesthetic performance has long been a mainstay of treatment and rehabilitation protocol. 


\subsection{Pain-Induced Impairment of Proprioceptive Function}

Impaired proprioceptive performance is well documented in individuals suffering from neck pain. This is significant because cervical afferent information is an important contributor to many aspects of the postural control system. As detailed above, the cervical region boasts extensive connections to the central nervous system and is directly involved with several postural reflexes. In addition, the cervical region is the only source of somatosensory information that is directly linked to visual and vestibular centres (Kristjansson \& Treleaven, 2009). The sensitive nature of the cervical region leaves it vulnerable, especially to trauma such as whiplash. It has been proposed that disturbances in afferent input from cervical proprioceptors may contribute to the sensorimotor disturbances observed in neck pain sufferers (Brandt \& Bronstein, 2001; Cheng, Wang, Lin, Wang, \& Lin, 2010).

Two possible mechanisms by which neck pain may directly impede the function of proprioceptive organs include direct mechanical trauma to tissues and irritation of chemosensitive receptors by the inflammatory mediators associated with tissue injury and fatigue (Falla \& Farina, 2008; Martin, Weerakkody, Gandevia, \& Taylor, 2008; Pickar, 2002; Schabrun \& Hodges, 2012; Triano, 2001). The response of muscle spindles to pain has been demonstrated experimentally with several studies reporting that muscle spindles become hypersensitive to stretch following chemically induced muscle pain (Matre, Sinkjær, Svensson, \& Arendt-Nielsen, 1998; Ro \& Capra, 2001; Thunberg et al., 2001). It was seen that the activation of nociceptors within muscles and paraspinal tissues excited fusimotor neurones, which in turn altered the sensitivity of muscle spindle afferents (Thunberg et al., 2001). Of note was that subsequent injection of anaesthetic (Thunberg et al., 2001) or intersection of the nerve supplying the muscle (Pedersen, Sjölander, Wenngren, \& Johansson, 1997) reduced spindle sensitivity. It was seen that the activation of nociceptors within muscles and paraspinal tissues excited fusimotor neurones, which in turn altered the sensitivity of muscle spindle afferents (Thunberg et al., 2001). Clinically, these findings have implications for the development of proprioceptive deficits and muscular tension in musculoskeletal conditions. 
Clinical neck pain of both traumatic and non-traumatic origin may also provide the necessary environment with which to facilitate such disturbances in the fusimotor system. A traumatic onset to neck pain is associated with the release of inflammatory irritants and also delivers a massive, transient afferent input onto the fusimotor neurones from nociceptors and mechanoreceptors within the paraspinal and muscular tissue (Thunberg et al., 2001). Although it is not associated with trauma, insidious onset, or work related, neck pain may nevertheless provide ischemic conditions and inflammatory mediators as a result of extended periods of static, strained postures and repetitive strain (Gosselin, Rassoulian, \& Brown, 2004; Windhorst, 2007). It has been suggested that impaired function of cervical proprioceptors in individuals with neck pain may be a contributing factor to the development of functional deficits such as impaired oculomotor performance, poor kinaesthetic acuity and increased postural sway (Kristjansson \& Treleaven, 2009; Ruhe et al., 2011; Uthaikhup, Jull, Sungkarat, \& Treleaven, 2012; Vuillerme, Pinsault, \& Vaillant, 2005).

The importance of cervical proprioceptive information in postural control has been demonstrated in experimental studies. Vibration to cervical musculature is reported to result in increased postural sway and induce body deviations during both walking and running in healthy individuals (Courtine, Papaxanthis, Laroche, \& Pozzo, 2003; Vuillerme, Danion, Forestier, \& Nougier, 2002). Similar responses were observed following injection of anaesthetic into cervical structures, surgical sectioning of cervical nerves (De Jong, De Jong, Cohen, \& Jongkees, 1977) and the development of fatigue in cervical musculature (Gosselin et al., 2004; Schieppati et al., 2003; Stapley et al., 2006; Vuillerme et al., 2002; Vuillerme et al., 2005). These disturbances in postural control are thought to result from the mismatch that is created between visual, vestibular and somatosensory input which then interferes with the estimation of body orientation (Röijezon, Björklund, \& Djupsjöbacka, 2011)

In order to form useful kinaesthetic sensation the CNS must be able to interpret the proprioceptive signals within the reference framework provided by the internal schema of the 
body (Lackner \& DiZio, 2005). The effect of altered proprioceptive input on this internal map is illustrated by the 'Pinocchio' illusion. Lackner (1988) found that an illusion of nose elongation can be induced if, while a participant is holding their nose, vibration is applied to the biceps brachii muscle. It is possible that impairment of cervical proprioception may influence the internal schema in a similar manner. This is supported by the observation that vibration of cervical musculature in healthy individuals results in increased repositioning error of the upper limb (Knox, Skoss, Cordo, Durrant, \& Hodges, 2006) and illusory changes in head (Taylor \& McCloskey, 1991) and trunk position (Ceyte, Cian, Nougier, Olivier, \& Roux, 2006) as well as the position of a visual target (Karnath, Reich, Rorden, Fetter, \& Driver, 2002).

Similar findings of impaired upper limb (Haavik \& Murphy, 2011; Knox, Beilstein, et al., 2006) and head repositioning accuracy have been documented in individuals with clinical neck pain when compared to controls (Heikkilä \& Wenngren, 1998; Palmgren, Sandström, Lundqvist, \& Heikkilä, 2006; Sjölander, Michaelson, Jaric, \& Djupsjöbacka, 2008). In addition, individuals suffering neck pain of both traumatic, and insidious onset, have been shown to exhibit impaired performance of smooth pursuit and saccadic eye movement tests in comparison to asymptomatic controls (Gimse, Tjell, Bjôrgen, \& Saunte, 1996; Heikkilä \& Wenngren, 1998; Treleaven, 2008b; Uthaikhup et al., 2012). These tests are commonly utilised to examine efficiency in oculomotor performance, a system that involves the cervico-collic and cervicocular reflexes which are generated by cervical afferents and work in conjunction with vestibular and visual system to coordinate stability of the head and eye movement control (Treleaven, Jull, \& Grip, 2011). Interestingly, these studies also reported concurrent findings that participants with neck pain demonstrated reduced joint position sense, impaired perception of verticality and an increase in postural sway (Heikkilä \& Wenngren, 1998; Uthaikhup et al., 2012).

The mechanisms underlying the functional disturbances observed in neck pain patients are complex. The above studies illustrate the importance of cervical proprioception to numerous components of the postural control system and highlight the consequences of aberrant cervical 
proprioception in terms of reduced kinaesthetic acuity, impaired oculomotor performance, and increases in postural sway. These findings are important as they may provide an explanation for the feelings of dizziness and instability that are often associated with neck pain disorders (Gimse et al., 1996; Kristjansson \& Treleaven, 2009). As a progression from this work, a separate body of research has concentrated on the effect of pain and altered proprioception on the function of the central nervous system. Findings from these studies suggest that maladaptive changes within the central nervous system may also play a significant role in the development and maintenance of functional impairments observed in neck pain patients (Haavik \& Murphy, 2012; Paulus \& Brumagne, 2008; Röijezon et al., 2011; Treleaven, ClamaronCheers, \& Jull, 2011; Yu, Stokell, \& Treleaven, 2011).

\subsection{Changes within the Central Nervous System}

The ability of the central nervous system to undergo plastic changes in response to changes in environment and sensory input is well recognised (Henderson et al., 2006; Wall et al., 2002). The response to pain is especially profound. Observations of the brain have identified a large number of structures that respond to nociceptive input. These include the primary and secondary somatosensory areas, thalamus, insula, prefrontal cortex, primary motor cortex, cingulate motor area, the brainstem and areas associated with movement imagery and somatic perception of limb movement (Apkarian, Bushnell, Treede, \& Zubieta, 2005; Le Pera et al., 2001; Peyron, Laurent, \& García-Larrea, 2000; Wall et al., 2002). These changes are surprisingly rapid. Both human and primate studies have reported that changes in cortical activity take place within the first few weeks following injury (Merzenich et al., 1983; Mogilner et al., 1993) and that chronic changes begin within the first two months (Churchill, Muja, Myers, Besheer, \& Garraghty, 1998). These changes take place in several forms including alteration of normal inhibition/excitation processes, atrophy of normal structures and formation of new connections (Wall et al., 2002).

Changes in proprioceptive input have also been shown to initiate neuroplastic change.

Observations of cortical activity in individuals following limb immobilisation (Avanzino et al., 
2013; Bassolino, Bove, Jacono, Fadiga, \& Pozzo, 2012; Roll et al., 2012) and transient deafferentation of the upper limb (Tinazzi et al., 1997) have found that plastic changes emerge rapidly within both motor and sensory cortices. Of interest was the finding that these neuroplastic changes did not occur in those patients who received supplementary proprioceptive stimulation through the duration of their immobilisation (Avanzino et al., 2013; Roll et al., 2012). The importance of proprioceptive input on functional performance is illustrated by a study by Bassolino et al. (2012) who demonstrated that a period of just 10 hours of immobilisation resulted in altered performance of a simple motor task. Although performance rapidly returned to baseline levels, these findings emphasise the importance of proprioception in maintaining motor efficiency. It has recently been hypothesised that the aberrant proprioceptive input associated with neck pain may be sufficient to induce maladaptive plastic changes in regions associated with sensorimotor integration (Haavik \& Murphy, 2012).

The ability of the brain to undergo plastic change, even during adulthood, is beneficial in terms of adaptation to new environments and the acquisition of new skillsets. It is now apparent however, that prolonged periods of pain and abnormal sensory stimulation may induce maladaptive change within the nervous system that has consequences in terms of sensorimotor integration and functional performance (Murphy, Haavik-Taylor, Wilson, Oliphant, \& Mathers, 2003; Nelson, Brooke, Mcllroy, Bishop, \& Norrie, 2001). It has been suggested that these neuroplastic changes, in conjunction with the effects of impaired cervical proprioception, may be responsible for the development of functional and proprioceptive impairments in neck pain sufferers (Brumagne, Cordo, Lysens, Verschueren, \& Swinnen, 2000; Haavik \& Murphy, 2012; Kristjansson \& Treleaven, 2009; Paulus \& Brumagne, 2008).

\subsubsection{Changes within the Sensory Cortex}

A substantial body of research has explored the influence of pain on sensorimotor processing. Findings from these studies have identified changes that suggest that pain induces changes in 
the internal body schema and that it influences the manner in which sensory information is processed within the central nervous system

A study by Paulus and Brumange (2008) investigated the interpretation of proprioceptive information from the upper limb in individuals with recurrent neck pain. This was achieved by passively moving the shoulder and upper limb and then examining alterations in head and trunk position. The results showed that participants with neck pain moved their head in a different direction to asymptomatic controls and that the magnitude of these movements were greater than those of control participants (Paulus \& Brumagne, 2008). Upon subjective appraisal of shoulder position during passive movement, the symptomatic group appraised the position of their shoulder to be significantly higher than the control group (Paulus \& Brumagne, 2008). Although the participants in the symptomatic group all had a history of recurrent neck pain, none of the participants reported any pain at the time of testing which suggests that the effect of pain on fusimotor drive and thus spindle sensitivity is unlikely to have been a contributing factor. Instead it is proposed that the modified interpretation of proprioceptive signals from the upper limb demonstrated by individuals with recurrent neck pain may represent alterations in the internal body schema (Paulus \& Brumagne, 2008). This theory is supported by studies which demonstrate that painful conditions are associated with changes in cortical activity that is suggestive of a reorganisation of the representation of painful regions within cortical maps, or schema (Flor, 2008; Flor, Braun, Elbert, \& Birbaumer, 1997; Pleger et al., 2004; Wall et al., 2002).

Further studies have reported findings that suggest that the manner in which sensory information is processed is altered in individuals suffering from painful conditions. A group led by Tinazzi used somatosensory evoked potentials (SEPs) to observe the passage of sensory information from the periphery up, through the spinal cord to supraspinal centres. The results from their studies indicated that symptomatic individuals (including carpal tunnel syndrome, cervical radicular pain and trigeminal neuralgia) have shown greater amplitudes of SEP spinal $\mathrm{N} 13$, brainstem P14, parietal N20 and N27 and the frontal N30 peaks in response to stimulation 
of the painful side, than nerves of asymptomatic individuals (Tinazzi, Fiaschi, et al., 2000; Tinazzi et al., 2004; Tinazzi et al., 1998). The specificity of these changes in peak amplitudes is significant. The N20 peak reflects the arrival of the afferent impulse at the primary somatosensory cortex (Mauguiere, 1999). Subsequent peaks are therefore thought to reflect somatosensory processing (Mauguiere, 1999). The generator of the N30 peak is still a matter of debate however, it is thought to be related to early sensorimotor integration (Rossi et al., 2003). Recent studies suggest that the N30 peak is related to a complex loop involving the basal ganglia, premotor cortex, supplementary motor area, primary motor cortex and thalamus (Cebolla, Palmero-Soler, Dan, \& Cheron, 2011; Kaňovský, Bareš, \& Rektor, 2003; Till et al., 1999). These altered SEP peak amplitudes are thought to reflect altered sensorimotor integration that may be due to neuroplastic changes within the sensory and motor cortex. While the exact mechanisms underlying these changes are yet to be determined it is interesting to note that the increases in SEP amplitudes shown by Tinazzi et al. were positively correlated with the magnitude of the patients pain (Tinazzi, Fiaschi, et al., 2000; Tinazzi et al., 2004).

\subsubsection{Changes within the Motor Cortex}

Control over upright stance is achieved via the coordinated action of postural muscles throughout the body. The generation and execution of motor commands that govern these muscles is the primary function of the motor cortex (Tsao, Galea, \& Hodges, 2010). Recent research into the effect of pain on this area of the brain has revealed that patients, in comparison to asymptomatic individuals, demonstrate altered excitability of the motor cortex (Kirveskari, Vartiainen, Gockel, \& Forss, 2010; Le Pera et al., 2001; Martin et al., 2008) and changes in the cortical representation of postural musculature (Tsao, Galea, \& Hodges, 2008).

A number of studies have observed a reduction in motor evoked potentials from the primary motor cortex following the induction of experimental muscle pain (Le Pera et al., 2001; Martin et al., 2008; Schabrun \& Hodges, 2012). These findings were thought to represent suppression of cortical motor cells and that they may reflect a protective mechanism to restrict movement of the painful area (Le Pera et al., 2001; Martin et al., 2008; Schabrun \& Hodges, 2012). The 
processes of short interval intracortical inhibition (SICI) and Intracortical facilitation (ICF) were explored as possible mechanisms to explain the observed reduction of cortical output. It was found that experimentally induced tonic pain resulted in increased $\mathrm{SICl}$ and reduced ICF (Schabrun \& Hodges, 2012). These findings suggest a complementary mechanism that may explain the inhibition of muscular activity seen in many studies (Schabrun \& Hodges, 2012).

A study of patients with recurrent back pain observed that the representation of trunk musculature in the motor cortex was different to that of asymptomatic individuals (Tsao et al., 2008). EMG activity from the transversus abdominus was recorded during rapid arm movement tasks. In addition, motor thresholds of transcranial magnetic stimulation (TMS) were determined for responses both ipsilateral and contralateral to the stimulated cortex. Responses of the transverse abdominus to TMS were also mapped over the contralateral cortex during voluntary contraction. Comparison of motor thresholds and map parameters between asymptomatic controls and individuals with lower back pain revealed significant differences in map parameters and motor thresholds between the two groups. Of interest was the concurrent observation that the lower back pain group exhibited delayed feed forward activation of abdominal muscular in comparison to controls. While this is well documented in patients with lower back (Hodges, 2001; Silfies, Mehta, Smith, \& Karduna, 2009) and neck pain (Falla, Jull, \& Hodges, 2004a), Tsao and colleagues noted that the degree of impairment in muscular engagement appeared to correlate with the reorganisation of trunk muscle schema in the motor cortex (Tsao et al., 2008). Similar observations of pain-induced reorganisation of muscular representation within the motor cortex have been reported by other authors (Sanes \& Donoghue, 2000; Tsao et al., 2010; Wall et al., 2002). Interestingly, motor training to improve feed forward activation of trunk musculature is reported to induce changes in the motor cortical representation of the abdominal muscles closer toward those seen in asymptomatic individuals (Tsao et al., 2010). This suggests that the plastic changes in cortical representation may be involved in the development of altered motor performance seen in symptomatic individuals. It has been suggested that, once these neuroplastic changes have become 
established, there may be no need for on-going afferent input to maintain the altered corticomotor output patterns (Wall et al., 2002).

While the research in this field is limited, the above findings give evidence of pain induced neuroplasticity within areas responsible for sensory processing, sensorimotor integration and the generation of motor commands. The functional changes seen in clinical patients provide further illustration of the far reaching effects of the pain response and may provide weight to the theory that some of the neuroplastic changes described above may, in reality, be maladaptive in nature.

\subsection{Pain-Induced Changes in Functional Performance}

The behaviour of skeletal muscle in the presence of pain has been the focus of much research. The findings from these studies demonstrate profound changes in functional performance including altered patterns of muscular recruitment (Arendt-Nielsen, Graven-Nielsen, Svarrer, \& Svensson, 1996; Madeleine, 2010), delayed postural responses (Falla, Jull, \& Hodges, 2004a; Hodges, 2001), reduced endurance (Falla, Rainoldi, Merletti, \& Jull, 2003; Jull, O'Leary, \& Falla, 2008) and altered force output of skeletal musculature (Lindstrøm et al., 2011).

\subsubsection{Altered Muscle Patterning During Functional Tasks}

In their resting state, muscles display only a minimal response to painful stimulation (GravenNielsen, Svensson, \& Arendt-Nielsen, 1997; Madeleine \& Arendt-Nielsen, 2005; Schabrun \& Hodges, 2012). Upon voluntary contraction however, pain is associated with significant changes in muscle excitability.

Observations of the activity of muscle groups during functional motor tasks have shown that symptomatic individuals demonstrate different patterns of muscular recruitment than asymptomatic individuals. This phenomenon is well documented in the cervical musculature but has also been noted in other areas of the body including musculature of the abdomen, 
shoulder girdle, lower limb and lumbar spine (Falla, 2004; Graven-Nielsen et al., 1997; Hodges, 2001; Selles, Wagenaar, Smit, \& Wuisman, 2001; Stackhouse et al., 2012; van der Hulst, Vollenbroek-Hutten, Rietman, \& Hermens, 2010).

The craniocervical flexion test was developed as a tool to assess the functional performance of the cervical flexors with a particular emphasis on the deep muscles; the longus capitis and colli (Jull, O'Leary, et al., 2008). Use of this test has demonstrated that patients suffering neck pain characteristically display impaired activation of these deep flexors with a concurrent increase in activity of superficial musculature (Falla, 2004; Falla \& Farina, 2008; Jesus-Moraleida, Ferreira, Pereira, Vasconcelos, \& Ferreira, 2011; Jull, 2004; O'Leary, Falla, \& Jull, 2011). The relationship between cervical pain and the magnitude of these changes has been explored and it has been noted that the degree of superficial muscle activity during dynamic contraction appears to have a correlation with reported pain levels (Lindstrøm et al., 2011; O'Leary et al., 2011).

These changes in muscle recruitment may have negative consequences for the functional performance of the cervical spine. Individuals with neck pain have been seen to demonstrate reduced range of motion across all stages of the craniocervical flexion test in comparison to asymptomatic controls (Falla, Jull, \& Hodges, 2004b). While this may be an attempt by the body to protect the painful area from further harm, emerging evidence suggests that the observed alterations in cervical muscle patterning may actually be maladaptive in nature. Correlations have been noted between these changes in functional performance and impairments such as increased fatigability of the effected musculature, altered ability to generate force in painful muscles, and morphological changes within the structure of the muscle tissues themselves (Falla, Jull, \& Hodges, 2004a)

\subsubsection{Accelerated Muscular Fatigability}

Numerous studies have shown that pain induced changes in motor function are accompanied by an increased rate of fatigability in the affected musculature. A study of 46 individuals with neck pain and 47 controls investigated EMG activity of neck musculature during the cranio- 
cervical flexion test. Their results showed that the neck pain group had a significant deficit in the force generated by their maximum voluntary contraction and reduced endurance at both moderate load ( $50 \%$ of maximum voluntary contraction) and low load ( $25 \%$ maximum voluntary contraction) sustained isometric contractions (O'Leary, Jull, Kim, \& Vicenzino, 2007). Similar demonstrations of reduced endurance have been seen in other studies of patients with chronic neck pain (Falla, Jull, Rainoldi, \& Merletti, 2004; Falla, Rainoldi, Jull, Stavrou, \& Tsao, 2004; Falla et al., 2003; O'Leary et al., 2007). The specificity of this impaired muscular function was investigated in a study of individuals with unilateral neck pain. Fatigability of the anterior cervical musculature was compared between the symptomatic and asymptomatic side. The results showed greater EMG signs of muscle fatigue on the painful side at both $50 \%$ and $25 \%$ of maximum voluntary contraction (Falla, Jull, Rainoldi, et al., 2004).

The retraining of the deep neck flexors is a focus for many neck pain rehabilitation programmes (Brukner \& Kahn, 2009; Jull, O'Leary, et al., 2008). A study by Falla et al. (2004) lends support to this protocol as their findings suggest that the characteristic pattern of superficial flexor dominance seen in neck pain patients may, indeed, be highly inefficient (Falla, Jull, Edwards, Koh, \& Rainoldi, 2004). EMG signals were recorded from the anterior scalene and sternocleidomastoid in 20 participants with chronic neck pain and 20 controls. The results showed significant differences between groups with the symptomatic individuals demonstrating reduced neuromuscular efficiency, as measured using the generated force and the integrated EMG, in both the sternocleidomastoid and anterior scalene muscles (Falla, Jull, Edwards, et al., 2004).

A possible explanation for these observed reductions in muscular endurance is the presence of morphological changes within the musculature itself (Falla \& Farina, 2005; Mannion, 1999; Mannion et al., 2000). Biopsy studies of patients with both lumbar and cervical pain have showed an increased proportion of the rapidly fatiguing type II fast twitch glycolytic and oxidative fibres in comparison to the slow twitch type I oxidative fibres than seen in matched controls (Mannion, 1999; Mannion et al., 2000; Uhlig, Weber, Grob, \& Müntener, 1995). In 
patients with neck pain, the average fibre conduction velocity was higher than that seen in asymptomatic controls. Furthermore the exercise induced decrease in conduction velocity was enhanced in neck pain patients (Falla \& Farina, 2005). These results are consistent with the increased proportion of Type II fibres noted in biopsy studies (Falla \& Farina, 2005). No such change in conduction velocity was seen in a study of experimentally induced pain in asymptomatic individuals (Farina, Arendt-Nielsen, \& Graven-Nielsen, 2005; Farina, ArendtNielsen, Roatta, \& Graven-Nielsen, 2008). While the duration of symptoms was shown to be a determining factor for degree of morphological changes (Mannion et al., 2000) another study of 20 patients with chronic neck pain of between 1 and 25 years showed no correlation between duration of symptoms and the degree of muscular fatigue (Falla, Rainoldi, Jull, et al., 2004). This then suggests that the fatigue is not exclusively due to morphological changes in tissue type. Although it is still unclear whether these changes precede, or are a consequence of pain, these findings present a strong case for the importance of early intervention and may present another mechanism by which changes seen in neck pain may persist to become chronic.

\subsubsection{Alterations in Muscular Force Output}

In contrast to the consistent measures of increased fatigability of painful musculature, the results from studies investigating the effect of pain on muscle force output are less conclusive. Theories to explain the variation of findings include redistribution of load between synergists (Falla \& Farina, 2008; Graven-Nielsen et al., 1997), redistribution of activity within the muscle itself (Falla, Farina, \& Graven-Nielsen, 2007; Hodges, 2011) and potentiation within the muscle fibres that allow the muscle to maintain force output on its own (Rassier \& Macintosh, 2000; Sohn, Graven-Nielsen, Arendt-Nielsen, \& Svensson, 2004). The consistent reporting of increased fatigability of painful muscles does not help to negate any of these proposed mechanisms as both the overuse of the motor units and the non-physiological use of muscles precipitate early fatigue (Falla, 2004; Rassier \& Macintosh, 2000).

During experimental muscle pain, maximum voluntary contraction has been seen to be reduced (Graven-Nielsen et al., 1997; Stackhouse et al., 2012). In clinical studies maximum voluntary 
contraction force was lower in symptomatic individuals than in asymptomatic controls (Lindstrøm et al., 2011; Schomacher, Farina, Lindstroem, \& Falla, 2012). The presumption that adaptions in response to pain are an attempt to prevent further harm may be supported by an accessory finding by Lindstrøm et al. (2011). In their study of 13 women with chronic neck pain, an inverse correlation was noted between the EMG activity of splenius capitus and the force generated by patients during maximum cervical flexion contraction (Lindstrøm et al., 2011). Furthermore the average of the muscular EMG amplitude (averaged across both sides) was positively correlated with the patients self-reported pain and disability (Lindstrøm et al., 2011).

By comparison, experimental pain studies that required only low level muscular contraction have demonstrated unaltered force output (Falla et al., 2007; Sohn et al., 2004). A study by Sohn et al. (2004) on the single motor unit within the masseter muscle revealed that despite a decrease in motor unit firing rate in response to painful stimulation, the muscle as a whole maintained force output (Sohn et al., 2004). Also in agreement with this is a study by Falla et al. (2007) which reported maintained force output despite a decrease in surface EMG activity over the trapezius muscle during voluntary contraction (Falla et al., 2007).

Although the mechanisms underlying these observed changes in force output are still to be elucidated, they are an illustration of the complex nature of the neuromuscular response to pain. Further research is warranted to determine how these observations may influence the development of future treatment and rehabilitation protocol.

\subsubsection{Impairment of Postural Responses}

Feed forward activation describes the engagement of postural muscles prior to the initiation of voluntary movement, for example waving of the arm. Research on healthy individuals has shown that this muscular activation occurs within $50 \mathrm{~ms}$ of the onset of arm movement which is too fast for even the swiftest of reflexes. Instead, this activation of postural muscles is considered to be pre-planned by the central nervous system (Falla, Rainoldi, Merletti, \& Jull, 2004). Studies on neck pain patients have found delayed activation of cervical musculature 
upon voluntary head movement, and also upon initiation of voluntary movement of the upper limb. This was seen especially in the deep cervical flexors (Falla, Jull, \& Hodges, 2004a, 2004b). Similar observations have been noted in individuals with lower back pain who displayed delayed feed forward activation of both the lumbar erector spinae (Silfies et al., 2009) and abdominal musculature in comparison to asymptomatic individuals (Hodges, 2001; Hodges, Moseley, Gabrielsson, \& Gandevia, 2003; Hodges, van den Hoorn, Dawson, \& Cholewicki, 2009).

A study of 21 patients with persistent neck pain used a helical axis model to describe the rotation and translation of cervical spine segments during functional movement tasks. The results showed that the symptomatic individuals demonstrated a general increase in irregularity of the axis of rotation of their cervical spines in comparison to controls (Grip, Sundelin, Gerdle, \& Stefan Karlsson, 2008). In addition, during a ball catching task, the symptomatic individuals demonstrated slower, more restricted, upper body movements. The increased irregularity in rotational axis was shown to be correlated with the patient's selfreported pain intensity (Grip et al., 2008).

The results of these studies clearly illustrate the extent of functional impairment in neck pain patients. The cervical musculature, in particular the longus colli and longus capitus, have an essential role in providing structure and support to the highly mobile cervical joint and lordotic structure (Jull, O'Leary, et al., 2008; Mayoux-Benhamou et al., 1994; Winters \& Peles, 1990). The observed impairment in their ability to control the movement of the head and neck and to execute efficient feed-forward stabilisation may leave the spine vulnerable to strain and potentially, further injury as a result of the redistribution of the forces toward structures that are unaccustomed to such loads (Falla \& Farina, 2008; Falla, Jull, \& Hodges, 2004a; Hodges, 2011; Hodges et al., 2009).

The studies above provide a perspective on the extensive effect that neck pain has on the functional performance of neck pain sufferers. Both clinical and experimental studies indicate that proprioceptive disturbances in the cervical spine and maladaptive changes in the central 
nervous system may be an important factor in the development, maintenance and progression of sensorimotor disturbances such as increased postural sway. Therefore, addressing these deficits is an essential step toward the development of effective treatment and rehabilitation programmes for neck pain patients.

\subsection{Treatment of Neck Pain Conditions}

The maintenance of quiet, upright stance is typically achieved without conscious effort until balance becomes compromised and results in feelings of instability and vulnerability (Tucker, Kavanagh, Morrison, \& Barrett, 2010a). To date, there is no conclusive evidence that manual therapy is an effective treatment option for increased postural sway. Due to the numerous causative factors of altered or increased postural sway it would seem impossible that a single treatment regime would provide a solution. A recent body of research however, has provided evidence to suggest that spinal manipulation may influence some of the fundamental factors contributing to increased postural sway in neck pain patients namely pain, peripheral proprioceptors and the process of sensorimotor integration.

\subsection{Spinal Manipulation and Segmental Dysfunction}

Manual therapy and spinal manipulation are not new. Records dating back to the middle ages describe the use of manual therapies in countries throughout the world, including Thailand, China, Egypt and Greece (Fryer, 2003; Pickar \& Bolton, 2012). Modern spinal manipulation techniques are defined by both the manner in which the techniques are applied and the intention with which they are used. During spinal manipulation, the practitioner delivers a dynamic thrust (impulse) to a specific vertebra. The velocity, magnitude and direction of the thrust is controlled by the practitioner (Pickar, 2002). The aim of manipulation techniques is to achieve joint cavitation, which is often accompanied by a "popping" sound (Gibbons \& Tehan, 2010). Manipulation is distinguished from mobilization in that it is delivered at or near the end of the physiological range of motion but not exceeding the anatomical limits of motion (Pickar, 
2002). One of the most common forms of spinal manipulation used by Osteopaths is the highvelocity, low-amplitude (HVLA) thrust (Gibbons \& Tehan, 2010; Pickar, 2002). The technique involves a dynamic thrust being delivered through a short-lever arm by manually contacting paraspinal tissues overlying the spinous, or transverse, process of the vertebra being manipulated (Pickar, 2002).

The thrust is targeted to a specific segment, a manipulable lesion, which is detected by palpation. The terminology used to describe this targeted spinal segment varies between professions. Osteopaths often use the term "somatic dysfunction", "segmental dysfunction" or “Osteopathic lesion”(Fryer, 2003; Gibbons \& Tehan, 2010; Parsons \& Marcer, 2006) while Chiropractors may use "vertebral subluxation" or "spinal fixation" (Haavik \& Murphy, 2012). Although the given name is variable, the diagnostic criteria are very similar. Skilled palpation is used to identify altered tissue texture, pain or tenderness upon palpation temperature change and asymmetry in terms of range of motion and muscular tone which are considered characteristic qualities of segmental dysfunction (Fryer, 2003; Haavik \& Murphy, 2012; Parsons \& Marcer, 2006).

\subsubsection{The Nature of Segmental Dysfunction}

Over the years there have been a number of theories that have sought to explain the nature of a segmental dysfunction and the changes in tissue texture and motion restriction that are characteristic of these segments. Some of the more popular include the entrapment of meniscoids, zygopophyseal strains and the commonly cited 'pain-spasm-pain cycle' (Bogduk, 1997; Korr, 1975). Each of these has fallen out of favour in response to a lack of supporting evidence. A more recent theory proposes that the characteristic features of segmental dysfunction are a result of a series of concurrent functional and neurological mechanisms that are initiated by trauma to the paraspinal tissues (Fryer, 2003). Fryer suggests that the initial activation of nociceptors and inflammatory processes produces the altered tissue texture, restricted range of motion and local tenderness identifiable by palpation (Fryer, 2003). Once this acute stage has resolved, the neurological disturbance created by the barrage of 
nociceptive input may preserve these changes through processes such as central sensitisation, altered motor strategy and impairment of proprioceptive function (Fryer, 2003). These factors, discussed in detail above, are thought to predispose the cervical structures to overuse and further injury through the imposition of unaccustomed mechanical stress upon the tissues, loss of proprioceptive accuracy and maladaptive changes in motor strategy, thus initiating a perpetual cycle of further pain and dysfunction (Falla, 2004; Fryer, 2003; Hodges, 2011; Pickar, 2002; Stone, 1999).

Recently, it has been proposed that regions of segmental dysfunction may also affect the central mechanisms of sensory processing and sensorimotor integration (Haavik-Taylor \& Murphy, 2008, 2010a). It is thought that changes to the normal anatomical, physiological and biomechanical dynamics of the symptomatic vertebral segments creates a stream of abnormal sensory input to the central nervous system (Haavik-Taylor \& Murphy, 2008; Schieppati et al., 2003; Treleaven, 2008a; Yu et al., 2011). This region of altered afferent information may also create an abnormal environment into which afferent feedback from the spine and limbs is received and processed (Haavik \& Murphy, 2012). As a consequence, the process of sensorimotor integration of this afferent information is affected, which has implications for the subsequent generation of accurate motor output (Treleaven, 2008a). Several authors have proposed that such alterations in central processing may contribute to the functional impairments seen in neck pain patients (Haavik \& Murphy, 2012; Paulus \& Brumagne, 2008; Treleaven, 2008a; Yu et al., 2011).

Researchers from a group led by Haavik and Murphy propose that spinal manipulation may normalise the afferent activity surrounding the dysfunctional segments thus helping to correct sensorimotor integration (Haavik-Taylor \& Murphy, 2007b, 2010a; Haavik \& Murphy, 2012). Their work is supported by a growing body of research surrounding the effects of spinal manipulation on sensory processing, motor patterning and output, sensorimotor integration and functional performance (Coronado et al., 2012; Haavik-Taylor \& Murphy, 2008; Haavik \& 
Murphy, 2012; Heikkilä et al., 2000; Jesus-Moraleida et al., 2011; Maigne \& Vautravers, 2003; Smith \& Mehta, 2008).

\subsection{Spinal Manipulation to Address Abnormal Sensorimotor Integration and Motor Function}

Despite its long history of use, the exact mechanisms underlying the therapeutic effects of HVLA manipulation are still largely unknown. Spinal manipulations are, by their very nature, a mechanical input to the tissues. During the thrust itself, forces are imposed on the joints and paraspinal tissues only very briefly $(<150 \mathrm{~ms})$ however, the effects elicited are widespread throughout the biomechanical and neurological systems and are known to persist long after the initial event (Pickar \& Bolton, 2012).

Findings from recent studies have provided evidence that the manipulation of dysfunctional segments improves range of motion in restricted joints and has an analgesic effect on both central and peripheral sites (Coronado et al., 2012; Passmore, Burke, Good, Lyons, \& Dunn, 2010; Passmore \& Descarreaux, 2012). Functional changes subsequent to spinal manipulation range from alteration in muscular activity to improvements in kinaesthetic performance (Haavik-Taylor \& Murphy, 2007b; Haavik \& Murphy, 2011; Heikkilä et al., 2000; Palmgren, Lindeberg, Nath, \& Heikkilä, 2009).

The functional changes seen in response to manipulation indicate a neurological basis behind the therapeutic effects of the technique. This is supported by observations that spinal manipulation is associated with changes in both central and peripheral nervous system activity (Dishman \& Burke, 2003; Dishman, Greco, \& Burke, 2008; Haavik-Taylor \& Murphy, 2007b, 2010a). It has been hypothesised that these changes are the product of reduced nociceptive activity and a synchronous barrage of afferent input produced by direct activation of peripheral receptors within the paraspinal structures (Maigne \& Vautravers, 2003; Pickar, 2002; Pickar \& 
Bolton, 2012; Pickar, Sung, Kang, \& Ge, 2007; Triano, 2001). Concurrent measurements of improved proprioceptive performance and decreased pain levels lends support to this theory (Fernández-de-las-Peñas, Palomeque-del-Cerro, Rodríguez-Blanco, Gómez-Conesa, \& Miangolarra-Page, 2007; Martínez-Segura, Fernández-de-las-Peñas, Ruiz-Sáez, López-Jiménez, \& Rodríguez-Blanco, 2006; Passmore et al., 2010; Van Schalkwyk \& Parkin-Smith, 2000).

\subsection{Analgesic Effects of Spinal Manipulation}

The effect of spinal manipulation on both clinical and experimental pain levels has been heavily researched. A number of authors have conducted reviews on these studies in order to gain a coherent perspective on the available data. Due to factors such as the heterogeneous nature of neck and back pain populations, variability of manipulative techniques and the subjectivity of some outcome measures, the ability to draw conclusions from studies is limited (Coronado et al., 2012; Ernst, 2003; Goertz, Pohlman, Vining, Brantingham, \& Long, 2012; Gross et al., 2010). Despite these limitations there is general consensus amongst reviewing authors that there is evidence that spinal manipulation does indeed have an analgesic effect.

\subsubsection{Spinal Manipulation in Clinical Pain}

The relief of pain is a primary factor that motivates a person to seek manual therapy treatment. As such, subjective patient reported outcome measures are commonly used in manual therapy research. Four systematic reviews (Bronfort, Haas, Evans, Kawchuk, \& Dagenais, 2008; Bronfort, Haas, Evans, \& Bouter, 2004; Vernon \& Humphreys, 2008; Vernon, Humphreys, \& Hagino, 2007) and one Cochrane review (Gross et al., 2010) have recently been conducted on the effectiveness of spinal manipulation in the treatment of lower back and neck pain. In these reviews, the authors focussed on patient reported outcome measures such as the visual analogue scale, the 11 point numerical pain reporting scale, and the neck disability index.

In regard to patient reported pain levels, Bronfort et al. (2004) and Bronfort et al. (2008) found a moderate level of evidence to suggest that spinal manipulation is comparable in effect to a 
prescribed Non-Steroidal Anti-Inflammatory Drug (NSAID) for the short (<3months) and long term (>3 months) relief of chronic lower back pain. These authors also found a moderate level of evidence that spinal manipulation is more effective than general practitioner care and other methods of physical therapy in the treatment for chronic lower back pain (Bronfort et al., 2004). In regard to interventions that utilised more than one treatment, there was "limited to moderate" evidence to suggest that manipulation is superior to other manual therapy and home exercise in both the short and long term treatment of chronic lower back pain (Bronfort et al., 2008; Bronfort et al., 2004). In regard to placebo, Bronfort et al. (2008) reported a moderate level of evidence that manipulation is superior in effect for the treatment of chronic lower back pain, however, (Bronfort et al., 2004) found only limited evidence of its efficacy.

The number of studies that have explored the effect of spinal manipulation on neck pain is limited. In a Cochrane review of the effect of spinal manipulation on neck pain, Gross et al. (2010) found only low quality evidence (3 trials) that cervical manipulation alone is superior to control in providing immediate and short term pain relief in individuals with acute or sub-acute neck pain. This is in contrast to two systematic reviews that reported moderate-to-high quality evidence that cervical spine manipulation results in immediate improvements in pain levels (Vernon \& Humphreys, 2008) that may last up to several months post treatments (Vernon et al., 2007). Bronfort et al. (2004) reported inconclusive evidence as only one trial in their review met their inclusion criteria. This disagreement between authors may not simply be due to the release of new literature but may possibly also stem from differences in methodology used in the review process. When comparing spinal manipulation to other interventions Gross et al. (2010) reported low quality evidence to suggest that cervical manipulation in isolation is superior to Transcutaneous Electrical Nerve Stimulation (TENS) (1 trial) and equivalent to certain medication ( 2 trials), acupuncture ( 2 trials) and certain soft tissue techniques ( 1 trial) in the relief of sub-acute and chronic neck pain. By comparison, Bronfort et al. (2004) declined to comment on pain relief outcomes due to inadequate evidence. In regard to functional performance outcomes however, this review reported moderate evidence to suggest that spinal manipulation is superior to general practice medical care and physical therapy in the 
short term for improving physical functional ability and that it is equivalent to high-technology rehabilitative exercise in the short and long term (Bronfort et al., 2004).

The above reviews provide an interesting perspective on the collection of randomised controlled trials that are available to date. While the results from these articles must be interpreted with care, it appears that spinal manipulation does have a small but consistent effect on patient reported pain levels. The ability of these reviews to make accurate conclusions regarding the efficacy of the technique may be limited by several factors. A number of authors have remarked upon the large degree of heterogeneity that exists in study design, intervention protocol and measurement and reporting of pain outcomes. These inconsistencies considerably reduce the number of studies that meet the criteria to be included in meta-analysis or subgroup analysis. Furthermore, the strict methodology of these review articles excludes all but those studies that follow a randomised controlled design. These two factors severely limit the number of studies that meet the inclusion criteria for consideration. Therefore, it is possible that the results of the above reviews present only a conservative estimate of the true efficacy of spinal manipulation.

\subsubsection{Spinal Manipulation in Superficial Pain}

A small collection of randomised controlled trials have explored the effect of spinal manipulation on experimental pain, as measured by pressure-pain thresholds. The results from these studies demonstrated that cervical spine manipulation of symptomatic individuals is associated with improved pressure pain thresholds. A study on 37 individuals with neck pain recorded statistically significant increases in pain threshold over the cervical region, upper trapezius and deltoid following an HVLA thrust to C5/6 (Maduro de Camargo et al., 2011). Findings in agreement with this study have been seen in other studies on cervical manipulation of symptomatic participants (Mansilla-Ferragut, Fernández-de-las Peñas, Alburquerque-Sendín, Cleland, \& Boscá-Gandía, 2009; Parkin-Smith \& Renter, 1998; Sterling, Jull, \& Wright, 2001; Suter \& McMorland, 2002). Improvements have also been noted after cervical and thoracic 
manipulation of asymptomatic participants (Fernández-de-las-Peñas, Alonso-Blanco, Cleland, Rodríguez-Blanco, \& Alburquerque-Sendín, 2008; Fryer, Carub, \& Mclver, 2004).

Increases in pressure pain thresholds following spinal manipulation have also been reported in peripheral sites. These include a bilateral increase in pressure pain thresholds over the lateral epicondyle in individuals suffering lateral epicondylagia (Fernández-Carnero, Fernández-de-lasPeñas, \& Cleland, 2008) and in the upper trapezius and deltoid region of individuals with neck pain (Maduro de Camargo et al., 2011). In contrast to these studies, several authors failed to show statistical improvement of pressure pain thresholds following manipulation to participants with neck pain (Van Schalkwyk \& Parkin-Smith, 2000), or asymptomatic individuals (Bishop, Beneciuk, \& George, 2011).

Due to the fact that pain is a subjective measurement, the phenomenon of a placebo effect must be acknowledged. The common perception that a vertebra has been 'put back in place', the audible cracking sound and the manual contact preceding the technique are all thought to contribute to a placebo analgesic effect (Maigne \& Vautravers, 2003). Nevertheless, the body of research currently available provide substantial evidence to suggest that spinal manipulation is effective in relieving pain in both local and peripheral tissues. The significance of this is profound when considering the influence that pain has on the many components of the postural control system.

\subsection{Neurophysiological response to manipulation}

In addition to its analgesic effects, spinal manipulation has been seen to affect neurological processes from peripheral proprioceptors to central processing of sensory information (Haavik \& Murphy, 2012; Jesus-Moraleida et al., 2011; Maigne \& Vautravers, 2003; Pickar \& Bolton, 2012; Smith \& Mehta, 2008). This work has been built upon by a series of studies conducted by Haavik and Murphy. Their findings suggest that manipulation of the cervical spine of individuals with neck pain may alter, not only sensory processing, but motor output, functional performance and sensorimotor integration (Haavik-Taylor \& Murphy, 2007b, 2010a; Haavik \& 
Murphy, 2012). The group suggests that spinal manipulation may act to normalise the afferent activity surrounding the dysfunctional segments and thus help in the treatment and rehabilitation of sensorimotor disturbances.

\subsubsection{Activation of Peripheral Receptors}

Improved kinaesthetic performance in the form of head repositioning accuracy and upper limb joint position sense has been reported following cervical spine manipulation of symptomatic individuals (Haavik \& Murphy, 2011; Palmgren et al., 2006; Passmore et al., 2010; Rogers, 1997). In one study, improvements in head repositioning accuracy were accompanied by concurrent reductions in reported episodes of dizziness and vertigo (Heikkilä et al., 2000). The authors of these studies hypothesised that these results may be the product of an alteration in proprioceptive input arising from the direct activation of proprioceptive receptors located within the cervical paraspinal tissues.

Research into the properties of various peripheral receptors have identified four classes of primary afferents neurons that may be expected to respond to the mechanical force applied by the average HVLA thrust. These are the group Ia, Ib, and II(Ab), III(Ad) IV(C) afferent fibres which represent the muscle spindles, golgi tendon organs and the mechanically and metabolically sensitive nociceptors within cutaneous and muscular tissue (Pickar \& Bolton, 2012; Williams, Smith, O'brien, Mitchell, \& Garry, 2008). The particular efficacy of manipulation in comparison to other manual techniques may be due to the mechanical properties of the technique. It appears that the thrust delivered during manipulation may offer unique sensory input to the nervous system, as compared to pre-thrust positioning and joint loading and control conditions (Dishman et al., 2008). For example paraspinal muscle spindles have shown to increase their resting discharge by $200 \%$ upon application of a manipulative thrust. This is comparable to the mere $30 \%$ in response to the culminating preload of forces before thrust delivery (Pickar, 2002). Golgi tendon organs, which are normally silent at rest, have also been shown to be activated more by manipulative thrust than the preload in preparation for the thrust (Vuillerme et al., 2002). These findings suggest that spinal manipulation results in a 
relatively synchronous, high frequency, barrage of sensory input from the activation of these receptors, as well as the physical event of the movement itself. This would all occur over the very brief (<150 ms) duration of the manipulative thrust (Pickar, 2002; Pickar \& Bolton, 2012; Pickar et al., 2007).

Experimental studies have found that the stimulation of group la, II muscle afferents, and small diameter A- and C sensory fibres affects the synaptic efficacy of motor neurons (Collins, Honig, \& Mendell, 1984; Davis, Collins, \& Mendell, 1985). Synaptic efficacy reflects the ability of an individual synaptic input to evoke somatic postsynaptic potentials sufficient to trigger, or alter spiking activity (Komendantov \& Ascoli, 2009). Even simple forms of synaptic regulation can have a profound effect on neural function. Although the regulation of synaptic efficacy represents but one form of neural plasticity, the fact that it can be synapse-specific means that it provides a high degree of precision in terms of the modification of neural pathways (Clark, 2001). The importance of these findings is seen when considering the role of Group la and II fibres in the postural control system. Proprioceptive information is drawn largely from the group la fibres, which form their strongest connections with the $\alpha$-motor neurons involved with postural muscles (Burke, 2011 ). Group II afferents arise from secondary muscle spindle endings. These fibres make a smaller contribution to the $\alpha$-motor neuron excitation but are also involved in several inhibitory and excitatory reflexes that influence $\alpha$-motor neurone pools.

HVLA spinal manipulation has been shown to be associated with improvements in kinaesthetic performance and reduced pain levels at both local and peripheral sites. It has been proposed that these changes may be due to the correction of spinal dysfunction and thus the normalisation of afferent input to the CNS. It has also been suggested that they may result from the synchronous barrage of afferent input created by the manipulative thrust itself. While the exact mechanisms responsible for the neurophysiological effects of HVLA spinal manipulation are still to be determined, the extent of the changes associated with the technique has been shown to be extensive. Recent studies suggest that, in addition to the findings discussed above, 
cervical spine manipulation may also be capable of influencing supraspinal processing of sensory input and improve functional performance of individuals with neck pain.

\subsubsection{Cervical Spine Manipulation and Sensory Processing}

There is a growing base of evidence that suggests that pain has profound effect on the manner in which sensory information is processed and integrated within supraspinal centres. Recent studies on individuals with neck pain have reported cortical changes following cervical spine manipulation that suggest that the technique may influence the manner in which subsequent afferent information is processed within cortical centres.

Through the use of Somatosensory Evoked Potentials (SEPs), Haavik and Murphy (2007) observed a significant reduction in N20 and N30 SEP peak amplitudes, when compared to baseline measures, following a single HVLA manipulation to the cervical spine of 13 participants with recurrent neck pain (Haavik-Taylor \& Murphy, 2007b). Similar findings have been noted in several other studies of the effects of cervical manipulation on individuals with neck pain (Haavik-Taylor \& Murphy, 2010a, 2010b). These findings are significant as previous studies have noted that SEP peak amplitudes generated from painful regions are greater than those elicited from asymptomatic regions, or from controls (Kakigi, Shibasaki, \& Ikeda, 1989; Tinazzi, Fiaschi, et al., 2000; Tinazzi, Priori, et al., 2000; Tinazzi et al., 2004; Tinazzi et al., 1998). It is proposed that the reductions in SEP amplitudes seen in Haavik and Murphy's studies may therefore reflect alterations in cortical sensory processing and sensorimotor integration. As mentioned above, the parietal N20 and frontal N30 peaks are thought to be associated with sensorimotor processing. The lack of significant change in the peripheral, spinal, or brainstem SEP peaks following manipulation suggest that the changes took place within the brain itself (Haavik-Taylor \& Murphy, 2007b). Of interest was the observation that the changes in SEP amplitude persisted for up to 30 minutes post manipulation. Similar findings of persistent cortical changes following cervical manipulation of symptomatic individuals were also noted in a number of other studies by the group (Haavik-Taylor \& Murphy, 2010a, 2010b). 
Significantly, no changes in cortical activity were observed in any of the control groups (HaavikTaylor \& Murphy, 2007b, 2010a). In these studies, Haavik and Murphy utilised a passive head movement control that replicated the pre-thrust preparation but did not involve loading of the joint, nor a manipulative thrust. This control technique was designed as a physiological control for any possible changes produced by the cutaneous, muscular or vestibular input that may occur as a result of the pre-thrust phase of the technique (Haavik-Taylor \& Murphy, 2007b, 2010a). The lack of cortical changes within the control group therefore eliminates the possibility that the observed responses were due to mechanical or vestibular input resulting from the pre thrust movement and must therefore be a product of the thrust itself.

It has been proposed that the increased N30 SEP amplitudes observed in symptomatic individuals may be the product of inefficient sensory processing and integration and that they may reflect pain induced neuroplastic changes within the sensorimotor system (Tinazzi, Fiaschi, et al., 2000; Tinazzi, Priori, et al., 2000; Tinazzi et al., 2004). Haavik and Murphy have hypothesised that the reduction in N20 and N30 SEP peaks observed following cervical spine manipulation may reflect an improvement in sensory processing and integration, or possibly a normalisation of the pain/injury induced neuroplastic changes (Haavik-Taylor \& Murphy, 2007b). The observation that the changes persisted for up to 30 minutes after manipulation is, in itself, significant as and may suggest a lasting effect that has implications for the use of cervical spine manipulation as a therapeutic tool.

\subsubsection{Cervical Spine Manipulation and Surround Inhibition}

One possible explanation for the decreased SEP amplitudes seen in the above study is that cervical spine manipulation influences the process of surround inhibition. Surround, or lateral inhibition is a mechanism by which the nervous system amplifies information from one area by reducing the excitability of adjacent areas (Haavik-Taylor \& Murphy, 2010b). This acts to enhance the contrast between different stimuli, for example borders between colours and contours on objects. Within the motor system surround inhibition is essential for the selective activation of musculature in order to execute a desired movement and is associated with the 
development of fine motor skills. An example of this is the increased efficiency and dexterity of movement seen in dominant hands (Murphy et al., 2003; Nelson et al., 2001; H.-W. Shin, Sohn, \& Hallett, 2009).

It is possible to examine surround inhibition by recording SEPs whilst simultaneously stimulating two peripheral nerves, for example the median $(\mathrm{M})$ and the ulnar $(\mathrm{U})$ nerves. The amplitudes of the SEP peaks elicited by this dual stimulation (MU) are then compared with the sum of the SEP amplitudes obtained by stimulating each nerve separately $(M+U)$. In a healthy individual with efficient surround inhibition, the magnitude of SEPs elicited by simultaneous stimulation of the adjacent nerves (MU) is generally less than the sum of potentials evoked by stimulation of each nerve individually $(\mathrm{M}+\mathrm{U})$ (Cardini, Longo, \& Haggard, 2011; Tinazzi, Priori, et al., 2000). In individuals suffering from painful conditions however, an increase in the dual SEP peak ratio has been noted and is thought to reflect impaired surround inhibition (Tinazzi, Priori, et al., 2000). Such inefficient sensory processing is thought to contribute to the inaccurate motor output and subsequent functional impairment seen in sufferers of dystonia and Parkinson's disease (H. Shin, Kang, \& Sohn, 2007; Tinazzi, Priori, et al., 2000). In stroke patients, improvement in surround inhibition is related to recovery of motor function (Liepert, Haevernick, Weiller, \& Barzel, 2006; Manganotti et al., 2002).

Haavik and Murphy have conducted two studies that suggest that improved surround inhibition may be one mechanism behind the cortical changes observed following HVLA manipulation of dysfunctional cervical joints in individuals with a history of recurrent neck pain (Haavik-Taylor \& Murphy, 2010a, 2010b). In a study of 13 participants SEP amplitudes were measured during the dual stimulation of the median (M) and ulnar (U) nerves. SEP ratios were calculated before and after cervical manipulation and a passive head movement control intervention. The results demonstrated a significant decrease in the $\mathrm{MU}: \mathrm{M}+\mathrm{U}$ ratio for the cortical P22-N30 peak following cervical manipulation. No such changes were reported following the control intervention (Haavik-Taylor \& Murphy, 2010a). In a separate study, the same SEP ratio technique was used on 11 participants. Measurements were taken before and after a 20- 
minute typing task, and again when the typing task was preceded with cervical spine manipulation. The findings showed a significant increase in the $M U: M+U$ ratio for the $N 20$ and N30 cortical peaks following the 20-minute repetitive contraction task. This did not occur when the motor task was preceded with spinal manipulation. Instead, there was a significant decrease in the $\mathrm{MU}: \mathrm{M}+\mathrm{U}$ ratio for the cortical N30 SEP component. The ratio changes appear to be due to an improved ability to suppress the dual input as concurrent changes in the MU amplitudes were observed (Haavik-Taylor \& Murphy, 2010b).

The processing of sensory information is a vital component of motor control. The sensorimotor system continuously monitors and responds to the incoming stream of afferent input by appropriately altering the connectivity and strength of synaptic connections. The development and retention of such alterations is thought to underpin the acquisition of motor skills. In circumstances such as adaptation to injury or the sustained performance of a repetitive activity however, these changes may become maladaptive. Such maladaptive plastic changes are proposed to contribute to the perpetuation of chronic pain and dysfunctional motor performance. Previous studies have demonstrated that even short periods of repetition of a motor task is sufficient to initiate changes in SEP amplitude in the primary somatosensory cortex (N20) and in regions associated with sensorimotor integration (N30) (Haavik-Taylor \& Murphy, 2007a). This may reflect the natural process of skill acquisition however it may also reflect the mechanisms by which maladaptive motor patterns, such as those seen in neck pain patients, are developed. The findings from Haavik and Murphy's study indicate that manipulation of a dysfunctional cervical joint may alter the manner in which sensory information is processed (Haavik-Taylor \& Murphy, 2010a, 2010b). If the reduced sensory filtering following repetitive motor tasks reflects the process which may lead to the acquisition of maladaptive plastic changes within the CNS, then it is possible that manipulation of a dysfunctional cervical segment may prevent this process from occurring in patients with neck pain. The role of these cortical changes in terms of a patient's clinical presentation and functional performance is still to be elucidated. 


\subsubsection{Cervical Spine Manipulation and Motor Performance}

Research has shown that neck pain sufferers commonly demonstrate decreased recruitment of deep cervical flexors with concomitant over-recruitment of superficial musculature. This change is thought to be an example of maladaptive motor patterning and the retraining of the deep neck flexors is frequently endorsed as part of neck pain rehabilitation (Brukner \& Kahn, 2009; Falla, 2004; Jull, O'Leary, et al., 2008). Recent evidence suggests that cervical spine manipulation may influence the activity of the cervical musculature, and also that of the upper limb.

Sterling (2001) conducted a double blinded RCT on 30 participants with insidious onset mid to low cervical pain of at least three months duration. Pre-post measurements of deep flexor activity during the cranio-cervical flexion test were recorded using EMG. The results showed that the cervical manipulation intervention was followed by a significant increase in deep neck flexor activity during the initial three levels of the cranio-cervical flexion test. The placebo intervention by contrast, resulted in a significant increase in superficial muscle recruitment. Similar observations were made by Jesus-Moraleida et al. (2011) who used ultrasound to measure muscular activity in a study comparing individuals with neck pain to matched asymptomatic controls. Although the symptomatic group still displayed decreased deep neck flexor activity in comparison to controls there was a significant increase in recruitment following cervical manipulation. The amplitude of superficial muscular contraction decreased following manipulation. No significant changes were noted in the control group (JesusMoraleida et al., 2011). The mechanisms underlying this change in motor strategy are still unknown. It is possible that the recruitment of deep neck flexors may have been inhibited by painful spinal segments that were relieved by manipulation. However, during Sterling's study no patients reported pain whilst performing the cranio-cervical test, which may suggest that an analgesic effect may not be the primary mechanism of improved functional performance (Sterling et al., 2001). Of note was the lack of response from asymptomatic controls (JesusMoraleida et al., 2011). The fact that significant change was only seen in symptomatic 
individuals may support work from previous authors surrounding pain induced plastic changes in sensorimotor integration and motor strategy (Hodges, 2011; Wall et al., 2002).

In addition to alterations in activity of the neck musculature, cervical spine manipulation has also been associated with functional changes in the muscles of the upper extremity. Suter and McMorland (2002) explored the effect of manipulation to levels C5/6/7 on the strength and excitability of the biceps brachii muscle. In a test-retest design measurements of cervical range of motion and pressure-pain thresholds were taken from 16 participants with chronic neck pain. Biceps activation during a maximal voluntary contraction was assessed using the interpolated twitch technique and EMG. The baseline measures found that $87 \%$ of participants showed greater inhibition of their biceps than would be expected in healthy individuals, indicating that this muscle group cannot be fully utilised. Following manipulation there was a statistically significant reduction in muscular inhibition bilaterally, the force of elbow contraction increased as did the corresponding EMG readings (Suter \& McMorland, 2002). Several other authors have yielded similar results in muscular activity (Dunning \& Rushton, 2009; Maduro de Camargo et al., 2011) and force output (Fernández-Carnero et al., 2008) following cervical spine manipulation. The longevity of these effects however, was not explored in these studies.

The above studies provide evidence that cervical manipulation elicits short term effects on the functional performance of both paraspinal and upper limb musculature. However, due to a paucity of studies in this area, the long term effects of the technique and the effect of cervical spine manipulation on musculature without direct neurological links to the cervical spine has not been explored. As such, the full extent of the change in motor activity following spinal manipulation is yet to be established.

\subsubsection{Cervical Spine Manipulation and Postural Sway}

Increased magnitude of postural sway is well documented in neck pain sufferers of both traumatic and non-traumatic origin (Dehner et al., 2008; Field et al., 2008; Jull, Sterling, et al., 
2008; Ruhe et al., 2011; Sjostrom et al., 2003; Vuillerme \& Pinsault, 2009). As discussed previously, postural control is achieved through the complex process of sensorimotor integration, a process that cervical proprioceptive input contributes substantially. This design renders the postural control system vulnerable to the effects of maladaptive neuroplastic change and alterations in cervical proprioceptive input that are associated with neck pain conditions (Haavik \& Murphy, 2012; Kristjansson \& Treleaven, 2009; Ruhe et al., 2011; Treleaven, 2008a).

Findings from recent studies suggest that spinal manipulation may have a number of analgesic (Bronfort et al., 2008), neuromodulatory (Pickar, 2002; Pickar \& Bolton, 2012) and local functional effects (Passmore \& Descarreaux, 2012; Sterling et al., 2001). The research surrounding the wider functional effects, and possible clinical applications of the technique however, is limited. A small number of studies have reported significant improvements in postural stability following treatment interventions involving asymptomatic (Hawk, Pfefer, Strunk, Ramcharan, \& Uhl, 2007; Jones, 2003) and symptomatic individuals (Hawk, Cambron, \& Pfefer, 2009; Karlberg, Magnusson, Eva-Maj, Agneta, \& Moritz, 1996). The treatment protocols included the use of spinal manipulation amongst other techniques such as massage, trigger point, and hot/cold therapy. As an isolated intervention however, research into the effect of spinal manipulation on postural sway is very limited.

In a pre-post test design study of 23 asymptomatic individuals Nolan (2009) reported immediate reductions in postural sway following a single HVLA spinal manipulation to either $\mathrm{CO} / \mathrm{C} 1$ or $\mathrm{C} 1 / \mathrm{C} 2$. No such improvements were seen in the control group of 22 asymptomatic individuals that received a sham intervention involving a detuned ultrasound device applied to the same cervical levels. Due to the lack of age, gender and anthropometric differences between the control and test groups, the author concluded that the observed improvements in postural sway in the test group were due to the effects of the cervical spine manipulation intervention itself (Nolan, 2009). Similar findings of improved postural sway in asymptomatic individuals were reported by Smith and Mehta (2008). Their study of 11 asymptomatic 
participants observed significant reductions in postural sway parameters following HVLA manipulation to the upper cervical spine. No changes in postural sway was observed in 10 asymptomatic controls (Smith \& Mehta, 2008). In comparison to these studies, a time series study of six asymptomatic participants failed to report any statistical difference in postural sway following either cervical spine manipulation to $\mathrm{C} 5 / 6$, or a unilateral anaesthetic blockade of the spinal nerves above and below the C5/6 facet joint (Palmgren et al., 2009). Comparison of changes in respect to baseline revealed that all participants showed differences in postural sway however, this response was inconsistent and varied greatly between individuals. A similar trend was also seen following facet nerve blockade (Palmgren et al., 2009). To date, there are no known studies that have investigated the effect of cervical spine manipulation on the postural sway of individuals with neck pain.

The contrast between the results reported by Palmgren et al. (2009) to those from the studies conducted by Nolan (2009) and Smith and Mehta (2008) may be due to the level of the cervical spine to which the HVLA manipulations were applied. Anatomical and physiological studies of the cervical spine suggest that the upper cervical region may make a greater contribution to the postural control system than lower levels. In particular, it has been noted that the numerous connections that exist between cervical afferents and the vestibular, visual and reflex subsystems that contribute to head and eye orientation as well as postural control, arise predominantly from the upper cervical region (Barmack, 2003; Dubrovsky \& Barbas, 1977; Liu et al., 2003; Morningstar et al., 2005; Rose, Wainwright, \& Neuber-Hess, 1992; Shinoda, Ohgaki, Sugiuchi, \& Futami, 1989). In addition, it has been found that the muscles of the suboccipital region possess far greater numbers of proprioceptive muscle spindles than the deep musculature of the lower cervical spine. This difference is illustrated by a recent study of human cadavers which found that the superior oblique muscle possesses around 190 spindles/gram of muscle. The inferior oblique was found to contain around 242 spindles/gram of muscle and the rectus capitus posterior major and minor around 98 spindles/gram of muscle (Kulkarni et al., 2001). By comparison, dissection of the longus colli and multifidus from levels C5-C7 revealed that these muscles possess a mere 49 spindles/gram and 24 muscles/gram 
respectively (Boyd-Clark et al., 2002). This marked difference in proprioceptive sensitivity may be reflective of the dominant role that the upper cervical region plays in supplying afferent information to supraspinal centres. This increased sensitivity may also render the region more sensitive to the mechanical and neurological effects of HVLA spinal manipulation.

The unique anatomical and physiological characteristics of the upper cervical region may provide rationale for the greater effect size reported by Nolan (2009) and Smith and Mehta (2008) in comparison to Palmgren et al. (2009). However, it is unclear what mechanisms are responsible for improving postural stability in individuals who were believed to be asymptomatic and therefore not suffering any impairment in postural control.

The above findings indicate that HVLA spinal manipulation may have an influence the postural control system. However, the ability to draw conclusions in regard to the efficacy of the technique is limited by the small number of studies that are currently available.

\subsection{Summary}

Individuals with neck pain represent a significant proportion of the patients seen by manual therapists. In addition to subjective feelings of pain and discomfort, the clinical presentation of these patients often includes symptoms such as dizziness and feelings of unsteadiness. Upon examination, many studies have also found that many of these individuals also demonstrate signs of impaired sensorimotor performance in the form of reduced neck and upper limb proprioceptive acuity, oculomotor disturbances and impairments in postural control.

These disturbances in sensorimotor function are through to be the result of altered input from cervical proprioceptors and maladaptive neuroplastic changes within the central nervous system itself. A series of studies have demonstrated that neuroplastic changes take place in a number of areas including regions associated with sensory processing, sensorimotor integration and motor control. Their development is thought to be driven by the pain and impaired cervical proprioceptive input that are associated with neck pain disorders. It has been proposed that 
the persistence of these maladaptive changes may be responsible for the development, maintenance and progression of functional disturbances seen in neck pain patients. It is therefore vitally important that treatment and rehabilitation protocol for neck pain conditions include measures to address these disturbances to sensorimotor performance, and the neurophysiological disturbances that drive them.

Recent studies have demonstrated that HVLA manipulation to the cervical spine of individuals with neck pain is associated with a reduction in pain levels as well as a range of local neurophysiological and functional effects. These include improvements in oculomotor performance, improved kinaesthetic and motor function of the cervical region and upper limb and alterations in cortical regions associated with sensory processing and sensorimotor integration. Collectively, these findings suggest that there may be a central mechanism of action behind the functional effects of HVLA spinal manipulation. This is interesting when considering the possible clinical applications that the technique may have, particularly in the treatment of neck pain conditions. However, due to a paucity of studies that have investigated the wider effects of the technique, further research is necessary before any conclusions may be drawn in regard to the effectiveness of the technique in treating sensorimotor disturbances.

This study aims to further the existing body of research by determining the magnitude of effect of a single HVLA spinal manipulation on the postural sway of individuals with non-specific neck pain. This work will extend on the small number of studies that have demonstrated improvements in sway following cervical manipulation to asymptomatic individuals. In addition, the findings from this study may contribute to the growing base of research that aims to understand the complex mechanisms that underpin the functional and neurological effects of the technique. 


\subsection{References}

Accident Compensation Corporation. (2012, 1 December). Injury statistics tool Retrieved 10 December, 2012, from http://www.acc.co.nz/for-individuals/injury-statistics/index.htm\#results

Alexander, K. M., \& LaPier, T. L. (1998). Differences in static balance and weight distribution between normal subjects and subjects with chronic unilateral low back pain. Journal of Orthopaedic \& Sports Physical Therapy, 28(6), 378-383.

Allain, H., Bentue-Ferrer, D., Polard, E., Akwa, Y., \& Patat, A. (2005). Postural instability and consequent falls and hip fractures associated with use of hypnotics in the elderly. Drugs \& aging, 22(9), 749765. doi: 10.2165/00002512-200522090-00004

Apkarian, A. V., Bushnell, M. C., Treede, R. D., \& Zubieta, J. K. (2005). Human brain mechanisms of pain perception and regulation in health and disease. European Journal of Pain, 9(4), 463-463. doi: 10.1016/j.ejpain.2004.11.001

Arendt-Nielsen, L., Graven-Nielsen, T., Svarrer, H., \& Svensson, P. (1996). The influence of low back pain on muscle activity and coordination during gait: a clinical and experimental study. Pain, 64(2), 231-240. doi: 10.1016/0304-3959(95)00115-8

Avanzino, L., Pelosin, E., Abbruzzese, G., Bassolino, M., Pozzo, T., \& Bove, M. (2013). Shaping motor cortex plasticity through proprioception. Cerebral Cortex. doi: 10.1093/cercor/bht139

Bandler, R., Keay, K. A., Floyd, N., \& Price, J. (2000). Central circuits mediating patterned autonomic activity during active vs. passive emotional coping. Brain Research Bulletin, 53(1), 95-104. doi: 10.1016/S0361-9230(00)00313-0

Barmack, N. H. (2003). Central vestibular system: vestibular nuclei and posterior cerebellum. Brain Research Bulletin, 60(5-6), 511-541. doi: 10.1016/S0361-9230(03)00055-8

Bascand, G. (2012). National Population Estimates: December 2011 quarter, 2013, from http://www.stats.govt.nz/browse for stats/population/estimates and projections/NationalPo pulationEstimates HOTPDec11qtr.aspx 
Bassolino, M., Bove, M., Jacono, M., Fadiga, L., \& Pozzo, T. (2012). Functional effect of short-term immobilization: Kinematic changes and recovery on reaching-to-grasp. Neuroscience, 215(0), 127-134. doi: 10.1016/j.neuroscience.2012.04.019

Bie, B., Brown, D. L., \& Naguib, M. (2011). Synaptic plasticity and pain aversion. European Journal of Pharmacology, 667(1-3), 26-31. doi: 10.1016/j.ejphar.2011.05.080

Bishop, M., Beneciuk, J., \& George, S. (2011). Immediate reduction in temporal sensory summation after thoracic spinal manipulation The Spine Journal 11(5), 440-446.

Bogduk, N. (1997). Clinical anatomy of the lumbar spine and sacrum (3rd ed.). China Elsevier Churchill Livingstone

Bogduk, N. (2011). The anatomy and pathophysiology of neck pain. Physical Medicine and Rehabilitation Clinics of North America, 22(3), 367-382. doi: 10.1016/j.pmr.2011.03.008

Boyd-Clark, L. C., Briggs, C. A., \& Galea, M. P. (2002). Muscle spindle distribution, morphology, and density in longus colli and multifidus muscles of the cervical spine. Spine, 27(7), 694-701. doi: 10.1097/00007632-200204010-00005

Brandt, T., \& Bronstein, A. (2001). Cervical vertigo. Journal of Neurology, Neurosurgery \& Psychiatry, 71(1), 8-12. doi: 10.1136/jnnp.71.1.8

Bronfort, G., Haas, M., Evans, R., Kawchuk, G., \& Dagenais, S. (2008). Evidence-informed management of chronic low back pain with spinal manipulation and mobilization. The Spine Journal, 8(1), 213225. doi: 10.1016/j.spinee.2007.10.023

Bronfort, G., Haas, M., Evans, R. L., \& Bouter, L. M. (2004). Efficacy of spinal manipulation and mobilization for low back pain and neck pain: a systematic review and best evidence synthesis. The Spine Journal, 4(3), 335-356. doi: 10.1016/j.spinee.2003.06.002

Brukner, P., \& Kahn, K. (2009). Clinical sports medicine (Revised 3rd ed.). North Ryde: McGraw-Hill medical.

Brumagne, S., Cordo, P., Lysens, R., Verschueren, S., \& Swinnen, S. (2000). The role of paraspinal muscle spindles in lumbosacral position sense in individuals with and without low back pain. Spine, 25(8), 989-994. doi: 10.1097/00007632-200004150-00015 
Brumagne, S., Cordo, P., \& Verschueren, S. (2004). Proprioceptive weighting changes in persons with low back pain and elderly persons during upright standing. Neuroscience Letters, 366(1), 63-66. doi: 10.1016/j.neulet.2004.05.013

Burke, R. E. (2011 ). Motor units: anatomy, physiology, and functional organization. In J. M. Brookhart \& V. B. Mountcastle (Eds.), Handbook of Physiology. The Nervous System, Motor Control (Vol. 2, pp. 345-422). Bethesda, MD: American Physiological Society ( First published in print 1981). doi: 10.1002/cphy.cp010210

Cardini, F., Longo, M. R., \& Haggard, P. (2011). Vision of the body modulates somatosensory intracortical inhibition. Cerebral Cortex, 21(9), 2014-2022. doi: 10.1093/cercor/bhq267

Cebolla, A. M., Palmero-Soler, E., Dan, B., \& Cheron, G. (2011). Frontal phasic and oscillatory generators of the N30 somatosensory evoked potential. Neurolmage, 54(2), 1297-1306. doi: 10.1016/j.neuroimage.2010.08.060

Ceyte, H., Cian, C., Nougier, V., Olivier, I., \& Roux, A. (2006). Effects of neck muscles vibration on the perception of the head and trunk midline position. Experimental Brain Research, 170(1), 136140. doi: 10.1007/s00221-006-0389-7

Cheng, C.-H., Wang, J.-L., Lin, J.-J., Wang, S.-F., \& Lin, K.-H. (2010). Position accuracy and electromyographic responses during head reposition in young adults with chronic neck pain. Journal of Electromyography and Kinesiology, 20(5), 1014-1020. doi: 10.1016/j.jelekin.2009.11.002

Churchill, J., Muja, N., Myers, W., Besheer, J., \& Garraghty, P. (1998). Somatotopic consolidation: a third phase of reorganization after peripheral nerve injury in adult squirrel monkeys. Experimental brain research, 118(2), 189-196.

Clark, G. A. (2001). Synaptic efficacy, regulation of. In J. S. Editors-in-Chief: Neil \& B. B. Paul (Eds.), International Encyclopedia of the Social \& Behavioral Sciences (pp. 15371-15378). Oxford: Pergamon.

Cohen, H., Blatchly, C. A., \& Gombash, L. L. (1993). A study of the clinical test of sensory interaction and balance. Physical Therapy, 73(6), 346-351. 
Collins, W., Honig, M., \& Mendell, L. (1984). Heterogeneity of group la synapses on homonymous alphamotoneurons as revealed by high-frequency stimulation of la afferent fibers journal of Neurophysiology, 52(5), 980-993.

Coronado, R. A., Gay, C. W., Bialosky, J. E., Carnaby, G. D., Bishop, M. D., \& George, S. Z. (2012). Changes in pain sensitivity following spinal manipulation: a systematic review and meta-analysis. Journal of Electromyography and Kinesiology(0). doi: 10.1016/j.jelekin.2011.12.013

Côté, P., Cassidy, J. D., \& Carroll, L. (1998). The saskatchewan health and back pain survey: the prevalence of neck pain and related disability in saskatchewan adults. Spine, 23(15), 1689-1698. doi: 10.1097/00007632-199808010-00015

Côté, P., van der Velde, G., Cassidy, J. D., Carroll, L. J., Hogg-Johnson, S., Holm, L. W., . . Peloso, P. M. (2009). The burden and determinants of neck pain in workers: results of the bone and joint decade 2000-2010 task force on neck pain and its associated disorders. Journal of Manipulative and Physiological Therapeutics, 32(2, Supplement), S70-S86. doi: 10.1016/j.jmpt.2008.11.012

Courtine, G., Papaxanthis, C., Laroche, D., \& Pozzo, T. (2003). Gait-dependent integration of neck muscle afferent input. Neuroreport, 14(18), 2365-2368. doi: 10.1097/00001756-200312190-00015

Dallinga, J. M., Benjaminse, A., \& Lemmink, K. A. P. M. (2012). Which screening tools can predict injury to the lower extremities in team sports?: a systematic review. Sports Medicine, 42(9), 791-815. doi: 10.2165/11632730-000000000-00000

Davis, B., Collins, W., \& Mendell, L. (1985). Potentiation of transmission at la-motoneuron connections induced by repeated short bursts of afferent activity. Journal of Neurophysiology, 54(6), 15411552.

De Jong, P., De Jong, J., Cohen, B., \& Jongkees, L. (1977). Ataxia and nystagmus induced by injection of local anesthetics in the neck. Annals of Neurology, 1(3), 240-246. doi: 10.1002/ana.410010307

de Noronha, M., Refshauge, K., Herbert, R., \& Kilbreath, S. (2006). Do voluntary strength, proprioception, range of motion, or postural sway predict occurrence of lateral ankle sprain? British Journal of Sports Medicine, 40(10), 824-828. doi: 10.1136/bjsm.2006.029645 
Dehner, C., Heym, B., Maier, D., Sander, S., Arand, M., Elbel, M., . . Kramer, M. (2008). Postural control deficit in acute QTF grade II whiplash injuries. Gait \& Posture, 28(1), 113-119. doi: 10.1016/j.gaitpost.2007.10.007

Deliagina, T. G., Zelenin, P. V., Beloozerova, I. N., \& Orlovsky, G. N. (2007). Nervous mechanisms controlling body posture. Physiology \& Behavior, 92(1-2), 148-154. doi: 10.1016/j.physbeh.2007.05.023

Dishman, D., \& Burke, J. (2003). Spinal reflex excitability changes after cervical and lumbar spinal manipulation: a comparative study. The Spine Journal, 3(3), 204-212. doi: 10.1016/S15299430(02)00587-9

Dishman, D., Greco, D., \& Burke, J. (2008). Motor-evoked potentials recorded from lumbar erector spinae muscles: a study of corticospinal excitability changes associated with spinal manipulation. Journal of Manipulative and Physiological Therapeutics, 31(4), 258-270. doi: 10.1016/j.jmpt.2008.03.002

Dubrovsky, B. O., \& Barbas, H. (1977). Frontal projections of dorsal neck and extraocular muscles. Experimental Neurology, 55(3, Part 1), 680-693. doi: 10.1016/0014-4886(77)90293-X

Dunning, J., \& Rushton, A. (2009). The effects of cervical high-velocity low-amplitude thrust manipulation on resting electromyographic activity of the biceps brachii muscle. Manual Therapy, 14(5), 508-513. doi: 10.1016/j.math.2008.09.003

Falla, D. (2004). Unravelling the complexity of muscle impairment in chronic neck pain. Manual Therapy, 9(3), 125-133. doi: 10.1016/j.math.2004.05.003

Falla, D., \& Farina, D. (2005). Muscle fiber conduction velocity of the upper trapezius muscle during dynamic contraction of the upper limb in patients with chronic neck pain. Pain, 116(1-2), 138145. doi: 10.1016/j.pain.2005.03.038

Falla, D., \& Farina, D. (2008). Neuromuscular adaptation in experimental and clinical neck pain. Journal of electromyography and kinesiology : official journal of the International Society of Electrophysiological Kinesiology, 18(2), 255-261. doi: 10.1016/j.jelekin.2006.11.001 
Falla, D., Farina, D., \& Graven-Nielsen, T. (2007). Experimental muscle pain results in reorganization of coordination among trapezius muscle subdivisions during repetitive shoulder flexion. Experimental Brain Research, 178 .(3), 385-393. doi: 10.1007/s00221-006-0746-6

Falla, D., Jull, G., Edwards, S., Koh, K., \& Rainoldi, A. (2004). Neuromuscular efficiency of the sternocleidomastoid and anterior scalene muscles in patients with chronic neck pain. Disability and Rehabilitation, 26(12), 712-717. doi: 10.1080/09638280410001704287

Falla, D., Jull, G., \& Hodges, P. (2004a). Feedforward activity of the cervical flexor muscles during voluntary arm movements is delayed in chronic neck pain. Experimental brain research, 157(1), 43-48. doi: 10.1007/s00221-003-1814-9

Falla, D., Jull, G., \& Hodges, P. (2004b). Patients with neck pain demonstrate reduced electromyographic activity of the deep cervical flexor muscles during performance of the craniocervical flexion test. Spine, 29(19), 2108-2114. doi: 10.1097/01.brs.0000141170.89317.0e

Falla, D., Jull, G., Rainoldi, A., \& Merletti, R. (2004). Neck flexor muscle fatigue is side specific in patients with unilateral neck pain. European Journal of Pain, 8(1), 71-77. doi: 10.1016/S10903801(03)00075-2

Falla, D., Rainoldi, A., Jull, G., Stavrou, G., \& Tsao, H. (2004). Lack of correlation between sternocleidomastoid and scalene muscle fatigability and duration of symptoms in chronic neck pain patients. Neurophysiologie Clinique/Clinical Neurophysiology, 34(3-4), 159-165. doi: 10.1016/j.neucli.2004.04.004

Falla, D., Rainoldi, A., Merletti, R., \& Jull, G. (2003). Myoelectric manifestations of sternocleidomastoid and anterior scalene muscle fatigue in chronic neck pain patients. Clinical Neurophysiology, 114(3), 488-495. doi: 10.1016/S1388-2457(02)00418-2

Falla, D., Rainoldi, A., Merletti, R., \& Jull, G. (2004). Spatio-temporal evaluation of neck muscle activation during postural perturbations in healthy subjects. Journal of Electromyography and Kinesiology, 14(4), 463-474. doi: 10.1016/j.jelekin.2004.03.003

Farina, D., Arendt-Nielsen, L., \& Graven-Nielsen, T. (2005). Experimental muscle pain decreases voluntary EMG activity but does not affect the muscle potential evoked by transcutaneous 
electrical stimulation. Clinical Neurophysiology, 116(7), 1558-1565. doi:

10.1016/j.clinph.2005.03.009

Farina, D., Arendt-Nielsen, L., Roatta, S., \& Graven-Nielsen, T. (2008). The pain-induced decrease in lowthreshold motor unit discharge rate is not associated with the amount of increase in spiketriggered average torque. Clinical Neurophysiology, 119(1), 43-51. doi:

10.1016/j.clinph.2007.10.003

Fernández-Carnero, J., Fernández-de-las-Peñas, C., \& Cleland, J. A. (2008). Immediate hypoalgesic and motor effects after a single cervical spine manipulation in subjects with lateral epicondylalgia. Journal of Manipulative and Physiological Therapeutics, 31(9), 675-681. doi: 10.1016/j.jmpt.2008.10.005

Fernández-de-las-Peñas, C., Alonso-Blanco, C., Cleland, J. A., Rodríguez-Blanco, C., \& AlburquerqueSendín, F. (2008). Changes in Pressure Pain Thresholds Over C5-C6 Zygapophyseal Joint After a Cervicothoracic Junction Manipulation in Healthy Subjects. Journal of Manipulative and Physiological Therapeutics, 31(5), 332-337. doi: 10.1016/j.jmpt.2008.04.006

Fernández-de-las-Peñas, C., Palomeque-del-Cerro, L., Rodríguez-Blanco, C., Gómez-Conesa, A., \& Miangolarra-Page, J. C. (2007). Changes in Neck Pain and Active Range of Motion After a Single Thoracic Spine Manipulation in Subjects Presenting with Mechanical Neck Pain: A Case Series. Journal of Manipulative and Physiological Therapeutics, 30(4), 312-320. doi: 10.1016/j.jmpt.2007.03.007

Field, S., Treleaven, J., \& Jull, G. (2008). Standing balance: a comparison between idiopathic and whiplash-induced neck pain. Manual Therapy, 13(3), 183-191. doi: 10.1016/j.math.2006.12.005

Flor, H. (2008). Maladaptive plasticity, memory for pain and phantom limb pain: review and suggestions for new therapies. Expert Review of Neurotherapeutics, 8(5), 809-818. doi: $10.1586 / 14737175.8 .5 .809$

Flor, H., Braun, C., Elbert, T., \& Birbaumer, N. (1997). Extensive reorganization of primary somatosensory cortex in chronic back pain patients. Neuroscience Letters, 224(1), 5-8. doi: 10.1016/S03043940(97)13441-3 
Fryer, G. (2003). Intervertebral dysfunction: a discussion of the manipulable spinal lesion. Journal of Osteopathic Medicine, 6(2), 64-73. doi: 10.1016/S1443-8461(03)80016-3

Fryer, G., Carub, J., \& Mclver, S. (2004). The effect of manipulation and mobilisation on pressure pain thresholds in the thoracic spine. Journal of Osteopathic Medicine, 7(1), 8-14. doi: $10.1016 / \mathrm{S} 1443-8461(04) 80003-0$

Gibbons, P., \& Tehan, P. (2010). Manipulation of the spine, thorax and pelvis (3rd ed.): Elsevier Limited.

Gimse, R., Tjell, C., Bjôrgen, I. A., \& Saunte, C. (1996). Disturbed eye movements after whiplash due to injuries to the posture control system. Journal of Clinical and Experimental Neuropsychology, 18(2), 178-186. doi: 10.1080/01688639608408273

Goertz, C. M., PohIman, K. A., Vining, R. D., Brantingham, J. W., \& Long, C. R. (2012). Patient-centered outcomes of high-velocity, low-amplitude spinal manipulation for low back pain: a systematic review. Journal of Electromyography and Kinesiology, 22(5), 670-691. doi:

10.1016/j.jelekin.2012.03.006

Gosselin, G., Rassoulian, H., \& Brown, I. (2004). Effects of neck extensor muscles fatigue on balance. Clinical Biomechanics, 19(5), 473-479. doi: 10.1016/j.clinbiomech.2004.02.001

Graven-Nielsen, T., Svensson, P., \& Arendt-Nielsen, L. (1997). Effects of experimental muscle pain on muscle activity and co-ordination during static and dynamic motor function. Electroencephalography and Clinical Neurophysiology/Electromyography and Motor Control, 105(2), 156-164. doi: 10.1016/S0924-980X(96)96554-6

Grip, H., Sundelin, G., Gerdle, B., \& Stefan Karlsson, J. (2008). Cervical helical axis characteristics and its center of rotation during active head and upper arm movements-comparisons of whiplashassociated disorders, non-specific neck pain and asymptomatic individuals. Journal of Biomechanics, 41(13), 2799-2805. doi: 10.1016/j.jbiomech.2008.07.005

Gross, A., Miller, J., D’Sylva, J., Burnie, S. J., Goldsmith, C. H., Graham, N., . . Hoving, J. L. (2010). Manipulation or mobilisation for neck pain: a cochrane review. Manual Therapy, 15(4), 315-333. doi: 10.1016/j.math.2010.04.002 
Guyton, A. C., \& Hall, J. E. (2006). Textbook of medical physiology (11th ed.). Philadelphia: Elsevier Saunders.

Haavik-Taylor, H., \& Murphy, B. (2007a). Altered cortical integration of dual somatosensory input following the cessation of a 20 min period of repetitive muscle activity. Experimental Brain Research, 178(4), 488-498. doi: 10.1007/s00221-006-0755-5

Haavik-Taylor, H., \& Murphy, B. (2007b). Cervical spine manipulation alters sensorimotor integration: a somatosensory evoked potential study. Clinical Neurophysiology, 118(2), 391-402. doi: 10.1016/j.clinph.2006.09.014

Haavik-Taylor, H., \& Murphy, B. (2008). Altered sensorimotor integration with cervical spine manipulation. Journal of Manipulative and Physiological Therapeutics, 31(2), 115-126. doi: 10.1016/j.jmpt.2007.12.011

Haavik-Taylor, H., \& Murphy, B. (2010a). Altered central integration of dual somatosensory input after cervical spine manipulation. Journal of Manipulative and Physiological Therapeutics, 33(3), 178188. doi: 10.1016/j.jmpt.2010.01.005

Haavik-Taylor, H., \& Murphy, B. (2010b). The effects of spinal manipulation on central integration of dual somatosensory input observed after motor training: a crossover study. Journal of Manipulative and Physiological Therapeutics, 33(4), 261-272. doi: 10.1016/j.jmpt.2010.03.004

Haavik, H., \& Murphy, B. (2011). Subclinical neck pain and the effects of cervical manipulation on elbow joint position sense. Journal of Manipulative and Physiological Therapeutics, 34(2), 88-97. doi: 10.1016/j.jmpt.2010.12.009

Haavik, H., \& Murphy, B. (2012). The role of spinal manipulation in addressing disordered sensorimotor integration and altered motor control. Journal of Electromyography and Kinesiology, 22(5), 768776. doi: 10.1016/j.jelekin.2012.02.012

Harringe, M. L., Halvorsen, K., Renström, P., \& Werner, S. (2008). Postural control measured as the center of pressure excursion in young female gymnasts with low back pain or lower extremity injury. Gait \& Posture, 28(1), 38-45. doi: 10.1016/j.gaitpost.2007.09.011 
Hawk, C., Cambron, J. A., \& Pfefer, M. T. (2009). Pilot Study of the Effect of a Limited and Extended Course of Chiropractic Care on Balance, Chronic Pain, and Dizziness in Older Adults. Journal of Manipulative and Physiological Therapeutics, 32(6), 438-447. doi: 10.1016/j.jmpt.2009.06.008

Hawk, C., Pfefer, M. T., Strunk, R., Ramcharan, M., \& Uhl, N. (2007). Feasibility study of short-term effects of chiropractic manipulation on older adults with impaired balance. Journal of Chiropractic Medicine, 6(4), 121-131. doi: 10.1016/j.jcme.2007.08.002

Heikkilä, H., Johansson, M., \& Wenngren, B. I. (2000). Effects of acupuncture, cervical manipulation and NSAID therapy on dizziness and impaired head repositioning of suspected cervical origin: a pilot study. Manual Therapy, 5(3), 151-157. doi: 10.1054/math.2000.0357

Heikkilä, H., \& Wenngren, B. I. (1998). Cervicocephalic kinesthetic sensibility, active range of cervical motion, and oculomotor function in patients with whiplash injury. Archives of Physical Medicine and Rehabilitation, 79(9), 1089-1094. doi: 10.1016/S0003-9993(98)90176-9

Henderson, L. A., Bandler, R., Gandevia, S. C., \& Macefield, V. G. (2006). Distinct forebrain activity patterns during deep versus superficial pain. Pain, 120(3), 286-296. doi: 10.1016/j.pain.2005.11.003

Hodges, P. (2000). The role of the motor system in spinal pain: Implications for rehabilitation of the athlete following lower back pain. Journal of Science and Medicine in Sport, 3(3), 243-253. doi: $10.1016 / \mathrm{S} 1440-2440(00) 80033-\mathrm{X}$

Hodges, P. (2001). Changes in motor planning of feedforward postural responses of the trunk muscles in low back pain. Experimental Brain Research, 141(2), 261-266. doi: 10.1007/s002210100873

Hodges, P. (2011). Pain and motor control: from the laboratory to rehabilitation. Journal of Electromyography and Kinesiology, 21(2), 220-228. doi: 10.1016/j.jelekin.2011.01.002

Hodges, P., Gurfinkel, V., Brumagne, S., Smith, T., \& Cordo, P. (2002). Coexistence of stability and mobility in postural control: evidence from postural compensation for respiration. Experimental Brain Research, 144(3), 293-302. doi: 10.1007/s00221-002-1040-x 
Hodges, P., Moseley, G., Gabrielsson, A., \& Gandevia, S. (2003). Experimental muscle pain changes feedforward postural responses of the trunk muscles. Experimental Brain Research, 151(2), 262271. doi: $10.1007 / \mathrm{s} 00221-003-1457-x$

Hodges, P., van den Hoorn, W., Dawson, A., \& Cholewicki, J. (2009). Changes in the mechanical properties of the trunk in low back pain may be associated with recurrence. Journal of Biomechanics, 42(1), 61-66. doi: 10.1016/j.jbiomech.2008.10.001

Holm, S., Indahl, A., \& Solomonow, M. (2002). Sensorimotor control of the spine. Journal of Electromyography and Kinesiology, 12(3), 219-234. doi: 10.1016/S1050-6411(02)00028-7

Humphreys, B. (2008). Cervical outcome measures: testing for postural stability and balance. Journal of Manipulative and Physiological Therapeutics, 31(7), 540-546. doi: 10.1016/j.jmpt.2008.08.007

Jesus-Moraleida, F. R., Ferreira, P. H., Pereira, L. S. M., Vasconcelos, C. M., \& Ferreira, M. L. (2011). Ultrasonographic Analysis of the Neck Flexor Muscles in Patients with Chronic Neck Pain and Changes After Cervical Spine Mobilization. Journal of Manipulative and Physiological Therapeutics, 34(8), 514-524. doi: 10.1016/j.jmpt.2011.08.006

Jones, D. (2003). The Effect of Osteopathic Manipulative Therapy Applied tothe Lumbar Spine on Postual Stability: A Pilot Study. Master of Osteopathy, Victoria University, Melbourne, Victoria. Retrieved from http://vuir.vu.edu.au/835/1/Jones et.al 2004.pdf Victoria University Institutional Repository database.

Jull, G. (2004). Diagnosis of cervical disorders: exploring a mechanistic approach. Hong Kong Physiotherapy Journal, 22(1), 2-6. doi: 10.1016/S1013-7025(09)70043-0

Jull, G., O'Leary, S., \& Falla, D. (2008). Clinical assessment of the deep cervical flexor muscles: the craniocervical flexion test. Journal of Manipulative and Physiological Therapeutics, 31(7), 525533. doi: 10.1016/j.jmpt.2008.08.003

Jull, G., Sterling, M., Falla, D., Treleaven, J., \& O'Leary, S. (2008). The Cervical Spine and Sensorimotor Control Whiplash, Headache, and Neck Pain. Edinburgh: Churchill Livingstone. 
Kakigi, R., Shibasaki, H., \& Ikeda, A. (1989). Pain-related somatosensory evoked potentials following CO2 laser stimulation in man. Electroencephalography and Clinical Neurophysiology/Evoked Potentials Section, 74(2), 139-146. doi:10.1016/0168-5597(89)90019-1

Kaňovský, P., Bareš, M., \& Rektor, I. (2003). The selective gating of the N30 cortical component of the somatosensory evoked potentials of median nerve is different in the mesial and dorsolateral frontal cortex: evidence from intracerebral recordings. Clinical Neurophysiology, 114(6), 981991. doi: 10.1016/S1388-2457(03)00068-3

Karita, K., Nakao, M., Nishikitani, M., Iwata, T., Murata, K., \& Yano, E. (2006). Effect of overtime work and insufficient sleep on postural sway in information-technology workers. Journal of Occupational Health, 48(1), 65-68. doi: 10.1539/joh.48.65

Karlberg, M., Magnusson, M., Eva-Maj, M., Agneta, M., \& Moritz, U. (1996). Postural and symptomatic improvement after physiotherapy in patients with dizziness of suspected cervical origin. Archives of Physical Medicine and Rehabilitation, 77(9), 874-882. doi: 10.1016/S0003-9993(96)90273-7

Karnath, H. O., Reich, E., Rorden, C., Fetter, M., \& Driver, J. (2002). The perception of body orientation after neck-proprioceptive stimulation: Effects of time and of visual cueing. Experimental brain research, 143(3), 350-358. doi: 10.1007/s00221-001-0996-2

Keay, K., \& Bandler, R. (2002). Distinct central representations of inescapable and escapable pain: observations and speculation. Experimental Physiology, 87(2), 275-279.

Kirveskari, E., Vartiainen, N. V., Gockel, M., \& Forss, N. (2010). Motor cortex dysfunction in complex regional pain syndrome. Clinical Neurophysiology, 121(7), 1085-1091. doi: 10.1016/j.clinph.2010.01.032

Knox, J., Beilstein, D., Charles, S., Aarseth, G., Rayar, S., Treleaven, J., \& Hodges, P. (2006). Changes in Head and Neck Position Have a Greater Effect on Elbow Joint Position Sense in People With Whiplash-associated Disorders. The Clinical Journal of Pain, 22(6), 512-518 doi: 10.1097/01.ajp.0000210997.53082.c9

Knox, J., Skoss, R., Cordo, P., Durrant, S., \& Hodges, P. (2006). Illusory changes in head position induced by neck muscle vibration can alter the perception of elbow position. Behavioral Neuroscience, 120(6), 1211-1217. 
Komendantov, A., \& Ascoli, G. (2009). Dendritic Excitability and Neuronal Morphology as Determinants of Synaptic Efficacy. Journal of Neurophysiology, 101, 1847-1866. doi: 10.1152/jn.01235.2007

Korr, I. M. (1975). Proprioceptors and somatic dysfunction. The Journal of the American Osteopathic Association, 74(7), 638-650.

Kristjansson, E., \& Treleaven, J. (2009). Sensorimotor function and dizziness in neck pain: implications for assessment and management. Journal of orthopaedic and sports physical therapy, 39(5), 364377. doi: $10.2519 /$ jospt.2009.2834

Kulkarni, V., Babu, K., \& Chandy, M. (2001). Quantitative study of muscle spindles in suboccipital muscles of human foetuses. Neurology India, 49(4), 355-359.

Lackner, J. (1988). Some proprioceptive influences on the perceptual representation of body shape and orientation. Brain, 111(2), 281-297. doi: 10.1093/brain/111.2.281

Lackner, J., \& DiZio, P. (2000). Aspects of body self-calibration. Trends in Cognitive Sciences, 4(7), 279288. doi: 10.1016/S1364-6613(00)01493-5

Lackner, J., \& DiZio, P. (2005). Vestibular, proprioceptive, and haptic contributions to spatial orientation. Annual Review of Psychology, 56, 115-147. doi: 10.1146/annurev.psych.55.090902.142023

Le Pera, D., Graven-Nielsen, T., Valeriani, M., Oliviero, A., Di Lazzaro, V., Tonali, P., \& Arendt-Nielsen, L. (2001). Inhibition of motor system excitability at cortical and spinal level by tonic muscle pain. Clinical Neurophysiology, 112(9), 1633-1641. doi: 10.1016/S1388-2457(01)00631-9

Le Pera, D., Svensson, P., Valeriani, M., Watanabe, I., Arendt-Nielsen, L., \& Chen, A. C. (2000). Longlasting effect evoked by tonic muscle pain on parietal EEG activity in humans. Clinical Neurophysiology, 111(12), 2130-2137. doi: 10.1016/S1388-2457(00)00474-0

Liepert, J., Haevernick, K., Weiller, C., \& Barzel, A. (2006). The surround inhibition determines therapyinduced cortical reorganization. Neurolmage, 32(3), 1216-1220. doi: 10.1016/j.neuroimage.2006.05.028

Lindstrøm, R., Schomacher, J., Farina, D., Rechter, L., \& Falla, D. (2011). Association between neck muscle coactivation, pain, and strength in women with neck pain. Manual Therapy, 16(1), 80-86. doi: 10.1016/j.math.2010.07.006 
Liu, J.-X., Thornell, L., \& Pedrosa-Domellöf, F. (2003). Muscle Spindles in the Deep Muscles of the Human Neck: A Morphological and Immunocytochemical Study. Journal of Histochemistry \& Cytochemistry, 51(2), 175-186. doi: 10.1177/002215540305100206

Lund, J. P., Donga, R., Widmer, C. G., \& Stohler, C. S. (1991). The pain-adaptation model: a discussion of the relationship between chronic musculoskeletal pain and motor activity. Canadian Journal of Physiology and Pharmacology, 69(5), 683-694. doi: 10.1139/y91-102

Madeleine, P. (2010). On functional motor adaptations: From the quantification of motor strategies to the prevention of musculoskeletal disorders in the neck-shoulder region. Acta Physiologica, 199(SUPPL. 679), 1-46. doi: 10.1111/j.1748-1716.2010.02145.x

Madeleine, P., \& Arendt-Nielsen, L. (2005). Experimental muscle pain increases mechanomyographic signal activity during sub-maximal isometric contractions. Journal of Electromyography and Kinesiology, 15(1), 27-36. doi: 10.1016/j.jelekin.2004.06.006

Maduro de Camargo, V., Alburquerque-Sendín, F., Bérzin, F., Cobos Stefanelli, V., Rodrigues de Souza, D. P., \& Fernández-de-las-Peñas, C. (2011). Immediate Effects on Electromyographic Activity and Pressure Pain Thresholds After a Cervical Manipulation in Mechanical Neck Pain: A Randomized Controlled Trial. Journal of Manipulative and Physiological Therapeutics, 34(4), 211-220. doi: 10.1016/j.jmpt.2011.02.002

Maigne, J.-Y., \& Vautravers, P. (2003). Mechanism of action of spinal manipulative therapy. Joint Bone Spine, 70(5), 336-341.

Manganotti, P., Patuzzo, S., Cortese, F., Palermo, A., Smania, N., \& Fiaschi, A. (2002). Motor disinhibition in affected and unaffected hemisphere in the early period of recovery after stroke. Clinical Neurophysiology, 113(6), 936-943. doi: 10.1016/S1388-2457(02)00062-7

Mannion, A. (1999). Fibre type characteristics and function of the human paraspinal muscles: normal values and changes in association with low back pain. Journal of Electromyography and Kinesiology, 9(6), 363-377. doi: 10.1016/S1050-6411(99)00010-3

Mannion, A., Käser, L., Weber, E., Rhyner, A., Dvorak, J., \& Müntener, M. (2000). Influence of age and duration of symptoms on fibre type distribution and size of the back muscles in chronic low back pain patients. European Spine Journal, 9(4), 273-281. doi: 10.1007/s005860000189 
Mansilla-Ferragut, P., Fernández-de-las Peñas, C., Alburquerque-Sendín, F., Cleland, J. A., \& BoscáGandía, J. J. (2009). Immediate Effects of Atlanto-Occipital Joint Manipulation on Active Mouth Opening and Pressure Pain Sensitivity in Women With Mechanical Neck Pain. Journal of Manipulative and Physiological Therapeutics, 32(2), 101-106. doi: 10.1016/j.jmpt.2008.12.003

Martin, P., Weerakkody, N., Gandevia, S., \& Taylor, J. (2008). Group III and IV muscle afferents differentially affect the motor cortex and motoneurones in humans. The Journal of Physiology, 586(5), 1277-1289. doi: 10.1113/jphysiol.2007.140426

Martínez-Segura, R., Fernández-de-las-Peñas, C., Ruiz-Sáez, M., López-Jiménez, C., \& Rodríguez-Blanco, C. (2006). Immediate Effects on Neck Pain and Active Range of Motion After a Single Cervical High-Velocity Low-Amplitude Manipulation in Subjects Presenting with Mechanical Neck Pain: A Randomized Controlled Trial. Journal of Manipulative and Physiological Therapeutics, 29(7), 511517. doi: 10.1016/j.jmpt.2006.06.022

Massion, J. (1994). Postural control system. Current Opinion in Neurobiology, 4(6), 877-887.

Matre, D. A., Sinkjær, T., Svensson, P., \& Arendt-Nielsen, L. (1998). Experimental muscle pain increases the human stretch reflex. Pain, 75(2-3), 331-339. doi: 10.1016/S0304-3959(98)00012-8

Mauguiere, F. (1999). Somatosensory evoked potentials. In E. Niedermeyer \& F. Lopes da Silva (Eds.), Electroencephalography: basic principles, clinical applications and related fields. Philadelphia: Lippincott Williams and Wilkins.

Mayoux-Benhamou, M., Revel, M., Vallee, C., Roudier, R., Barbet, J., \& Bargy, F. (1994). Longus colli has a postural function on cervical curvature. Surgical and Radiologic Anatomy, 16(4), 367-371. doi: 10.1007/BF01627655

McNair, P., Portero, P., Chiquet, C., Mawston, G., \& Lavaste, F. (2007). Acute neck pain: Cervical spine range of motion and position sense prior to and after joint mobilization. Manual Therapy, 12(4), 390-394. doi: 10.1016/j.math.2006.08.002

Merzenich, M. M., Kaas, J., Wall, J., Sur, M., Nelson, R., \& Felleman, D. (1983). Progression of change following median nerve section in the cortical representation of the hand in areas $3 \mathrm{~b}$ and 1 in adult owl and squirrel monkeys. Neuroscience, 10(3), 639-665. 
Millan, M. (1999). The induction of pain: an integrative review. Progress in Neurobiology, 57(1), 1-164. doi: 10.1016/S0301-0082(98)00048-3

Mogilner, A., Grossman, J., Ribary, U., Joliot, M., Volkmann, J., Rapaport, D., . . Llinas, R. R. (1993). Somatosensory cortical plasticity in adult humans revealed by magnetoencephalography. Proceedings of the National Academy of Sciences, 90(8), 3593-3597.

Morningstar, M. W., Pettibon, B. R., Schlappi, H., Schlappi, M., \& Ireland, T., V. (2005). Reflex control of the spine and posture: a review of the literature from a chiropractic perspective. Chiropractic \& Osteopathy, 13(16).

Murphy, B., Haavik-Taylor, H., Wilson, S., Oliphant, G., \& Mathers, K. (2003). Rapid reversible changes to multiple levels of the human somatosensory system following the cessation of repetitive contractions: a somatosensory evoked potential study. Clinical Neurophysiology, 114(8), 15311537. doi: 10.1016/S1388-2457(03)00127-5

Nelson, A. J., Brooke, J. D., Mcllroy, W. E., Bishop, D. C., \& Norrie, R. G. (2001). The gain of initial somatosensory evoked potentials alters with practice of an accurate motor task. Brain Research, 890(2), 272-279. doi: 10.1016/S0006-8993(00)03136-X

Nolan, J. H. (2009). The effect of cervical spine chiropractic manipulation on balance. Masters degree in Technology: Chiropractic Dissertation, University of Johannesburg, Johannesburg, South Africa. Retrieved from https://ujdigispace.uj.ac.za/bitstream/handle/10210/3119/Nolan\%20.pdf?sequence=1

O'Leary, S., Falla, D., \& Jull, G. (2011). The relationship between superficial muscle activity during the cranio-cervical flexion test and clinical features in patients with chronic neck pain. Manual Therapy, 16(5), 452-455. doi: 10.1016/j.math.2011.02.008

O'Leary, S., Jull, G., Kim, M., \& Vicenzino, B. (2007). Cranio-cervical flexor muscle impairment at maximal, moderate, and low loads is a feature of neck pain. Manual Therapy, 12(1), 34-39. doi: 10.1016/j.math.2006.02.010

Palmgren, P., Lindeberg, A., Nath, S., \& Heikkilä, H. (2009). Head repositioning accuracy and posturography related to cervical facet nerve blockade and spinal manipulative therapy in 
healthy volunteers: a time series study. Journal of Manipulative and Physiological Therapeutics, 32(3), 193-202. doi: 10.1016/j.jmpt.2009.02.003

Palmgren, P., Sandström, P., Lundqvist, F., \& Heikkilä, H. (2006). Improvement after chiropractic care in cervicocephalic kinesthetic sensibility and subjective pain intensity in patients with nontraumatic chronic neck pain. Journal of Manipulative and Physiological Therapeutics, 29(2), 100-106. doi: 10.1016/j.jmpt.2005.12.002

Panjabi, M. M., Cholewicki, J., Nibu, K., Grauer, J., Babat, L. B., \& Dvorak, J. (1998). Critical load of the human cervical spine: an in vitro experimental study. Clinical Biomechanics, 13(1), 11-17. doi: 10.1016/S0268-0033(97)00057-0

Parkin-Smith, G. F., \& Renter, C. S. (1998). A clinical trial investigating the effect of two manipulative approaches in the treatment of mechanical neck pain: A pilot study. Journal of the Neuromusculoskeletal System, 6(1), 6-16.

Parsons, J., \& Marcer, N. (2006). Osteopathy: Models for diagnosis, treatment and practice: Elsevier

Passmore, S., Burke, J., Good, C., Lyons, J., \& Dunn, A. (2010). Spinal Manipulation Impacts Cervical Spine Movement and Fitts' Task Performance: A Single-Blind Randomized Before-After Trial. Journal of Manipulative and Physiological Therapeutics, 33(3), 189-192. doi: 10.1016/j.jmpt.2010.01.007

Passmore, S., \& Descarreaux, M. (2012). Performance based objective outcome measures and spinal manipulation. Journal of Electromyography and Kinesiology, 22(5), 697-707. doi: 10.1016/j.jelekin.2012.02.005

Paulus, I., \& Brumagne, S. (2008). Altered interpretation of neck proprioceptive signals in persons with subclinical recurrent neck pain. Journal of Rehabilitation Medicine, 40(6), 426-432. doi: $10.2340 / 16501977-0189$

Pedersen, J., Sjölander, P., Wenngren, B. I., \& Johansson, H. (1997). Increased intramuscular concentration of bradykinin increases the static fusimotor drive to muscle spindles in neck muscles of the cat. Pain, 70(1), 83-91. doi: 10.1016/S0304-3959(96)03305-2 
Peyron, R., Laurent, B., \& García-Larrea, L. (2000). Functional imaging of brain responses to pain. A review and meta-analysis Neurophysiologie Clinique/Clinical Neurophysiology, 30(5), 263-288. doi: 10.1016/S0987-7053(00)00227-6

Pickar, J. (2002). Neurophysiological effects of spinal manipulation. The Spine Journal, 2(5), 357-371. doi: $10.1016 / \mathrm{S} 1529-9430(02) 00400-X$

Pickar, J., \& Bolton, P. (2012). Spinal manipulative therapy and somatosensory activation. Journal of Electromyography and Kinesiology, 22(5), 785-794. doi: 10.1016/j.jelekin.2012.01.015

Pickar, J., Sung, P., Kang, Y., \& Ge, W. (2007). Response of lumbar paraspinal muscles spindles is greater to spinal manipulative loading compared with slower loading under length control. The Spine Journal, 7(5), 583-595. doi: 10.1016/j.spinee.2006.10.006

Pleger, B., Tegenthoff, M., Schwenkreis, P., Janssen, F., Ragert, P., Dinse, H., . . Maier, C. (2004). Mean sustained pain levels are linked to hemispherical side-to-side differences of primary somatosensory cortex in the complex regional pain syndrome I. Experimental brain research, 155(1), 115-119. doi: 10.1007/s00221-003-1738-4

Proske, U., \& Gandevia, S. (2012). The Proprioceptive Senses: Their Roles in Signaling Body Shape, Body Position and Movement, and Muscle Force Physiological Reviews, 92 (4), 1651-1697. doi: 10. 1152/physrev.00048.2011

Rassier, D. E., \& Macintosh, B. R. (2000). Coexistence of potentiation and fatigue in skeletal muscle Brazilian Journal of Medical and Biological Research, 33(5), 499-508. doi: 10.1590/S0100$879 \times 2000000500003$

Ro, J. Y., \& Capra, N. F. (2001). Modulation of jaw muscle spindle afferent activity following intramuscular injections with hypertonic saline. Pain, 92(1-2), 117-127. doi: 10.1016/S03043959(00)00477-2

Rogers, R. (1997). The effects of spinal manipulation on cervical kinesthesia in patients with chronic neck pain: a pilot study. Journal of Manipulative and Physiological Therapeutics, 20(2), 80-85.

Röijezon, U., Björklund, M., \& Djupsjöbacka, M. (2011). The slow and fast components of postural sway in chronic neck pain. Manual Therapy, 16(3), 273-278. doi: 10.1016/j.math.2010.11.008 
Roll, R., Kavounoudias, A., Albert, F., Legré, R., Gay, A., Fabre, B., \& Roll, J. P. (2012). Illusory movements prevent cortical disruption caused by immobilization. Neurolmage, 62(1), 510-519. doi: 10.1016/j.neuroimage.2012.05.016

Rose, P. K., Wainwright, K., \& Neuber-Hess, M. (1992). Connections from the lateral vestibular nucleus to the upper cervical spinal cord of the cat: a study with the anterograde tracer PHA-L. Journal of Comparative Neurology, 321(2), 312-324. doi: 10.1002/cne.903210210

Rossi, S., della Volpe, R., Ginanneschi, F., Ulivelli, M., Bartalini, S., Spidalieri, R., \& Rossi, A. (2003). Early somatosensory processing during tonic muscle pain in humans: relation to loss of proprioception and motor 'defensive' strategies. Clinical Neurophysiology, 114(7), 1351-1358. doi: 10.1016/S1388-2457(03)00073-7

Rougier, P. R. (2008). What insights can be gained when analysing the resultant centre of pressure trajectory? Neurophysiologie Clinique/Clinical Neurophysiology, 38(6), 363-373.

Ruhe, A., Fejer, R., \& Walker, B. (2010). The test-retest reliability of centre of pressure measures in bipedal static task conditions - a systematic review of the literature. Gait \& Posture, 32(4), 436445. doi: 10.1016/j.gaitpost.2010.09.012

Ruhe, A., Fejer, R., \& Walker, B. (2011). Altered postural sway in patients suffering from non-specific neck pain and whiplash associated disorder - a systematic review. Chiropractic \& Manual Therapies, 19(13). doi: 10.1186/2045-709X-19-13

Sack, D., Linz, D., Shukla, R., Rice, C., Bhattacharya, A., \& Suskind, R. (1993). Health status of pesticide applicators: postural stability assessments. Journal of Occupational and Environmental Medicine, 35(12), 1196-1202.

Sanes, J. N., \& Donoghue, J. P. (2000). Plasticity and primary motor cortex. Annual Review of Neuroscience, 23(1), 393-415.

Schabrun, S., \& Hodges, P. (2012). Muscle pain differentially modulates short interval intracortical inhibition and intracortical facilitation in primary motor cortex. The Journal of Pain, 13(2), 187194. doi: 10.1016/j.jpain.2011.10.013 
Schieppati, M., Nardone, A., \& Schmid, M. (2003). Neck muscle fatigue affects postural control in man. Neuroscience, 121(2), 277-285. doi: 10.1016/S0306-4522(03)00439-1

Schomacher, J., Farina, D., Lindstroem, R., \& Falla, D. (2012). Chronic trauma-induced neck pain impairs the neural control of the deep semispinalis cervicis muscle. Clinical Neurophysiology, 123(7), 1403-1408. doi: 10.1016/j.clinph.2011.11.033

Selles, R. W., Wagenaar, R. C., Smit, T. H., \& Wuisman, P. I. J. M. (2001). Disorders in trunk rotation during walking in patients with low back pain: a dynamical systems approach. Clinical Biomechanics, 16(3), 175-181. doi: 10.1016/S0268-0033(00)00080-2

Serpell, M. (2005). Anatomy, physiology and pharmacology of pain. Anaesthesia \& Intensive Care Medicine, 6(1), 7-10. doi: 10.1383/anes.6.1.7.57133

Shin, H.-W., Sohn, Y. H., \& Hallett, M. (2009). Hemispheric asymmetry of surround inhibition in the human motor system. Clinical Neurophysiology, 120(4), 816-819. doi: 10.1016/j.clinph.2009.02.004

Shin, H., Kang, S., \& Sohn, Y. (2007). Disturbed surround inhibition in preclinical parkinsonism. Clinical Neurophysiology, 118(10), 2176-2179. doi: 10.1016/j.clinph.2007.06.058

Shinoda, Y., Ohgaki, T., Sugiuchi, Y., \& Futami, T. (1989). Comparison of the branching patterns of lateral and medial vestibulospinal tract axons in the cervical spinal cord. Progress in Brain Research, 80, 137-147. doi: 10.1016/S0079-6123(08)62207-4

Silfies, S. P., Mehta, R., Smith, S. S., \& Karduna, A. R. (2009). Differences in feedforward trunk muscle activity in subgroups of patients with mechanical low back pain. Archives of Physical Medicine and Rehabilitation, 90(7), 1159-1169. doi: 10.1016/j.apmr.2008.10.033

Sjölander, P., Michaelson, P., Jaric, S., \& Djupsjöbacka, M. (2008). Sensorimotor disturbances in chronic neck pain-Range of motion, peak velocity, smoothness of movement, and repositioning acuity. Manual Therapy, 13(2), 122-131. doi: 10.1016/j.math.2006.10.002

Sjostrom, H., Allum, J., Carpenter, M., Adkin, A., Honegger, F., \& Ettlin, T. (2003). Trunk Sway Measures of Postural Stability During Clinical Balance Tests in Patients With Chronic Whiplash Injury Symptoms Spine, 28(15), 1725 - 1734. 
Smith, L., \& Mehta, M. (2008). The effects of upper cervical complex high velocity low amplitude thrust technique and sub-occipital muscle group inhibition techniques on standing balance. International Journal of Osteopathic Medicine, 11(4), 162-162. doi: :10.1016/j.ijosm.2008.08.020

Sohn, M. K., Graven-Nielsen, T., Arendt-Nielsen, L., \& Svensson, P. (2004). Effects of experimental muscle pain on mechanical properties of single motor units in human masseter. Clinical Neurophysiology, 115(1), 76-84. doi: 10.1016/S1388-2457(03)00318-3

Stackhouse, S. K., Eisennagel, A., Eisennagel, J., Lenker, H., Sweitzer, B. A., \& McClure, P. W. (2012). Experimental pain inhibits infraspinatus activation during isometric external rotation. Journal of Shoulder and Elbow Surgery(0). doi: 10.1016/j.jse.2012.05.037

Stapley, P. J., Beretta, M. V., Toffola, E. D., \& Schieppati, M. (2006). Neck muscle fatigue and postural control in patients with whiplash injury. Clinical Neurophysiology, 117(3), 610-622.

Sterling, M., Jull, G., \& Wright, A. (2001). Cervical mobilisation: concurrent effects on pain, sympathetic nervous system activity and motor activity. Manual Therapy, 6(2), 72-81. doi:

10.1054/math.2000.0378

Stone, C. (1999). Science in the Art of Osteopathy: Osteopathic Principles and Practice. Cheltenham: Nelson Thornes LTD.

Straka, H., Vibert, N., Vidal, P. P., Moore, L. E., \& Dutia, M. B. (2005). Intrinsic membrane properties of vertebrate vestibular neurons: function, development and plasticity. Progress in Neurobiology, 76(6), 349-392. doi: 10.1016/j.pneurobio.2005.10.002

Suter, E., \& McMorland, G. (2002). Decrease in elbow flexor inhibition after cervical spine manipulation in patients with chronic neck pain. Clinical Biomechanics, 17(7), 541-544. doi: 10.1016/S02680033(02)00025-6

Taylor, J., \& McCloskey, D. (1991). Illusions of head and visual target displacement induced by vibration of neck muscles. Brain, 114(2), 755-759. doi: 10.1093/brain/114.2.755

Thunberg, J., Hellström, F., Sjölander, P., Bergenheim, M., Wenngren, B.-I., \& Johansson, H. (2001). Influences on the fusimotor-muscle spindle system from chemosensitive nerve endings in 
cervical facet joints in the cat: possible implications for whiplash induced disorders. Pain, 91(12), 15-22. doi: 10.1016/s0304-3959(00)00415-2

Till, D., Buchner, H., Perkuhn, M., Gobbelé, R., Wagner, M., Kücker, W., \& Silny, J. (1999). N30 and the effect of explorative finger movements: a model of the contribution of the motor cortex to early somatosensory potentials. Clinical Neurophysiology, 110(9), 1589-1600. doi: 10.1016/S13882457(99)00092-9

Tinazzi, M., Fiaschi, A., Rosso, T., Faccioli, F., Grosslercher, J., \& Aglioti, S. (2000). Neuroplastic changes related to pain occur at multiple levels of the human somatosensory system: a somatosensoryevoked potentials study in patients with cervical radicular pain. Journal of Neuroscience, 20(24), 9277-9283.

Tinazzi, M., Priori, A., Bertolasi, L., Frasson, E., Mauguière, F., \& Fiaschi, A. (2000). Abnormal central integration of a dual somatosensory input in dystonia: Evidence for sensory overflow. Brain, 123(1), 42-50. doi: 10.1093/brain/123.1.42

Tinazzi, M., Valeriani, M., Moretto, G., Rosso, T., Nicolato, A., Fiaschi, A., \& Aglioti, S. M. (2004). Plastic interactions between hand and face cortical representations in patients with trigeminal neuralgia: a somatosensory-evoked potentials study. Neuroscience, 127(3), 769-776. doi: 10.1016/j.neuroscience.2004.05.020

Tinazzi, M., Zanette, G., Polo, A., Volpato, D., Manganotti, P., Bonato, C., . . Fiaschi, A. (1997). Transient deafferentation in humans induces rapid modulation of primary sensory cortex not associated with subcortical changes: A somatosensory evoked potential study. Neuroscience Letters, 223(1), 21-24. doi: 10.1016/S0304-3940(97)13382-1

Tinazzi, M., Zanette, G., Volpato, D., Testoni, R., Bonato, C., Manganotti, P., . . Fiaschi, A. (1998). Neurophysiological evidence of neuroplasticity at multiple levels of the somatosensory system in patients with carpal tunnel syndrome. Brain, 121(9), 1785-1794. doi: 10.1093/brain/121.9.1785

Travell, J., Rinzler, S., \& Herman, M. (1942). Pain and disability of the shoulder and arm. Journal of the American Medical Association, 120(6), 417-422. doi: 10.1001/jama.1942.02830410005002 
Treleaven, J. (2008a). Sensorimotor disturbances in neck disorders affecting postural stability, head and eye movement control. Manual Therapy, 13(1), 2-11. doi: 10.1016/j.math.2007.06.003

Treleaven, J. (2008b). Sensorimotor disturbances in neck disorders affecting postural stability, head and eye movement control-part 2: case studies. Manual Therapy, 13(3), 266-275. doi: 10.1016/j.math.2007.11.002

Treleaven, J., Clamaron-Cheers, C., \& Jull, G. (2011). Does the region of pain influence the presence of sensorimotor disturbances in neck pain disorders? Manual Therapy, 16(6), 636-640. doi: 10.1016/j.math.2011.07.008

Treleaven, J., Jull, G., \& Grip, H. (2011). Head eye co-ordination and gaze stability in subjects with persistent whiplash associated disorders. Manual Therapy, 16(3), 252-257. doi: 10.1016/j.math.2010.11.002

Triano, J. J. (2001). Biomechanics of spinal manipulative therapy. The Spine Journal, 1(2), 121-130. doi: $10.1016 / \mathrm{S} 1529-9430(01) 00007-9$

Tsao, H., Galea, M., \& Hodges, P. (2008). Reorganization of the motor cortex is associated with postural control deficits in recurrent low back pain. Brain: a Journal of Neurology 131(8), 2161-2171. doi: 10.1093/brain/awn154.

Tsao, H., Galea, M., \& Hodges, P. (2010). Driving plasticity in the motor cortex in recurrent low back pain. European Journal of Pain, 14(8), 832-839. doi: 10.1016/j.ejpain.2010.01.001

Tucker, M., Kavanagh, J., Morrison, S., \& Barrett, R. (2009). Voluntary sway and rapid orthogonal transitions of voluntary sway in young adults, and low and high fall-risk older adults. Clinical Biomechanics, 24(8), 597-605.

Tucker, M., Kavanagh, J., Morrison, S., \& Barrett, R. (2010a). Differences in rapid Initiation and termination of voluntary postural sway associated with ageing and falls-risk. Journal of Motor Behavior, 42(5), 277-287.

Tucker, M., Kavanagh, J., Morrison, S., \& Barrett, R. (2010b). What Are the Relations Between Voluntary Postural Sway Measures and Falls-History Status in Community-Dwelling Older Adults? Archives of Physical Medicine and Rehabilitation, 91(5), 750-758. doi: 10.1016/j.apmr.2010.01.004 
Uhlig, Y., Weber, B. R., Grob, D., \& Müntener, M. (1995). Fiber composition and fiber transformations in neck muscles of patients with dysfunction of the cervical spine. Journal of Orthopaedic Research, 13(2), 240-249. doi: 10.1002/jor.1100130212

Uthaikhup, S., Jull, G., Sungkarat, S., \& Treleaven, J. (2012). The influence of neck pain on sensorimotor function in the elderly. Archives of Gerontology and Geriatrics, 55(3), 667-672. doi: 10.1016/j.archger.2012.01.013

van der Hulst, M., Vollenbroek-Hutten, M. M., Rietman, J. S., \& Hermens, H. J. (2010). Lumbar and abdominal muscle activity during walking in subjects with chronic low back pain: Support of the "guarding" hypothesis? Journal of Electromyography and Kinesiology, 20(1), 31-38. doi: 10.1016/j.jelekin.2009.03.009

Van Dieën, J. H., Selen, L. P. J., \& Cholewicki, J. (2003). Trunk muscle activation in low-back pain patients, an analysis of the literature. Journal of Electromyography and Kinesiology, 13(4), 333-351. doi: $10.1016 / \mathrm{S} 1050-6411(03) 00041-5$

Van Schalkwyk, R., \& Parkin-Smith, G. F. (2000). A clinical trial investigating the possible effect of the supine cervical rotatory manipulation and the supine lateral break manipulation in the treatment of mechanical neck pain: A pilot study. Journal of Manipulative and Physiological Therapeutics, 23(5), 324-331. doi: 10.1067/mmt.2000.106868

Vernon, H., \& Humphreys, B. (2008). Chronic mechanical neck pain in adults treated by manual therapy: a systematic reveiw of change scores in randomised controlled trials of a single session. Journal of Manual and Manipulative Therapy, 16(2).

Vernon, H., Humphreys, B., \& Hagino, C. (2007). Chronic mechanical neck pain in adults treated by manual therapy: a systematic review of change scores in randomized clinical trials. Journal of Manipulative and Physiological Therapeutics, 30(3), 215-227. doi: 10.1016/j.jmpt.2007.01.014

Visser, J., Carpenter, M., van der Kooij, H., \& Bloem, B. (2008). The clinical utility of posturography. Clinical Neurophysiology, 119(11), 2424-2436. doi: 10.1016/j.clinph.2008.07.220

Vuillerme, N., Danion, F., Forestier, N., \& Nougier, V. (2002). Postural sway under muscle vibration and muscle fatigue in humans. Neuroscience Letters, 333(2), 131-135. doi: 10.1016/S03043940(02)00999-0 
Vuillerme, N., \& Pinsault, N. (2009). Experimental neck muscle pain impairs standing balance in humans. Experimental Brain Research, 192(4), 723-729. doi: 10.1007/s00221-008-1639-7

Vuillerme, N., Pinsault, N., \& Vaillant, J. (2005). Postural control during quiet standing following cervical muscular fatigue: effects of changes in sensory inputs. Neuroscience Letters, 378(3), 135-139. doi: 10.1016/j.neulet.2004.12.024

Wall, J. T., Xu, J., \& Wang, X. (2002). Human brain plasticity: an emerging view of the multiple substrates and mechanisms that cause cortical changes and related sensory dysfunctions after injuries of sensory inputs from the body. Brain Research Reviews, 39(2-3), 181-215. doi: 10.1016/S01650173(02)00192-3

Williams, M. A., Smith, S. A., O'brien, D. E., Mitchell, J. H., \& Garry, M. G. (2008). The group IV afferent neuron expresses multiple receptor alterations in cardiomyopathyic rats: Evidence at the cannabinoid CB 1 receptor. Journal of Physiology, 586(3), 835-845. doi:

10.1113/jphysiol.2007.140392

Windhorst, U. (2007). Muscle proprioceptive feedback and spinal networks. Brain Research Bulletin, 73(4-6), 155-202. doi: 10.1016/j.brainresbull.2007.03.010

Winters, J. M., \& Peles, J. D. (1990). Neck muscle activity and 3D head kinematics during quasistatic and dynamic tracking movements. In J. M. Winters \& S. L.-Y. Woo (Eds.), Multiple muscle systems: biomechanics and movement organisation (pp. 461-480). Berlin, Heidelberg, New York: Springer-Verlag.

Yu, L.-J., Stokell, R., \& Treleaven, J. (2011). The effect of neck torsion on postural stability in subjects with persistent whiplash. Manual Therapy, 16(4), 339-343. doi: 10.1016/j.math.2010.12.006 


\section{Section Two Manuscript}

Note: This manuscript was prepared in general accordance with the Instructions for Authors (See Appendix F) for the Journal of manipulative and physiological therapeutics, however, there are two main deviations: i) For ease of reading, the Figure is typeset in the text; and ii) The text is one and half spaced, as opposed to the double spaced format prescribed by the journal. 


\title{
The Effect of Cervical Spine Manipulation on the Postural Sway of Patients with Nonspecific Neck Pain
}

\author{
Alison Fisher
}




\section{Abstract}

Objective: Neck pain has been associated with impaired proprioceptive performance which may be improved by cervical manipulation. This crossover study aimed to determine whether a high velocity, low amplitude manipulation affected postural sway in adults with nonspecific neck pain.

Methods: Ten participants received, in random order, 7-days apart, a high velocity, low amplitude manipulation applied to a dysfunctional spinal segment and a passive headmovement control. Four parameters of postural sway were measured before, immediately following, and at 5 and 10 minutes after each procedure.

Results: Results showed no differences between interventions in change in any of the parameters. When changes before and immediately following each procedure were analysed separately, only the control showed a significant change in the length of centre of pressure path (an increase from median $=118 \mathrm{~mm} ; \mathrm{IQR}=93-137 \mathrm{~mm}$ to an increase to $132 \mathrm{~mm} ; 112-147$; $p=0.02)$.

Conclusion: This study failed to show any evidence that manipulation of a dysfunctional cervical segment influences postural sway. Given the ability of the postural control system to reweight the hierarchy of sensory information in order to compensate for inadequacies in any one component, it is possible that any improvements in the mechanisms controlling postural sway elicited by the manipulative intervention may have been concealed.

Key Indexing Terms: Neck Pain; Central Nervous System; Cervical Manipulation; Neuronal Plasticity; Balance, Postural 


\section{Introduction}

Postural sway is a natural feature of upright stance that reflects the interplay between the destabilising forces acting upon the body and the compensatory actions of the postural control system $(1,2)$. Numerous disorders have been seen to interfere with the function of the postural control system and therefore the body's ability to effectively respond to perturbations of balance (3-6). This reduced efficiency can result in increased postural sway, impaired reaction times, dysfunctional motor performance and an increase in energy expenditure required to maintain upright stance $(1,7)$. Effective control over posture is essential in order to stabilise the body and enable upright stance, locomotion and to safely perform voluntary movements that would otherwise disturb postural equilibrium (7). The inability to maintain effective control over balance can lead to a sense of instability, vulnerability particularly for the elderly, as well as predispose falls and further injury (8-10). The restoration of effective postural control is therefore a core aim of many rehabilitation programmes.

Postural sway is most commonly measured using a force plate (11). These mechanically sensitive platforms are a popular choice due to their relative ease of use and their ability to provide detailed, quantitative data regarding deviations in the position of the body's centre of pressure over time (12). Using this tool, several studies have noted that individuals with both experimental (13) and clinical neck pain (14-18) exhibit 130\% - 170\% greater measurements of postural sway, during normal stance with eyes open, when compared to asymptomatic controls. The mechanism underlying this disturbance in postural control is thought to be related to altered proprioceptive input arising from the cervical region and pain-induced, maladaptive changes within the musculoskeletal and central nervous systems $(3,19,20)$.

The theory of maladaptation is supported by an extensive body of research surrounding the body's response to pain. These studies have found that somatic pain is associated with extensive neuroplastic changes in areas responsible for sensory processing and interpretation, 
motor planning and emotional and behavioural responses (21-26). It is thought that these changes may be responsible for the development and maintenance of functional impairments seen in neck pain sufferers $(22,23,27,28)$. Some of the functional impairments seen in patients with neck pain include altered processing of sensory information (29), reduced kinaesthetic sensibility of the cervical spine $(30,31)$, delayed feed-forward activation of postural musculature, inefficient muscle patterning, increased fatigability, and altered force output (3235). It is thought that increased postural sway is the product of these impairments in sensorimotor integration and motor performance.

The extent of these changes reflects the profound effect that pain and maladaptation have on sensorimotor performance and also the important role that the cervical region plays within the postural control system. The cervical region plays an important role in supplying proprioceptive information to the postural control system. This is reflected by the dense concentration of proprioceptive organs within cervical musculature and the extensive network of connections that cervical afferents form with numerous components of the postural control system. These include visual and vestibular centres, supraspinal centres, key cervical nuclei and several postural reflexes that contribute to maintaining homeostasis of the head, neck and body (3639). Considering the many systems that draw information from cervical afferents, it is evident that the integrity of this information is essential to ensure accurate sensorimotor processing and motor output. The importance of cervical afferents has been eloquently demonstrated by experimental studies. These studies demonstrated that vibration of neck musculature in healthy individuals resulted in increased postural sway $(40,41)$, gait disturbances $(42,43)$ and reduced proprioceptive acuity of the neck and upper limb (44).

Despite the importance of postural control to the execution of daily tasks, and the prevalence of neck pain within the New Zealand population, there is a paucity of research surrounding rehabilitation for the sensorimotor disturbances that are associated with painful neck 
disorders. High velocity, low amplitude (HVLA) spinal manipulations have long been used by manual therapists in the treatment of musculoskeletal complaints. The mechanisms underlying this technique however, are still being explored. Recently, cervical spine manipulation to individuals with neck pain has been shown to be effective in reducing pain levels both locally and in peripheral sites (45-47). Functional improvements observed following application of cervical spine manipulation include increased force production, improved recruitment of inhibited musculature (48-50) and improved kinaesthetic performance $(51,52)$. Recently, a small body of research demonstrates that cervical spine manipulation to dysfunctional segments in patients with neck pain is followed by alterations in cortical activity in regions related to sensory processing and sensorimotor integration (53-55). Unlike functional improvements and changes in pain, these processing and integration responses were reported acutely, these effects were reported up to 30 mins following the manipulative intervention and are thought to reflect an improvement in processing and integration of sensory information. While no conclusions have been drawn, it has been proposed that the improvements seen in response to manipulation may be a result of the normalisation of the aberrant proprioceptive input that results from the pain and dysfunction associated with neck pain (20) and the analgesic effects of the technique itself (56).

Unfortunately, the inadequate body of research surrounding the clinical applications HVLA spinal manipulation means that the extent of the functional effects of the technique has not yet been established. A small number of studies have explored the effects of a single HVLA cervical manipulation on the postural sway of asymptomatic individuals. Two of these studies demonstrated significant reductions in postural sway following cervical manipulation with eyes open (57) and eyes closed (58). By contrast, a study by Palmgren, Lindeberg (51) reported no significant change in postural sway in measurements with both occluded vision and full vision. To date however, the potential for HVLA spinal manipulation to be utilised as a tool to improve postural sway in individuals with neck pain has not been explored. 
The highly proprioceptive structure of the cervical spine, with its extensive central connections undoubtedly plays an important role in the complex regulation of upright posture. If theories are correct that HVLA manipulation may acutely improve sensorimotor integration are correct, it is therefore plausible that a single HVLA manipulation to the cervical spine of individuals with neck pain may improve postural sway. This study aims to explore this theory by measuring the magnitude of effect that cervical spine manipulation has on the postural sway of participants with neck pain. 


\section{Methods}

\section{Participants}

Adults between the ages of 18 and 55 years who had experienced recent neck pain and were able to read and understand English language were invited to participate in this study. Participants were recruited via the placement of posters in the Unitec Clinic 41 and the participant recruitment website ResearchStudies.co.nz.

To be eligible, participants were required to have a dysfunctional segment, defined as the presence of restricted inter-segmental range of motion and tenderness on palpation of the joint (59). Assessments of these have been shown to have good to excellent inter-examiner reliability (60) in the case of palpation of tissue tenderness and good inter-examiner reliability (61) for cervical range of motion. This is in contrast to palpable paravertebral muscular tissue texture change, which is not supported by current literature $(59,62)$.

Interested participants were asked to complete a medical questionnaire that screened for possible contraindications to cervical spine manipulation as outlined by Gibbons and Tehan (63). Participants were also screened for the presence of vertebrobasilar insufficiency in accordance with Australian Physiotherapy Association clinical guidelines for assessing vertebrobasilar insufficiency prior to the application of cervical spine manipulation (64). This involved questions concerning subjective symptoms of vertebrobasilar insufficiency as well as an active provocative test, for which participants' heads were positioned in a posture of extension, side bending and rotation (65). Those who were identified as having factors that contraindicated the use of cervical spine manipulation, or who demonstrated evidence of vertebrobasilar insufficiency were excluded from the study.

Written, informed consent was obtained from each participant. This study was approved by Unitec research ethics committee (UREC 2011 - 1188). 


\section{Experimental Protocol}

A randomised controlled trial design with crossover was used. Each participant attended two sessions, one week apart, in which they received either the cervical spine manipulation or a passive head movement control. The passive head movement was designed as a physiological control for any possible changes occurring due to the vestibular or mechanical input of the practitioner's hands that would occur with the passive head movement involved in preparing a participant for the cervical manipulation intervention. The order in which the participants received the procedures was determined by random number generation.

\section{Procedures}

The procedures were performed by a registered osteopath, who had also conducted the screening examinations. The cervical spine manipulation intervention consisted of a single HVLA thrust to the identified dysfunctional segment. The passive head movement control involved the participant's head being gently and passively side bent and rotated into the position that the practitioner would normally manipulate. The participants head was then returned to a neutral position.

The participants were told that the study aimed to investigate the effects of two different techniques on postural sway. As a result, the participants were unaware that the cervical manipulation intervention was the technique of interest, and that the passive head movement was designed as a control.

\section{Measurement of Postural Sway}

Both baseline and post-procedure postural sway were measured using the Medicapteurs SPlate platform and associated S-Plate software, version 1.36. Centre of pressure (COP) deviations derived from a force platform has been shown to be a reliable measure of postural sway, as represented by $(15,66,67)$. Four variables of COP were measured: the length of COP path, the area covered by the COP path and the average speed in both medial/lateral and 
anterior/posterior directions. The reliability of these measures have been previously demonstrated on this force platform (68).

A standardised data collection procedure was used in order to emulate normal conditions of standing whilst providing consistency between measures. Participants were required to perform all measurements without footwear. They were asked to stand on the plate as naturally as possible with their eyes open, looking at a marked point on the wall $90 \mathrm{~cm}$ in front of them. The investigator was stationed behind them, out of sight. A standardised testing position was achieved by asking the participants to stand on a template that aligned their feet to a position with their heels $10 \mathrm{~cm}$ apart and at an angle of $30^{\circ}$, as measured along the medial border of the foot.

The total duration of each measurement period was $75 \mathrm{~s}$. This included $10 \mathrm{~s}$ prior to initiation of recording to allow the participant to settle into a standing posture, $60 \mathrm{~s}$ of data collection and 5 $\mathrm{s}$ following the completion of the recording to allow for any anticipatory movement near the completion of data capture.

To further reduce variability that might arise from trial-to-trial fluctuation of performance, two baseline measures of postural sway were recorded. Following this, the participant received their allocated procedure. The first post-procedure measurement of postural sway was taken immediately following administration of the procedure. Two subsequent measurements at 5 and 15 min post-procedure were made with the participant sitting quietly between measures. 


\section{Statistical Analysis}

Data were analysed using SPSS version 19 (SPSS and IBM company., Chicago IL). Changes from baseline for all sway variables at each of the three post-procedure time-points were assessed for violation of assumptions of normality, and non-parametric equivalents were applied when required (69).

ANOVA models and non-parametric equivalents were used to evaluate differences between procedures (manipulation intervention versus passive control) across the measurement timepoints. For all analyses, statistical significance was set to $p<0.05$. 


\section{Results}

Ten adults ( 7 men and 3 women) with a mean age of 37.2 years, ranging from 27 to 46 years, participated in this study.

Analysis for any systematic change in the magnitude of sway measures between the first and second baseline measures was conducted in order to establish whether reporting an average of these two measures was justified. Paired $t$-tests showed reductions in sway between the first and second measurements ( $p$ range from $0.003-0.1$ ). To adjust for this systematic change, but maintain the greater consistency afforded by duplicate measures, the mean difference between the two measurements was subtracted from the first baseline measurement. An average of $2^{\text {nd }}$ baseline and this adjusted $1^{\text {st }}$ baseline measurement was used for analysis.

Change from baseline for all of the sway variables showed at least at one post-procedure timepoint that displayed skewness or kurtosis which fell outside the $95 \%$ confidence interval for a normal distribution. Similarly, each change variable showed a significant Shapiro-Wilk statistic which indicated a violation of normality (69), for at least one post-procedure time-point.

In order to establish whether there were differences between the manipulation intervention and passive head movement control procedures in the pattern of change in sway variables over the four measurement points, 2-way (time-point x procedure) ANOVAs were run for each sway variable (length of path, area of path, speed in anterior-posterior-direction, speed in mediallateral-direction). Parametric statistics were applied here because no equivalent nonparametric analysis was available. No significant interactions for any of the four ANOVAs were shown, indicating a lack of difference in change between the manipulation intervention and passive head movement control condition ( $p$ values range from $0.4-0.6$ ) (Figure 1).

To determine whether there were changes in sway variables across measurements for the manipulation and passive movement procedures separately, eight 1-way Friedman's ANOVAs were applied. No change over time was shown for any of the sway variables for the 
manipulation intervention. For the passive control, these analyses showed changes over time for length of path in the passive condition $(p=0.02)$ and a trend towards this in the passive condition for area $(p=0.06)$. Visual inspection of the figures suggests that sway tended to increase immediately following the passive head movement control (Figure 1).

A
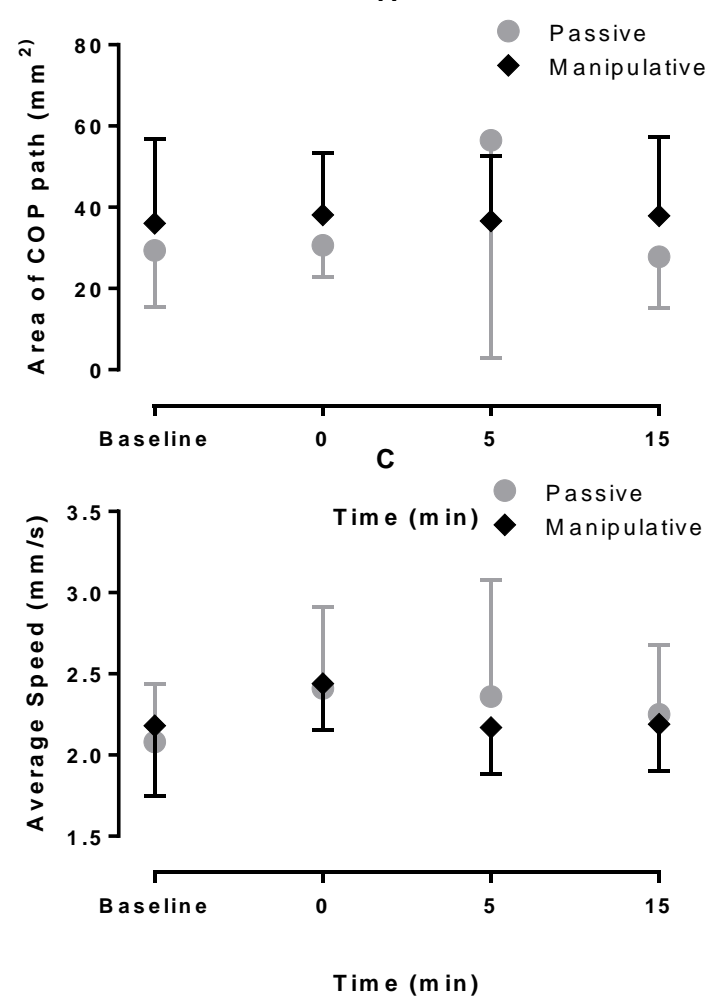

B
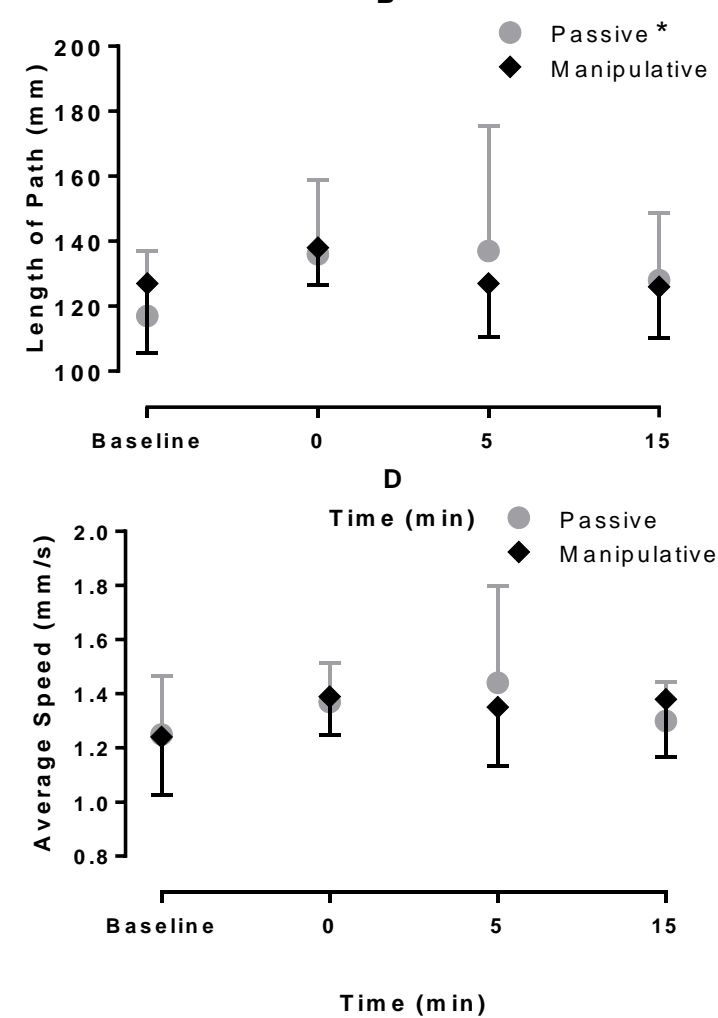

Figure 1: Change of the four Centre of Pressure parameters over time

Data show mean and unidirectional 95\% confidence intervals.

* Statistically significant overall Friedman's ANOVA for differences between measures for the procedure indicated

Graphs as follows:

A: Area of COP path

B: Length of COP path

C: Average speed of COP path in medial/lateral direction

D: Average speed of COP path in anterior/posterior direction 


\section{Discussion}

The aim of the present study was to determine whether HVLA manipulation of dysfunctional cervical segments in participants with neck pain would influence postural sway. No difference was shown between changes in sway for the manipulation compared to the passive control condition. These findings are in contrast to results from the few studies that have explored the effect of spinal manipulation, as an isolated intervention, on postural control. Whilst no studies have been identified that have investigated the effect of cervical spine manipulation on the postural sway of individuals with neck pain, three studies have been conducted on asymptomatic individuals. Two randomised controlled trials, Nolan (57) $(n=45)$ and Smith and Mehta (58) ( $n=11$ intervention +10 control), reported improvements in postural sway measurements following a single HVLA cervical manipulation compared to a sham treatment using a detuned ultrasound (57) or lying supine (58). By contrast, a crossover study of 6 asymptomatic participants, which compared the effects of bilateral manipulation, and cervical facet joint blockade to $\mathrm{C5} / 6$, noted no significant changes in either intervention (51).

A possible explanation for the failure to show any changes in postural sway in the current study is that pain may be associated with a reweighting of sensory information away from the cervical spine. An important feature of the postural control system is its ability to adapt to changes in environment and the available sensory information in order to maintain control over balance and posture. If the quality of information from one source is compromised, for example the loss of visual information at night, research suggests that the central nervous system can reorganise the hierarchy of sensory information to place more emphasis on other systems, such as vestibular or lower limb proprioception, a process referred to as sensory reweighting $(41,70$, 71). This reweighting of sensory information may be more likely to occur in the present study, that recruited symptomatic participants, as opposed to previous studies that recruited asymptomatic individuals $(57,58)$. As a result of this reweighting of sensory information, spinal manipulation may have appeared no more effective than the passive head movement. 
Evidence of sensory reweighting in the postural control system has been observed in the elderly $(72,73)$, patients with lower back pain $(74,75)$ and in healthy individuals following alteration of proprioceptive sensory information $(70,76)$. If sensory reweighting had occurred in the participants in the present study, postural sway prior to the intervention would not be expected to be different from that of asymptomatic adults of a similar age. It is difficult to determine whether initial sway measurements were comparable with previously-reported measures in asymptomatic adults. This difficulty lies in the large degree of heterogeneity between studies in terms of testing position, manipulation of sensory conditions i.e. vision, and the frequency and duration of data collection.

If sensory reweighting away from cervical proprioceptive input toward other sensory modalities was a factor in masking the effects of the intervention in the current study, then measures to occlude one of these systems, such as vision, may have amplified any change in cervical proprioceptive performance elicited by the manipulative intervention. In the past, several studies have demonstrated that individuals suffering from neck pain (77) lower back pain (73) and diabetic peripheral neuropathy (78) demonstrate greater increases in postural sway than healthy controls following the limitation of sensory modalities such as lower limb proprioception and vision. Sway has been reported to increase progressively with each additional measure taken to occlude a sensory modality (70), probably due to the increasing emphasis that is placed on the remaining sources of sensory information. Nonetheless, Nolan (2009) reported significant reductions in postural sway despite making no effort to occlude any other sensory system and Palmgren (2009) failed to detect any difference in postural sway between eyes open and closed conditions. Thus it appears that blindfolding participants may not be necessary for manipulation-induced changes in postural sway to be observed.

An alternative explanation for the present study's failure to detect any difference in postural sway between the manipulative and passive head movement interventions may be that the central changes that have been reported following cervical manipulation $(54,55,79-81)$ had not yet manifested as changes in functional motor output in the 15 minutes separating the intervention and the final measurement in the present study. The research surrounding the 
nature of the relationship between sensory and motor cortices is limited. To date, most studies have focussed on responses of the sensory and motor cortices as discrete regions in their own right. Recently however, the possibility has been explored of a direct link between the changes in excitability of the sensory cortex and the corticomotor output during pain. Schabrun et al. (82) used somatosensory evoked potentials and transcranial magnetic stimulation to monitor cortical responses to experimental muscle pain (82). Their results demonstrated changes in the somatosensory cortex both during and after pain whereas changes in the motor cortex emerged only after the pain had resolved. Baseline pain levels were restored within 15 min in all patients (82). The present study collected data over a 15 minute period. It is possible that a longer period of measurement may have revealed a delayed response from the motor system in the form of greater changes in postural sway.

A secondary finding from the results of the non-parametric, Friedman's ANOVA was that there was a significant $(p=0.02)$ change in sway over the four measurements (baseline and three post-procedure) when changes following the passive head movement intervention were analysed separately. This change in sway for the control condition was unanticipated. The passive head movement was designed as a physiological control for any changes elicited by the cutaneous, muscular or vestibular input that would occur as a result of the preparation phase of cervical manipulation. The design of this control is supported by findings that both muscle spindles and golgi tendon organs increase their discharge rate significantly more in response to the thrust phase of the spinal manipulation than the preload forces (83). These authors note that spindles within paraspinal tissues increase their resting discharge by up to $200 \%$ in the thrust phase compared to only $29 \%$ in the preload phase (83). Golgi tendon organs rarely responded to preload at all but also increased their discharge rate in the thrust phase (83). The same control condition as the present study was used by Haavik and Murphy's research group in a series of studies $(54,55,80,81)$. In each of these studies significant cortical findings were recorded in the cervical spine manipulation intervention but not as a result of the use of this control technique $(54,55,80,84)$. Abnormal cortical processing of sensory information has been proposed to be a significant factor in the development and persistence of impaired functional performance in individuals with spinal-region pain $(29,85)$. Therefore, in the current 
study it was deemed plausible that the improvements noted by Haavik and Murphy (2012) might result in subsequent improvement in postural sway (20).

One explanation for the increase in sway noted in the passive head movement condition is that individuals with neck pain may have an impaired ability to adapt to the sudden change from supine to upright posture and that the manipulation intervention could indeed have had a small effect on postural sway by attenuating this reduction in stability. Individuals with neck pain may exhibit increased sway following a change in posture compared to asymptomatic individuals due to the disruption to vestibular, visual or peripheral sensory information associated with moving from a supine posture to upright stance. This disruption may have accentuated any preexisting postural control deficits resulting from their neck pain. It is recognised that the ability of individuals to respond and adapt to changes in sensory information is increasingly impaired with each additional measure to occlude a sensory system. This was demonstrated by a recent study of 14 asymptomatic individuals in whom postural sway measurements were taken in three sensory conditions (no vision \pm muscle fatigue, no vision + soft foam surface, and vision). The results showed a progressive increase in postural sway from normal quiet standing to the inducement of muscle fatigue, removal of visual and then the addition of a foam platform that served to impair lower limb sensory information. The subsequent restoration of vision was followed by a reduction of postural sway (70). It must be emphasised however that a significant change following the control condition was noted only in one of the four sway parameters. In addition there was no significant difference in change noted between the manipulative and passive head movement condition. As such any interpretation of these results must be applied with caution.

A limitation of the present study is that it was performed with a small number of participants over a relatively short time-frame. These factors may have impaired the ability of the study to detect smaller changes that may have reached significance in a larger study. Despite this an inspection of the mean change following manipulation intervention does not show a trend toward decreasing postural sway. It is also possible that the heterogeneous nature of the participant group, in terms of factors such as the aetiology of their neck pain, their treatment 
history, and the duration of their symptoms, was in itself a limiting factor in the ability to show a consistent effect of manipulation on sway.

Examination of centre of pressure excursions through use of a force platform has been shown in the past to a reliable method of investigating postural stability and balance performance (11). It is possible however, that this method may have lower reliability when applied to people with chronic or sub-chronic pain, particularly in the situation of this study when people were recruited via a clinical research group. Nonetheless, sway platforms provide a useful method of assessing postural control in that they are an economical, easy to use means of obtaining quantitative data on different parameters of COP trajectory.

Overall, this study has shown no evidence that cervical spine manipulation improves postural sway in individuals with nonspecific neck pain. This is in contrast to the findings from Haavik and Murphy's body of research that suggests cervical manipulation improves sensory processing and early sensorimotor integration. Furthermore the findings of this study are contrary to the small group of studies that have demonstrated improvements in sway following lumbar manipulation of individuals with lower back pain (86) and cervical manipulation of asymptomatic individuals $(57,58)$. The observation that no such improvements were seen in this study may reflect an underlying reorganisation of the postural control system as part of the complex neuromuscular response to neck pain. Further investigation, with due consideration to the above factors, is warranted in order to gain further insight into the complex process of neurophysiological adaptation to neck pain and to develop more effective treatment protocol with which to manage these patients in clinical practice. 


\section{References}

1. Alexander KM, LaPier TL. Differences in static balance and weight distribution between normal subjects and subjects with chronic unilateral low back pain. Journal of orthopaedic $\&$ sports physical therapy. 1998;28(6):378-83.

2. Massion J. Postural control system. Current Opinion in Neurobiology. 1994;4(6):877-87.

3. Ruhe A, Fejer R, Walker B. Altered postural sway in patients suffering from non-specific neck pain and whiplash associated disorder - a systematic review. Chiropractic \& Manual Therapies. 2011;19(13). doi: 10.1186/2045-709X-19-13.

4. Mazaheri M, Coenen P, Parnianpour M, Kiers H, van Dieën JH. Low back pain and postural sway during quiet standing with and without sensory manipulation: a systematic review. Gait \& Posture. 2013;37(1):12-22. doi: 10.1016/j.gaitpost.2012.06.013.

5. O'Connell M, George K, Stock D. Postural sway and balance testing: a comparison of normal and anterior cruciate ligament deficient knees. Gait \& Posture. 1998;8(2):136-42. doi: 10.1016/S09666362(98)00023-X.

6. Redfern M, Furman J. Postural sway of patients with vestibular disorders during optic flow. Journal of vestibular research: equilibrium \& orientation. 1994;4(3):221 - 30.

7. Deliagina TG, Zelenin PV, Beloozerova IN, Orlovsky GN. Nervous mechanisms controlling body posture. Physiology \& Behavior. 2007;92(1-2):148-54. doi: 10.1016/j.physbeh.2007.05.023.

8. Tucker M, Kavanagh J, Morrison S, Barrett R. Differences in rapid Initiation and termination of voluntary postural sway associated with ageing and falls-risk. Journal of Motor Behavior. 2010;42(5):277-87.

9. Tucker M, Kavanagh J, Morrison S, Barrett R. Voluntary sway and rapid orthogonal transitions of voluntary sway in young adults, and low and high fall-risk older adults. Clinical Biomechanics. 2009;24(8):597-605.

10. Winter D. Human balance and posture control during standing and walking. Gait \& Posture. 1995;3(4):193-214.

11. Ruhe A, Fejer R, Walker B. The test-retest reliability of centre of pressure measures in bipedal static task conditions - a systematic review of the literature. Gait \& Posture. 2010;32(4):436-45. doi: 10.1016/j.gaitpost.2010.09.012.

12. Dehner C, Heym B, Maier D, Sander S, Arand M, Elbel M, et al. Postural control deficit in acute QTF grade II whiplash injuries. Gait \& Posture. 2008;28(1):113-9. doi:10.1016/j.gaitpost.2007.10.007

13. Vuillerme N, Pinsault N. Experimental neck muscle pain impairs standing balance in humans. Experimental Brain Research. 2009;192(4):723-9. doi: 10.1007/s00221-008-1639-7.

14. McPartland J, Brodeur R, Hallgren R. Chronic neck pain, standing balance, and suboccipital muscle atrophy - a pilot study. Journal of Manipulative \& Physiological Therapeutics. 1997;20(1):24-9. 
15. Field S, Treleaven J, Jull G. Standing balance: a comparison between idiopathic and whiplash-induced neck pain. Manual Therapy. 2008;13(3):183-91. doi: 10.1016/j.math.2006.12.005.

16. Karlberg M, Persson L, Magnusson M. Reduced postural control in patients with chronic cervicobrachial pain syndrome. Gait \& Posture. 1995;3(4):241-9. doi: 10.1016/0966-6362(96)828542.

17. Treleaven J, Jull G, LowChoy N. Standing balance in persistent whiplash: a comparison between subjects with and without dizziness. Journal of Rehabilitation Medicine. 2005;37(4):224-9.

18. Treleaven J. Sensorimotor disturbances in neck disorders affecting postural stability, head and eye movement control-part 2: case studies. Manual Therapy. 2008;13(3):266-75. doi: 10.1016/j.math.2007.11.002.

19. Röijezon U, Björklund M, Djupsjöbacka M. The slow and fast components of postural sway in chronic neck pain. Manual Therapy. 2011;16(3):273-8. doi: 10.1016/j.math.2010.11.008.

20. Haavik $H$, Murphy B. The role of spinal manipulation in addressing disordered sensorimotor integration and altered motor control. Journal of Electromyography and Kinesiology. 2012;22(5):76876. doi: 10.1016/j.jelekin.2012.02.012.

21. Flor $\mathrm{H}$, Braun $\mathrm{C}$, Elbert $\mathrm{T}$, Birbaumer $\mathrm{N}$. Extensive reorganization of primary somatosensory cortex in chronic back pain patients. Neuroscience Letters. 1997;224(1):5-8. doi: 10.1016/S03043940(97)13441-3.

22. Flor H. Maladaptive plasticity, memory for pain and phantom limb pain: review and suggestions for new therapies. Expert Review of Neurotherapeutics. 2008;8(5):809-18. doi: 10.1586/14737175.8.5.809. PubMed PMID: 14230766.

23. Wall JT, Xu J, Wang X. Human brain plasticity: an emerging view of the multiple substrates and mechanisms that cause cortical changes and related sensory dysfunctions after injuries of sensory inputs from the body. Brain Research Reviews. 2002;39(2-3):181-215. doi: 10.1016/S01650173(02)00192-3.

24. Tinazzi M, Fiaschi A, Rosso T, Faccioli F, Grosslercher J, Aglioti S. Neuroplastic changes related to pain occur at multiple levels of the human somatosensory system: a somatosensory-evoked potentials study in patients with cervical radicular pain. Journal of Neuroscience. 2000;20(24):9277-83. PMCID: PMC11125006.

25. Geha PY, Baliki MN, Harden RN, Bauer WR, Parrish TB, Apkarian AV. The brain in chronic CRPS pain: abnormal gray-white matter interactions in emotional and autonomic regions. Neuron. 2008;60(4):570-81. doi: 10.1016/j.neuron.2008.08.022.

26. Henderson LA, Bandler R, Gandevia SC, Macefield VG. Distinct forebrain activity patterns during deep versus superficial pain. Pain. 2006;120(3):286-96. doi: 10.1016/j.pain.2005.11.003.

27. Falla D, Farina D. Neuromuscular adaptation in experimental and clinical neck pain. Journal of electromyography and kinesiology : official journal of the International Society of Electrophysiological Kinesiology. 2008;18(2):255-61. doi: 10.1016/j.jelekin.2006.11.001. 
28. Hodges P. Pain and motor control: from the laboratory to rehabilitation. Journal of Electromyography and Kinesiology. 2011;21(2):220-8. doi: 10.1016/j.jelekin.2011.01.002.

29. Paulus I, Brumagne S. Altered interpretation of neck proprioceptive signals in persons with subclinical recurrent neck pain. Journal of rehabilitation medicine. 2008;40(6):426-32. doi: 10.2340/16501977-0189.

30. Cheng C-H, Wang J-L, Lin J-J, Wang S-F, Lin K-H. Position accuracy and electromyographic responses during head reposition in young adults with chronic neck pain. Journal of Electromyography and Kinesiology. 2010;20(5):1014-20. doi: 10.1016/j.jelekin.2009.11.002.

31. Heikkilä H, Wenngren BI. Cervicocephalic kinesthetic sensibility, active range of cervical motion, and oculomotor function in patients with whiplash injury. Archives of Physical Medicine and Rehabilitation. 1998;79(9):1089-94. doi: 10.1016/\$0003-9993(98)90176-9.

32. Jull G, O'Leary S, Falla D. Clinical assessment of the deep cervical flexor muscles: the craniocervical flexion test. Journal of Manipulative and Physiological Therapeutics. 2008;31(7):525-33. doi: 10.1016/j.jmpt.2008.08.003.

33. Falla D, Jull G, Edwards S, Koh K, Rainoldi A. Neuromuscular efficiency of the sternocleidomastoid and anterior scalene muscles in patients with chronic neck pain. Disability and Rehabilitation. 2004;26(12):712-7. doi: 10.1080/09638280410001704287.

34. Falla D. Unravelling the complexity of muscle impairment in chronic neck pain. Manual Therapy. 2004;9(3):125-33. doi: 10.1016/j.math.2004.05.003.

35. Falla D, Jull G, Hodges P. Feedforward activity of the cervical flexor muscles during voluntary arm movements is delayed in chronic neck pain. Experimental brain research. 2004;157(1):43-8. doi: 10.1007/s00221-003-1814-9.

36. Straka H, Vibert N, Vidal PP, Moore LE, Dutia MB. Intrinsic membrane properties of vertebrate vestibular neurons: function, development and plasticity. Progress in Neurobiology. 2005;76(6):34992. doi: 10.1016/j.pneurobio.2005.10.002.

37. Kristjansson E, Treleaven J. Sensorimotor function and dizziness in neck pain: implications for assessment and management. Journal of orthopaedic and sports physical therapy. 2009;39(5):36477. doi: 10.2519/jospt.2009.2834.

38. Treleaven J. Sensorimotor disturbances in neck disorders affecting postural stability, head and eye movement control. Manual Therapy. 2008;13(1):2-11. doi: 10.1016/j.math.2007.06.003.

39. Humphreys B. Cervical outcome measures: testing for postural stability and balance. Journal of Manipulative and Physiological Therapeutics. 2008;31(7):540-6. doi: 10.1016/j.jmpt.2008.08.007.

40. Ivanenko YP, Grasso R, Lacquaniti F. Neck muscle vibration makes walking humans accelerate in the direction of gaze. The Journal of physiology. 2000;525(3):803-14. doi: 10.1111/j.1469-7793.2000.t011-00803.x.

41. Vuillerme N, Danion F, Forestier N, Nougier V. Postural sway under muscle vibration and muscle fatigue in humans. Neuroscience Letters. 2002;333(2):131-5. doi: 10.1016/S0304-3940(02)00999-0. 
42. Bove $M$, Courtine $G$, Schieppati $M$. Neck muscle vibration and spatial orientation during stepping in place in humans. Journal of Neurophysiology. 2002;88(5):2232-41. doi: 10.1152/jn.00198.2002.

43. Courtine G, Papaxanthis C, Laroche D, Pozzo T. Gait-dependent integration of neck muscle afferent input. Neuroreport. 2003;14(18):2365-8. doi: 10.1097/00001756-200312190-00015.

44. Knox J, Skoss R, Cordo P, Durrant S, Hodges P. Illusory changes in head position induced by neck muscle vibration can alter the perception of elbow position. Behavioral Neuroscience. 2006;120(6):1211-7.

45. Coronado RA, Gay CW, Bialosky JE, Carnaby GD, Bishop MD, George SZ. Changes in pain sensitivity following spinal manipulation: a systematic review and meta-analysis. Journal of Electromyography and Kinesiology. 2012(0). doi: 10.1016/j.jelekin.2011.12.013.

46. Goertz CM, Pohlman KA, Vining RD, Brantingham JW, Long CR. Patient-centered outcomes of highvelocity, low-amplitude spinal manipulation for low back pain: a systematic review. Journal of Electromyography and Kinesiology. 2012;22(5):670-91. doi: 10.1016/j.jelekin.2012.03.006.

47. Gross A, Miller J, D’Sylva J, Burnie SJ, Goldsmith CH, Graham N, et al. Manipulation or mobilisation for neck pain: a cochrane review. Manual Therapy. 2010;15(4):315-33. doi: 10.1016/j.math.2010.04.002.

48. Suter $E$, McMorland G. Decrease in elbow flexor inhibition after cervical spine manipulation in patients with chronic neck pain. Clinical Biomechanics. 2002;17(7):541-4. doi: 10.1016/S02680033(02)00025-6.

49. Dunning J, Rushton A. The effects of cervical high-velocity low-amplitude thrust manipulation on resting electromyographic activity of the biceps brachii muscle. Manual Therapy. 2009;14(5):508-13. doi: 10.1016/j.math.2008.09.003.

50. Fernández-Carnero J, Fernández-de-las-Peñas C, Cleland JA. Immediate hypoalgesic and motor effects after a single cervical spine manipulation in subjects with lateral epicondylalgia. Journal of Manipulative and Physiological Therapeutics. 2008;31(9):675-81. doi: 10.1016/j.jmpt.2008.10.005.

51. Palmgren P, Lindeberg A, Nath S, Heikkilä H. Head repositioning accuracy and posturography related to cervical facet nerve blockade and spinal manipulative therapy in healthy volunteers: a time series study. Journal of Manipulative and Physiological Therapeutics. 2009;32(3):193-202. doi: 10.1016/j.jmpt.2009.02.003.

52. Palmgren $P$, Sandström $P$, Lundqvist $F$, Heikkilä $H$. Improvement after chiropractic care in cervicocephalic kinesthetic sensibility and subjective pain intensity in patients with nontraumatic chronic neck pain. Journal of Manipulative and Physiological Therapeutics. 2006;29(2):100-6. doi: 10.1016/j.jmpt.2005.12.002.

53. Haavik $\mathrm{H}$, Murphy B. Subclinical neck pain and the effects of cervical manipulation on elbow joint position sense. Journal of Manipulative and Physiological Therapeutics. 2011;34(2):88-97. doi: 10.1016/j.jmpt.2010.12.009.

54. Haavik-Taylor H, Murphy B. Cervical spine manipulation alters sensorimotor integration: a somatosensory evoked potential study. Clinical Neurophysiology. 2007;118(2):391-402. doi: 10.1016/j.clinph.2006.09.014. 
55. aavik-Taylor $\mathrm{H}$, Murphy B. Altered central integration of dual somatosensory input after cervical spine manipulation. Journal of Manipulative and Physiological Therapeutics. 2010;33(3):178-88. doi: 10.1016/j.jmpt.2010.01.005.

56. Ruhe A, Fejer R, Walker B. Does postural sway change in association with manual therapeutic interventions? a review of the literature. Chiropractic \& Manual Therapies. 2013;21(1):9. doi: 10.1186/2045-709X-21-9.

57. Nolan JH. The effect of cervical spine chiropractic manipulation on balance [Dissertation]. Johannesburg, South Africa: University of Johannesburg; 2009.

58. Smith L, Mehta M. The effects of upper cervical complex high velocity low amplitude thrust technique and sub-occipital muscle group inhibition techniques on standing balance. International Journal of Osteopathic Medicine. 2008;11(4):162-. doi:10.1016/j.ijosm.2008.08.020.

59. Fryer G, Morris T, Gibbons P. Paraspinal muscles and intervertebral dysfunction: part one. Journal of Manipulative and Physiological Therapeutics. 2004;27(4):267-74. doi: 10.1016/j.jmpt.2004.02.006.

60. Boline PD, Haas M, Meyer JJ, Kassak K, Nelson C, Keating JC. Interexaminer reliability of eight evaluative dimensions of lumbar segmental abnormality: part II. Journal of Manipulative and Physiological Therapeutics. 1993;16(6):363-74.

61. Rheault W, Albright B, Beyers C, Franta M, Johnson A, Skowronek M, et al. Intertester reliability of the cervical range of motion device. The Journal of orthopaedic and sports physical therapy. 1992;15(3):147-50.

62. Fryer G, Morris T, Gibbons P. Paraspinal muscles and intervertebral dysfunction: part two. Journal of Manipulative and Physiological Therapeutics. 2004;27(5):348-57. doi: 10.1016/j.jmpt.2004.04.008.

63. Gibbons P, Tehan P. Manipulation of the spine, thorax and pelvis. 3rd ed: Elsevier Limited; 2010.

64. Clinical guidelines for assessing vertebrobasilar insufficiency in the management of cervical spine disorders. . Australian Physiotherapy Association., 2006.

65. Arnold C, Bourassa R, Langer T, Stoneham G. Doppler studies evaluating the effect of a physical therapy screening protocol on vertebral artery blood flow. Manual Therapy. 2004;9(1):13-21. doi: 10.1016/S1356-689X(03)00087-0.

66. Schieppati M, Nardone A, Schmid M. Neck muscle fatigue affects postural control in man. Neuroscience. 2003;121(2):277-85. doi: 10.1016/S0306-4522(03)00439-1.

67. Treleaven J, Jull G, LowChoy N. The relationship of cervical joint position error to balance and eye movement disturbances in persistent whiplash. Manual Therapy. 2006;11(2):99-106. doi: 10.1016/j.math.2005.04.003.

68. Fisher ST. Intra- session and inter-session reliability of centre-of-pressure based measures of postural sway within a normal population. Auckland: Unitec Institute of technology; 2010.

69. Field A. Discovering statistics using SPSS 3rd ed. London: SAGE Publications 2009. 
70. Vuillerme N, Pinsault N, Vaillant J. Postural control during quiet standing following cervical muscular fatigue: effects of changes in sensory inputs. Neuroscience Letters. 2005;378(3):135-9. doi: 10.1016/j.neulet.2004.12.024.

71. Mahboobin APCM. A mechanism for sensory re-weighting in postural control. Medical \& Biological Engineering \& Computing. 2009;47(9):921-9. doi: 10.1007/s11517-009-0477-5. PubMed PMID: 43919628.

72. Woollacott M, Shumway-Cook A, Nashner L. Aging and posture control: changes in sensory organization and muscular coordination. The International Journal of Aging and Human Development. 1986;23(2):97 - 114. doi: 10.2190/VXN3-N3RT-54JB-X16X.

73. Brumagne $S$, Cordo $P$, Verschueren S. Proprioceptive weighting changes in persons with low back pain and elderly persons during upright standing. Neuroscience Letters. 2004;366(1):63-6. doi: 10.1016/j.neulet.2004.05.013.

74. Popa T, Bonifazi M, Della Volpe R, Rossi A, Mazzocchio R. Adaptive changes in postural strategy selection in chronic low back pain. Experimental Brain Research. 2007;177(3):411-8. doi: 10.1007/s00221-006-0683-4.

75. Claeys K, Brumagne S, Dankaerts W, Kiers H, Janssens L. Decreased variability in postural control strategies in young people with non-specific low back pain is associated with altered proprioceptive reweighting. European Journal of Applied Physiology. 2011;111(1):115-23. doi: 10.1007/s00421-0101637-x.

76. Peterka RJ, Loughlin PJ. Dynamic regulation of sensorimotor integration in human postural control. Journal of Neurophysiology. 2004;91(1):410-23. doi: 10.1152/jn.00516.2003.

77. Madeleine P, Nielsen M, Arendt-Nielsen L. Characterization of postural control deficit in whiplash patients by means of linear and nonlinear analyses - a pilot study. Journal of Electromyography and Kinesiology. 2011;21(2):291-7. doi: 10.1016/j.jelekin.2010.05.006.

78. Simoneau G, Ulbrecht J, Derr J, Cavanagh P. Role of somatosensory input in the control of human posture. Gait \& Posture. 1995;3(3):115-22. doi: 10.1016/0966-6362(95)99061-0.

79. Haavik-Taylor H, Murphy B. The effects of spinal manipulation on central integration of dual somatosensory input observed after motor training: a crossover study. Journal of Manipulative and Physiological Therapeutics. 2010;33(4):261-72. doi: 10.1016/j.jmpt.2010.03.004.

80. Haavik-Taylor H, Murphy B. Altered sensorimotor integration with cervical spine manipulation. Journal of Manipulative and Physiological Therapeutics. 2008;31(2):115-26. doi: 10.1016/j.jmpt.2007.12.011.

81. Haavik-Taylor H, Murphy B. Transient modulation of intracortical inhibition following spinal manipulation. Chiropractic Journal of Australia. 2007;37(3):106-16.

82. Schabrun S, Jones E, Kloster J, Hodges $\mathrm{P}$. Temporal association between changes in primary sensory cortex and corticomotor output during muscle pain. Neuroscience. 2013;235(0):159-64. doi: 10.1016/j.neuroscience.2012.12.072. 
83.Pickar J, Bolton P. Spinal manipulative therapy and somatosensory activation. Journal of Electromyography and Kinesiology. 2012;22(5):785-94. doi: 10.1016/j.jelekin.2012.01.015.

84. Haavik-Taylor H, Murphy B. Altered cortical integration of dual somatosensory input following the cessation of a 20 min period of repetitive muscle activity. Experimental Brain Research. 2007;178(4):488-98. doi: 10.1007/s00221-006-0755-5.

85. Brumagne S, Janssens L, Janssens E, Goddyn L. Altered postural control in anticipation of postural instability in persons with recurrent low back pain. Gait \& Posture. 2008;28(4):657-62. doi: 10.1016/j.gaitpost.2008.04.015.

86. Childs JD, Piva SR, Erhard RE. Immediate improvements in side-to-side weight bearing and iliac crest symmetry after manipulation in patients with low back pain. Journal of Manipulative and Physiological Therapeutics. 2004;27(5):306-13. doi: 10.1016/j.jmpt.2004.04.004. 


\section{Section Three}

Appendices 


\section{Appendix A: UREC Consent Form}

Alison Fisher

2b Fifth Ave

Mt Albert

Auckland 1025

23.6.2011

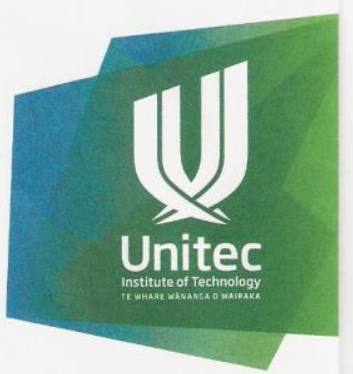

Dear Alison,

Your file number for this application: 2011-1188

Title: Can Osteopathic Manipulative Techniques Improve Postural Control in Patients With Neck

Pain?

Your application for ethics approval has been reviewed by the Unitec Research Ethics Committee (UREC) and has been approved for the following period:

Start date: 22.6 .2011

Finish date: 22.6.2012

Please note that:

1. The above dates must be referred to on the information AND consent forms given to all participants.

2. You must inform UREC, in advance, of any ethically-relevant deviation in the project. This may require additional approval.

You may now commence your research according to the protocols approved by UREC. We wish you every success with your project.

Yours sincerely,

p.p.

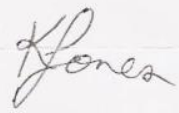

Scott Wilson

Deputy Chair, UREC

cc: Catherine Bacon

Cynthia Almeida 


\section{Appendix B: Recruitment Poster}

\section{U) Unitec \\ Are you suffering from neck pain?}

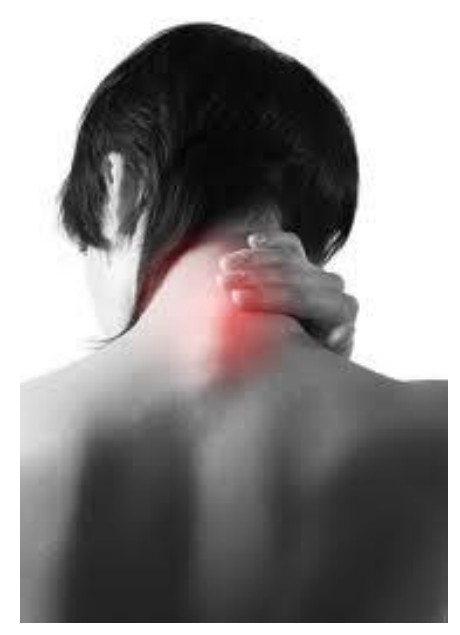

I am a Master of Osteopathy student at Unitec investigating the effect that two osteopathic techniques have on postural control.

These techniques are regularly used on the neck in everyday practice. I am looking for participants for my study who are experiencing neck pain. This may have started recently or be longstanding.

Participants will receive a fuel voucher as a token of appreciation for their time and contribution to this study UREC REGISTRATION NUMBER: 2011-1188

Contact Alison at 02102455904 or posturalswaystudy@gmail.com 


\section{Appendix C: Medical History Questionnaire}

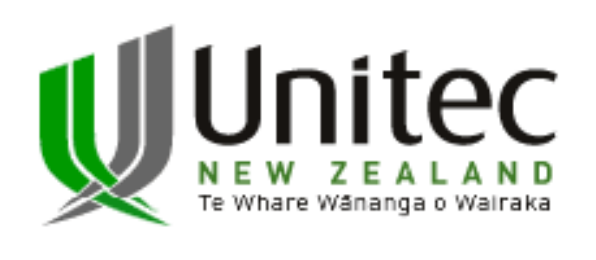

\section{Medical History Questionnaire}

\section{Name:}

The following questions gather information about your general health and provide important information about your spine and blood vessels that may affect the outcomes of this study. Answering yes to any of these questions does not necessarily exclude you from this study but it is important that we are aware of anything that may affect your safety and comfort. Please answer these questions honestly.

\section{Section one:}

Have you ever experienced any of the following conditions or pathologies?

Bone- Any pathology that has lead to significant bone weakening:

$\square$ Tumour, e.g. metastatic deposits

$\square$ Infection, e.g. tuberculosis

Metabolic disorders, e.g. osteomalacia

$\square$ Congenital conditions, e.g. hip dysplasia

$\square$ Drug/treatments that may affect bone health e.g. long-term

Corticosteroid medication

$\square$ Inflammation, e.g. rheumatoid arthritis

$\square$ Traumatic, e.g. fracture 
If Yes, Please Give Details:

Neurological (Conditions affecting the nerves or spinal cord)

$\square$ Disease or disorder affecting the neck (cervical myelopathy)

$\square$ Spinal cord compression

$\square$ Cauda equina compression

Nerve root compression with increasing neurological deficit

If Yes, Please Give Details:

Vascular (conditions affecting veins and arteries)

$\square$ Diagnosed vertebrobasilar insufficiency

Aortic aneurysm

Bleeding

$\square$ Hereditary or acquired blood or blood vessel condition e.g. haemophilia 
If Yes, Please Give Details:

Instability (Injury or hereditary conditions affecting the upper neck)

$\square$ Fracture or genetic weakness to the upper spine (e.g Incompetence of the odontoid process)

$\square$ Injury to or genetic weakness of ligaments of upper spine (e.g Incompetence of the transverse atlantal ligament)

If Yes, Please Give Details:

\section{Section Two:}

Have you ever experienced any of the following?

$\square$ Adverse reactions to previous manual therapy i.e. spinal manipulation

$\square$ Disc herniation or proplase

$\square$ Inflammatory arthritis of any kind 
$\square$ Current pregnancy or recent birth

$\square$ Osteoporosis

$\square$ Spondylolysis / Spondylolisthesis

$\square$ Degenerative joint disease and spondylosis

$\square$ Atherosclerosis/ Arterial calcification

$\square$ Scheurmann"s disease (even if non active)

$\square$ Abdominal hernia

$\square$ Psychological dependence on spinal manipulation techniques

If Yes, Please Give Details:

\section{Section three:}

Have you ever experienced any of the following in response to head movements or as a result to your head or neck being handled? (please tick)

$\square$ Abnormal eye movements e.g. repetitive, uncntrolled jerks, drooping of an eyelid or asymmetrical pupil constriciton

$\square$ Changes in vision e.g. double vision or blurring

$\square$ Ringing in your ears (Tinnitus)

$\square$ Changes to your voice or difficulty speaking or forming words

$\square$ Difficulty swallowing

$\square$ Balance or gait disturbances

$\square$ Dizziness or vertigo

$\square$ Feeling sick, Nausea

$\square$ Fainting, blackouts or collapsing

$\square$ Headaches at the back of your skull

$\square$ Changes in sensation to your face of limbs e.g numbness or tingling 
If Yes, Please Give Details:

Signature:

Date: 


\title{
Appendix D: Participant Information
}

\author{
RESEARCH INFORMATION FOR PARTICIPANTS
}

\section{Can Osteopathic Manipulative Techniques Improve Postural Control in Patients with Neck Pain?}

You are invited to participate in our research investigation. Please read carefully through this information sheet before you make a decision about volunteering.

\section{Principal Researcher}

Alison Fisher (Bachelor of Applied Science (Human Biology)) - Alison is currently in her 1st year of the Masters of Osteopathy programme at Unitec New Zealand.

\section{Our Purpose}

This study aims to determine if manual therapy techniques aimed at reducing dysfunction in the neck will improve postural control.

Postural control is the result of several different systems within the body coordinating the postural muscles of the body. These include the visual, balance and touch systems within the body. The neck, in particular, plays an important role in postural control. When any of these systems are disturbed or damaged the result is reduced control of posture. This is evident in an increase in the degree to which an individual sways to and fro during quiet stance.

Dysfunction within the neck has been shown to be connected with an increase in postural sway. By participating in this study you will help us to discover whether specific manual therapy techniques are effective at reducing this sway and improving postural control. You would also be helping us to build upon the information that exists on postural control and osteopathic techniques. Information that may contribute to further research in these areas. 


\section{Who may participate?}

We are looking for adults between the ages of 18 and 55 years who are experiencing neck pain that may have developed recently, or be long standing.

Unfortunately, you will not be included in the study if you have:

- A history of adverse effects with osteopathic treatment

- Any condition that may prevent you from receiving manipulation techniques to your neck, for example osteoporosis. These are explained in more detail in the patient health questionnaire

- Any evidence of vertebral artery problems or other if you are otherwise eligible and interested in participating in the study, you will receive a physical examination by a qualified, NZ registered osteopath to check the health of your neck and blood vessels. If problems are uncovered during this examination these will be explained to you along with your treatment options.

Please feel free to contact the lead researcher if you are unsure about your eligibility.

\section{What will happen in the study?}

If you choose to participate in the study you'll be asked to complete a set of questionnaires that provide basic information about your general health and neck pain. During the examination the practitioner will also determine the location of any dysfunctional segment within your neck. A dysfunctional segment is one that has restricted range of motion and is tender to touch.

Once this initial stage is complete, and if you are eligible to take part in the study, you will be asked to stand on a force plate that records your postural sway.

You will then be randomly assigned to one of two groups that each receives a different technique. You will not be told which of these techniques you will receive as the purpose of this study is to establish if there is a difference between the effects that each have on postural control. Both of these techniques are similar in nature in that they are both targeted at the dysfunctional segment within your neck. These techniques involve the practitioner handling your neck and head. If you have any questions or concerns regarding this, please feel free to contact the researcher at any time.

Two techniques will be used in this study. The first is a manipulation, or thrust, to the dysfunctional segment of your neck. The second involves movement of the head and neck into a series of positions, again focussing on the dysfunctional segment. Following the application of one of these techniques you will then be asked to stand on the force plate in order to gain your follow up measurements. 
A random selection of participants will be asked to return to the clinic for a second session that will be very similar to the first. A technique will be applied to the dysfunctional segment and another set of postural sway measurements will be taken.

\section{Discomforts/risks and benefits}

All of the techniques and examinations performed during this study will be conducted by a fully qualified NZ registered Osteopath with years of clinical experience. While there is a small risk associated with manipulation of the neck, the medical questionnaire and the physical examination, performed before any technique is applied, are designed to ensure your safety by identifying and excluding any individual that may be put at risk by any subsequent techniques.

Osteopathic treatment is gentle and consent is obtained before any manipulative techniques are implemented. There is the possibility of some discomfort following some techniques. Usually any aggravation lasts for less than 24 hours. Should it persist, assistance will be given to relieve the discomfort.

\section{What we do with the data and results, and how we protect your privacy.}

Personal information is collected and stored under the guidelines provided by the Privacy Act 1993 and the Health Information Privacy Code 1994. Your name will be recorded on the written consent form, your health questionnaire and on the VAS and NDI questionnaires. However, in all other instances of information collection your identity will remain anonymous and you will simply have an identification number. If the information you provide is reported or published, this will be done in a way that does not identify you as its source. All the data recorded will be stored securely and access to it will be limited to the principal researcher, the research supervisors, and yourself.

\section{Participation is voluntary}

The decision to participate in this study is totally voluntary. If at any time you feel uncomfortable with a technique you may inform the Osteopath and the technique will be ceased immediately with no repercussions. Data collected from your involvement in the study may be withdrawn up until 1 week following your final assessment.

Your participation in this study will help to further research into postural control mechanisms within 
the body and will provide a valuable addition to the ongoing research surrounding the effectiveness of osteopathic technique.

Please contact us if you need further information about the study.

\section{Contact Details}

Alison Fisher

Phone: 02102455904

Email: alison.fisher@hotmail.com

Dr Catherine Bacon or Dr Clive Standen

Phone: (09) 8494180 ext 5043

Email: cbacon@unitec.ac.nz

UREC REGISTRATION NUMBER: (2011 - 1188)

This study has been approved by the UNITEC Research Ethics Committee from $(23 / 6 / 11)$ to $(22 / 6 / 12)$. If you have any complaints or reservations about the ethical conduct of this research, you may contact the Committee through the UREC Secretary (ph: 09 815-4321 ext 6162). Any issues you raise will be treated in confidence and investigated fully, and you will be informed of the outcome. 


\title{
Appendix E: Participant Consent Form
}

\author{
Participant Consent Form
}

\section{Can Osteopathic Manipulative Techniques Improve Postural Control in \\ Patients With Neck Pain?}

This form is to ensure that you understand the requirements of your participation and that you aware of your rights. Please read carefully through the points below. If you are happy and agree with the points then please sign at the bottom of the page. If you have any questions at all please ask the researcher before signing this form.

- I have had the research project explained to me and I have read and understood the information sheet given to me.

- I understand that I don't have to be part of this if I don't want to and I may withdraw at any time.

- I understand that everything I say and the information I provide will be collected in accordance with the Health Information Privacy Code 1994 and kept confidential and in accordance with the Privacy Act 1993. I understand that the only persons who will have access to my information will be the researchers and relevant clinical staff.

- I understand that all the information I give will be stored securely on a computer at Unitec for a period of 5 years.

- I understand that I can see the finished research document.

- I have had time to consider the information provided, to ask questions, and to seek any guidance.

- I give my consent to be a part of this project

Participant Signature: Date:

Principal Researcher: Date:

UREC REGISTRATION NUMBER: 2011 - 1188

This study has been approved by the UNITEC Research Ethics Committee from $22 / 6 / 2011$ to $22 / 6 / 2012$. If you have any complaints or reservations about the ethical conduct of this research, you may contact the Committee through the UREC Secretary (ph: 09 815-4321 ext 6162). Any issues you raise will be treated in confidence and investigated fully, and you will be informed of the outcome. 


\section{Appendix F: Instructions to Authors}

Section two, manuscript, was prepared in accordance with the requirements of the Journal of Manipulative and Physiological Therapeutics (JMPT).

For further information please see: http://www.elsevier.com/journals/journal-ofmanipulative-and-physiological-therapeutics/0161-4754/guide-for-authors 